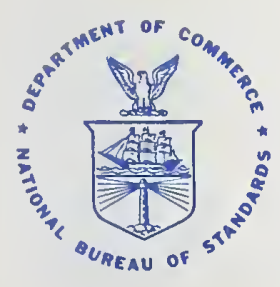

NBS SPECIAL PUBLICATION

413

1976 Edition

U.S. DEPARTMENT OF COMMERCE/ National Bureau of Standards

\title{
SPECIAL TECHNICAL FACILITIES at the National Bureau of Standards
}


The National Bureau of Standards ${ }^{1}$ was established by an act of Congress March 3, 1901. The Bureau's overall goal is to strengthen and advance the Nation's science and technology and facilitate their effective application for public benefit. To this end, the Bureau conducts research and provides: (1) a basis for the Nation's physical measurement system, (2) scientific and technological services for industry and government, (3) a technical basis for equity in trade, and (4) technical services to promote public safety. The Bureau consists of the Institute for Basic Standards, the Institute for Materials Research, the Institute for Applied Technology, the Institute for Computer Sciences and Technology, and the Office for Information Programs.

THE INSTITUTE FOR BASIC STANDARDS provides the central basis within the United States of a complete and consistent system of physical measurement; coordinates that system with measurement systems of other nations; and furnishes essential services leading to accurate and uniform physical measurements throughout the Nation's scientific community, industry, and commerce. The Institute consists of a Center for Radiation Research, an Office of Measurement Services and the following divisions:

Applied Mathematics - Electricity - Mechanics - Heat - Optical Physics - Nuclear

Sciences ${ }^{2}$ - Applied Radiation ${ }^{2}$ - Quantum Electronics ${ }^{3}$ - Electromagnetics ${ }^{3}$ - Time and Frequency $^{3}$ - Laboratory Astrophysics ${ }^{3}$ - Cryogenics ${ }^{3}$.

THE INSTITUTE FOR MATERIALS RESEARCH conducts materials research leading to improved methods of measurement, standards, and data on the properties of well-characterized materials needed by industry, commerce, educational institutions, and Government; provides advisory and research services to other Government agencies; and develops, produces, and distributes standard reference materials. The Institute consists of the Office of Standard Reference Materials and the following divisions:

Analytical Chemistry - Polymers - Metallurgy - Inorganic Materials - Reactor Radiation Physical Chemistry.

THE INSTITUTE FOR APPLIED TECHNOLOGY provides technical services to promote the use of available technology and to facilitate technological innovation in industry and Government; cooperates with public and private organizations leading to the development of technological standards (including mandatory safety standards), codes and methods of test; and provides technical advice and services to Government agencies upon request. The Institute consists of a Center for Building Technology and the following divisions and offices:

Engineering and Product Standards - Weights and Measures - Invention and Innovation Measurement Engineering - Structures, Materials, and Life Safety ${ }^{*}$ - Building Environment ${ }^{*}$ - Technical Evaluation and Application ${ }^{4}$ - Fire Technology - Product Evaluation Technology.

THE INSTITUTE FOR COMPUTER SCIENCES AND TECHNOLOGY conducts research and provides technical services designed to aid Government agencies in improving cost effectiveness in the conduct of their programs through the selection, acquisition, and effective utilization of automatic data processing equipment; and serves as the principal focus within the executive branch for the development of Federal standards for automatic data processing equipment, techniques, and computer languages. The Institute consists of the following divisions:

Computer Services - Systems and Software - Computer Systems Engineering - Information Technology.

THE OFFICE FOR INFORMATION PROGRAMS promotes optimum dissemination and accessibility of scientific information generated within NBS and other agencies of the Federal Government; promotes the development of the National Standard Reference Data System and a system of information analysis centers dealing with the broader aspects of the National Measurement System; provides appropriate services to ensure that the NBS staff has optimum accessibility to the scientific information of the world. The Office consists of the following organizational units:

Office of Standard Reference Data - Office of Information Activities - Office of Technical Publications - Library - Office of International Relations.

${ }^{1}$ Headquarters and Laboratories at Gaithersburg, Maryland. Unless otherwise noted: mailing address Washington, D.C. 20234.

2 Part of the Center for Radiation Research.

${ }^{3}$ Located at Boulder, Colorado 80302 .

- Part of the Center for Building Technology. 


\section{Special \\ Technical Facilities \\ at the \\ National Bureau of Standards}

H. L. Mason and Iris M. Lloyd

Editors

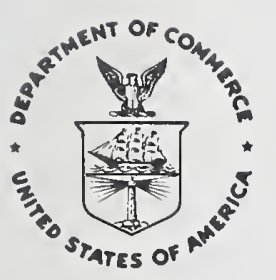

U.S. DEPARTMENT OF COMMERCE, Elliot L. Richardson, Secretary

James A. Baker, III, Under Secretary

Dr. Betsy Ancker-Johnson, Assistant Secretary for Science and Technology NATIONAL BUREAU OF STANDARDS, Ernest Ambler, Acting Director

Issued March 1976 


\section{National Bureau of Standards Special Publication 413}

Nat. Bur. Stand. (U.S.), Spec. Publ. 413, 1976 Edition, 50 pages (Mar. 1976)

Supersedes NBS Special Publication 413, 1975 Edition 


\title{
FOREWORD
}

For nearly seventy-five years, the National Bureau of Standards has been a national resource-a resource devoted to the development of that vast network of measurements and standards by which we define our societal existence. As one of the nation's largest physical science laboratories, the Bureau houses a number of special facilities which serve a vital role in addressing questions of basic research as well as technology application. One facility that has been improved this year is the Synchrotron Ultraviolet Radiation Facility. Having been converted into a storage ring, the facility is now capable of producing 100,000 times as much ultraviolet radiation and is being used on projects yielding standards and data meeting needs ranging from controlled nuclear fusion energy sources to fabrication of miniaturized electronic circuits. As a national resource, these facilities are available for cooperative use. The purpose of this catalog is to inform scientists about the existence, capabilities and availabilities of the equipment and facilities at the National Bureau of Standards.
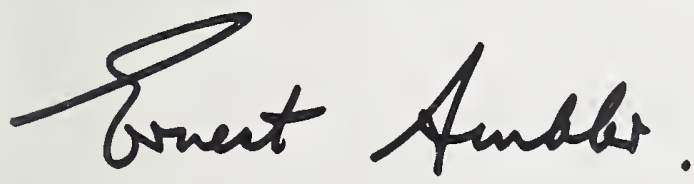

\author{
Ernest Ambler \\ Acting Director
}

\section{On the cover...}

Close-up view of a simulated experimental arrangement for laser excitation of a gas in the High Temperature Vaporization Laboratory. A laser beam is shown crossing a stream of gas directed at the sampling cone of a mass spectrometer. The bright spot visible at the intersection of the laser beam and the gas stream represents the region of initial excitation. 
Page

INTRODUCTION

\section{ACCELERATORS}

Electron Van de Graaff Accelerator, $4 \mathrm{MeV}$.... 2

Linear Electron Accelerator (LINAC) ........ 2

Positive-Ion Van de Graaff Accelerator, 3 MEV . 3

Synchrotron Ultraviolet Radiation Facility

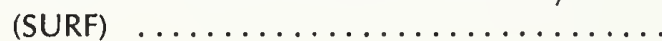

\section{ACOUSTIC FACILITIES}

Acoustic Anechoic Chamber ............ 4

Acoustic Reverberation Chamber .......... 4

\section{ANTENNAS}

Antenna Measurement Facilities ......... 5

Rooftop Antenna Test Facility ........... 6

\section{BUILDING RESEARCH FACILITIES}

Accelerated Weathering Laboratories ....... 6

Plumbing Research Laboratory .......... 7

Structures Laboratories .............. 7

Thermal Engineering Laboratories ......... 8

Thermographic Equipment ............ 9

\section{CALORIMETERS}

Fluorine Combustion Calorimeter ......... 10

Low-Temperature Adiabatic Calorimeter ..... 10

Microcalorimetry ............... 11

Platinum-lined Adiabatic Solution Calorimeter . 12

Rotating, Platinum-lined, Adiabatic Bomb

Calorimeter .................. 12

\section{COMPUTER}

Central Computer Facilities ............ 13

Automation Laboratory .............. 13

\section{ELECTRICAL MEASUREMENTS FACILITIES}

Automatic Network Analyzer
1 Electro-optical High Voltage Field Mapping

Page



Non-Magnetic Facility ............... 15

Reactance Bridge for Power Loss Measurement . 16

\section{ELECTRON MICROSCOPES}

Scanning Electron Microscope ........... 16

Transmission Electron Microscope, 200 kV .... 17

\section{ENVIRONMENTAL FACILITIES}

Chlorine Flux Monitor ............... 18

Precision Humidity Measurement .......... 18

\section{FIRE RESEARCH}

Fire Research Laboratory ............. 19

\section{HIGH PRESSURE FACILITIES}

High Pressure Generators ............. 20

High Pressure Optical Fluorescence System ... 20

High Pressure PVT Dilatometer ......... 21

\section{HIGH TEMPERATURE FACILITIES}

Alloy Preparation Laboratory ............ 21

High Temperature Controlled-Atmosphere

Furnace ................... 22

High Temperature Vaporization Laboratory ... 22

Inorganic Glasses: Preparation and Viscosity ... 23

Laser Materials Facility .............. 23

Millisecond High Temperature Thermophysical

Measurements .................... 24

\section{LOW PRESSURE FACILITY}

Mercury Manometer .............. 24

LOW TEMPERATURE FACILITIES

Acoustical Thermometer 


\section{Page}

Cryogenic Flow Research Facility .......... 25

Hydrogen Liquefaction Facility ............ 26

Liquefied Natural Gas Flow Facility ......... 26

\section{MACHINE TOOLS, NUMERICALLY CONTROLLED}

Machine Tools, Numerically Controlled ...... 26

\section{MECHANICAL MEASUREMENT FACILITIES}

Deadweight Force Calibration Machines .... . 27

Fluid Flow Measurement ............... 28

Three-Dimensional Precision Measurement .... 28

Universal Testing Machine, Twelve Million

Pound-Force ..................... . 29

Wind Tunnel for Unsteady Flows........... 29

\section{NUCLEAR REACTOR AND ASSOCIATED \\ FACILITIES}

Nuclear Reactor ...................... 30

Filtered Neutron Beams ................ 30

Intermediate-Energy Standard Neutron Field

(ISNF) ..................... 31

Isotope Separator Laboratory ........... 31

Neutron Diffractometers ... . . . . . . . . . . . 32

Neutron Radiography Facility ............ 33

Neutron Scattering Spectrometer ......... 33

Nuclear Irradiation Facilities ............... 34

Time-of-Flight Neutron Spectrometers ...... 34

\section{RADIOACTIVE SOURCE}

Cobalt-60 Irradiation Facility ........... 35

\section{RADIO STATIONS}

WWVL VLF Broadcast Station ............ 35

Special Announcements on WWV/WWVH ... 36

\section{SPECTROSCOPY FACILITIES}

Analytical Spectrophometer
Concave Grating Spectrographs, $10.7 \mathrm{~m} \ldots . . .37$

Czerny-Turner High-Dispersion Spectrograph . . 37

Electron Energy Loss Spectrometers for Gases . . 38

Far Infrared Spectroscopy .............. 38

Flame Emission Spectrometer with Repetitive

Optical Scanning ................ 38

Flash Photolysis Resonance Fluorescence Apparatus ................... 39

Fourier Transform Nuclear Magnetic

Resonance Spectrometer ............. 39

Gas Chromatograph-Mass Spectrometer System . 40

High Pressure Photoionization Mass

Spectrometer ............... 40

High Resolution Infrared Spectrometer ...... 41

Isotope Ratio Mass Spectrometers .......... 41

Microwave Spectroscopy Facility .......... 41

Mössbauer Spectroscopy of Metals ........ 42

Multichannel Flame Spectrometer ......... 42

Nuclear Magnetic Resonance Spectroscopy .... 43

Photoionization Spectrometry ........... 43

Raman Spectroscopy ................ 44

\section{SURFACE PROPERTIES FACILITIES}

Electron Probe Microanalyzer ........... 45

Ion Probe Microanalyzer ............. 45

Molecular Beam-Field Emission Microscope ... . 46

Molecular Beam Machine .............. 46

Surface Analysis Facility .............. 47

Surface Area Analyzer ............... 47

\section{X-RAY FACILITIES}

Rotating X-Ray Anode Diffraction Unit ...... 48

Soft X-Ray Spectrometer ............... 48

Three-Circle X-Ray Diffractometer ........ 49 


\section{INTRODUCTION}

Among the major technical facilities of the NBS laboratories in Gaithersburg, Md., and Boulder, Colo. are some which are unique and many which feature equipment that is relatively uncommon. These important resources deserve to be more widely known and used by the scientific and engineering community, including the Bureau's own staff, other Government agencies, industrial research associates, academic researchers, and postdoctoral fellows. However, it should be noted that the Bureau cannot accept work for these facilities which is more appropriately done by other organizations in or outside of the Federal Government.

Those facilities which are available for shared use, either occasional or extended, are briefly described in the pages of this publication. For each is indicated its technical capabilities, its potential applications, and whom to contact in making arrangements. Literature references which give more detailed information as to the structure and usefulness of these facilities are included for many of the units described. While there will be no charge made for use of the facility by NBS workers on RTS-funded projects, all activities funded from outside NBS will be required to pay costs intended to recover operating expenses. The staff will be glad to discuss with interested individuals a specific research or testing problem for which the equipment appears appropriate. Long term projects require a written agreement which specifies the extent of the participation of the staff responsible for the facility, the allocation of costs, and the provisions for publication of research results.

NBS capabilities related to scientific and technical equipment include also:

Calibration to U.S. national standards-contact J. M. Cameron, Chief of the Office of Measurement Services, Physics Building, Room A345, Phone 301/ 921-2805.

Provision of well-characterized substances-contact J. P. Cali, Chief of the Office of Standard Reference Materials, Chemistry Building, Room B306, Phone 301/921-3479.

Information on evaluated data for physical properties-contact Dr. D. R. Lide, Jr., Chief of the Office of Standard Reference Data, Administration Building, Room A537, Phone 301/921-2467.

Information on U.S. and foreign documents on voluntary engineering standards-contact W. J. Slattery, Standards Information Services, Technology Building, Room B160, Phone 301/921-2587.

Information on automatic data processing equipment and standards - contact Chief of Computer Information, Technology Building, Room B246, Phone 301/921-3517.

Visitors will find the Gaithersburg laboratories 20 miles northwest of Washington, D.C. (mail address, National Bureau of Standards, Washington, D.C. 20234) and the Boulder laboratories 25 miles northwest of Denver, Colorado (mail address, National Bureau of Standards, Boulder, Colo. 80302).
Micrograph made with the TRANSMISSION ELECTRON MICROSCOPE of the region surrounding a 200 gram Vickers microhardness indentation in sapphire $\left(\alpha-\mathrm{Al}_{2} \mathrm{O}_{3}\right)$. The instrument is being used to study plastic deformation and the structure of cracks (at $C$ ) in hard brittle materials. 


\section{ACCELERATORS}

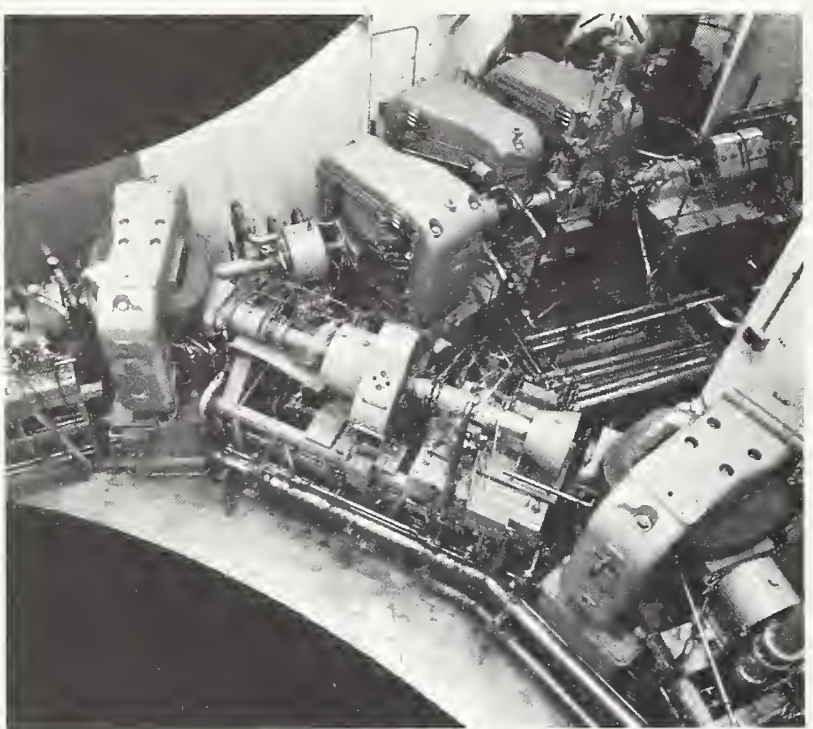

LINEAR ELECTRON ACCELERATOR. Linac beam handling system.

\section{ELECTRON \\ VAN DE GRAAFF ACCELERATOR, $4 \mathrm{MeV}$}

This accelerator, based on the principle of the Van de Graaff electrostatic generator, produces both continuous and pulsed beams of electrons with good energy resolution and continuous control of beam current and energy. Its capabilities make possible a wide variety of experiments using electrons or photons.

\section{Capability:}

ENERGY: continuously variable 0.8 to $4.0 \mathrm{MeV}$. ENERGY SPREAD: 0.2 percent.

OUTPUT CURRENT: $10^{-9}$ to $10^{-3}$ ampere dc. 500 microamperes peak current pulsed.

PULSE LENGTH: 1 microsecond.

REPETITION RATE: 50 to 500 pps or single shot. EXPERIMENTAL ROOMS: two, well shielded, total area $200 \mathrm{~m}^{2}$.

Applications: Interactions of electrons and photons with matter; dosimetry measurements; isomer activation; electron channeling in solids; bremsstrahlung production studies; characteristic radiation production; nuclear activation; photofission experiments; radiation simulation measurements; radiation damage and failure studies.

Availability: Beam time is available to NBS staff, other agency and university users, industrial users, and guest workers. Operation only by qualified X-Ray Physics Section staff, under Dr. Charles E. Dick.

Literature: NBS Technical News Bulletin, August 1962, Vol. 46, No. 8, pages 107-110.

Contact: Dr. C. E. Dick, Applied Radiation Division, Radiation Physics Building, Room C216, Phone 301921-2201.

\section{LINEAR ELECTRON ACCELERATOR (LINAC)}

The linear accelerator (linac) facility was designed for maximum flexibility, beam quality, and beam handling to satisfy the needs of a large variety of programs. It is a high-intensity source of electron, photon, and neutron beams with excellent stability and definition.

\section{Capability:}

ENERGY: continuously variable 10 to $150 \mathrm{MeV}$. POWER: 60 kilowatts, average.

CURRENT: 0.6 milliamperes, average.

3.5 amperes, peak (short pulse operation).

REPETITION RATE: variable to 720 pps.

PULSE LENGTH: 0.001 to 5 microseconds.

ENERGY SPREAD: from linac, 2 percent full width at half maximum; from beam handling system, 0.04 percent full width at half maximum.

EXPERIMENTAL ROOMS: four, with personnel access to one while beam is directed into another.

An on-line data handling system is available, and data reduction programs are available.

Applications: Neutron total cross section measurements by time of flight (above-ground facility); neutron fission yields; neutron flux standards; neutron capture cross sections; fast neutron activation analysis; electron and photon dosimentry; pulsed radiolysis of biochemical systems; electron scattering; electrodisintegration of light nuclei; photonuclear physics with monoenergetic and polarized photons; photon activation analysis; dosimetry and dose distribution using radiochromic dyes; electron and photon beam measurement standards; production of radioactive sources.

Availability: Beam time is available to NBS staff, other agency and university users, industrial users, and guest workers. Operation only by qualified Linac Operations Section staff under J. E. Rose.

Literature: NBS Technical News Bulletin, August 1962, 
Vol. 46, No. 8, pages 107-110. Scientific Research, June 1966, Vol. 1, No. 6, pages 24-26.

Contact: Dr. C. D. Bowman, Chief of Nuclear Sciences Division, Radiation Physics Building, Room B119, Phone 301-921-2234.

\section{POSITIVE-ION}

\section{VAN DE GRAAFF}

\section{ACCELERATOR, $3 \mathrm{MeV}$}

The positive-ion $3 \mathrm{MeV}$ Van de Graaff facility at the National Bureau of Standards has been designed primarily for experiments involving $\mathrm{keV}$ and $\mathrm{MeV}$ energy neutrons. It includes a HVEC model KN-3000 Van de Graaff accelerator and two target rooms. The accelerator is capable of operation in dc mode as well as in a variety of pulsed beam modes. Momentum analyzed beams can be supplied to any of six ports in a low scattering environment or to a single port in a heavily shielded room. Protons and deuterons are the ion species routinely accelerated.

Capability: Values listed are routinely available. Extended capabilities may be developed for special applications.

ENERGY: 0.8 to $3.0 \mathrm{MeV}$.

BEAM INTENSITY: 1 to $200 \mu \mathrm{A}$.

Analyzed Beam:

ENERGY: protons- 0.8 to $3.0 \mathrm{MeV}$; deuterons0.8 to $2.8 \mathrm{MeV}$.

BEAM INTENSITY: 0.3 to $20.9 \mu \mathrm{A}$.

ENERGY STABILITY: $2.0 \mathrm{keV}$.

ENERGY REPRODUCIBILITY: $5.0 \mathrm{keV}$.

Pulsating Capability:

Rf PULSING: 1.0 and $3.3 \mathrm{MHz}$ repetition rates with 15 and 4 ns burst width respectively. "Slow"pulsing: Burst width—variable from 0.1 to $5.0 \mu \mathrm{s}$; Rep. rate-variable from 100 $\mathrm{kHz}$ to dc.

An on-line data handling capability based on a DC $6024 / 5$ computer is available.

Applications: Standard neutron cross section measurements, neutron flux standards, neutron experiments involving time of flight, neutron capture cross section measurement, fast neutron activation analysis, neutron dosimetry, radiation damage studies, charged particle studies.

Availability: Accelerator time is available to NBS staff and outside users to the extent that the work does not conflict with the neutron standards program. The use of a member of the Van de Graaff staff is recommended for operation of the machine and set-up.

Contact: Dr. A. D. Carlson, Neutron Standards Section, Radiation Physics Building, Room B119, Phone 301-921-2677.

\section{SYNCHROTRON ULTRAVIOLET RADIATION FACILITY (SURF)}

Synchrotron radiation in the far ultraviolet is highly collimated, nearly linearly polarized, and of calculable intensity. It is well-suited for studies in atomic, molecular, biomolecular and solid-state physics, chemistry, engineering and medicine.

Capability: The NBS Synchrotron Ultraviolet Radiation Facility (SURF) has been converted into a storage ring. Beam currents of $2 \mathrm{~mA}$ have been accelerated and two beam lines are operative. The third beam line should be available in 1976. With a microtron injector the storage ring is expected to accelerate a $40 \mathrm{~mA}$ beam to a maximum energy of $260 \mathrm{MeV}$. The expected intensity in the region $600 \AA$ to $1200 \AA$ is $3 \times 10^{11}$ photons per second per milliradian of orbit for an instrumental resolution of $\Delta \lambda / \lambda=0.001$. Instrumentation planned and existing includes:

a) A source of smooth, calculable intensity distribution, $10,000 \AA$ to $40 \AA$.

b) $600 \AA-40 \AA 3$-m grazing incidence spectrograph and monochromator, resolution to 0.05 A.

c) Two $2000 \AA-60 \AA$ monochromators (toroidal grating), resolution $0.5 \AA$ to $1.0 \AA$.

d) $925 \AA-40 \AA 2.2$-m grazing incidence monochromator, resolution to $0.1 \AA$, with $10^{-10}$ torr vacuum chamber, photoelectron analyzer, and manipulators.

e) Medium temperature heat-pipe ovens, $0.3 \mathrm{~m}$ and $1.0 \mathrm{~m}$, to $1100 \mathrm{C}$. One oven of the rotating type handles materials that wet a wick with difficulty.

f) Calibrated detectors, $2000 \AA-200 \AA$.

g) Two spectrometer calibration lines with a direct view of the beam.

Applications: The enlarged SURF will be used for atomic and molecular absorption spectroscopy, optical properties of materials, electron density of states in solids, surface studies (including angular distribution of photoelectrons as a function of angle of incidence and polarization vector), radiation damage studies in substances (including those of biological origin), calibration studies, precision photoabsorption cross-section measurements in solids and vapors, and photoelectron spectroscopy of gases.

Availability: To any qualified research worker from NBS or other Federal agencies.

Contact: Dr. Robert P. Madden, Chief, Far UV Physics Section, Physics Building, Room A251, Phone 301. 921-2031. 


\section{ACOUSTIC FACILITIES}

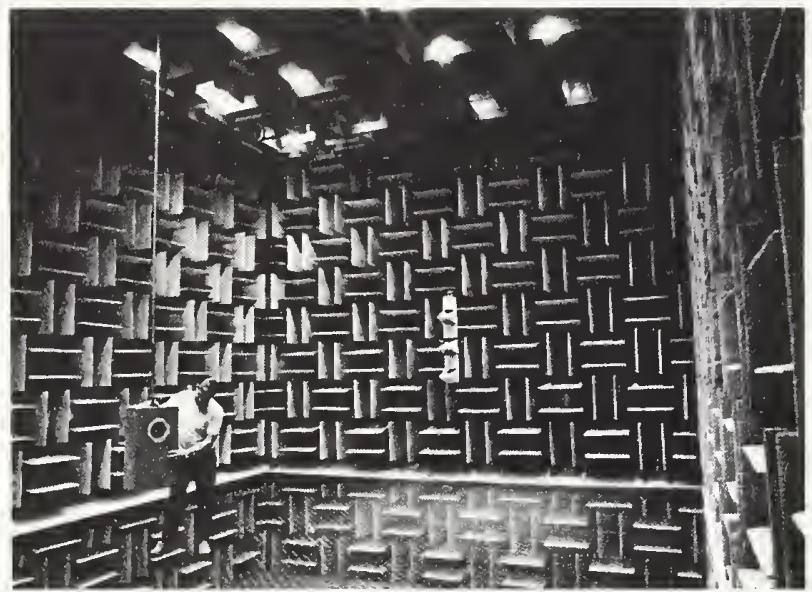

ACOUSTIC ANECHOIC CHAMBER, completely lined with sound absorbing wedges.

\section{ACOUSTIC}

\section{ANECHOIC CHAMBER}

This facility consists of a sound and vibration-isolated room whose inner surfaces are lined with 1.78-meter long glass-wool wedges and whose free-field dimensions are about $10 \times 6.7 \times 6.7$ meters. Access to the room is by means of a steel wire mesh floor supported by concealed I-beams. Instrument hangers, each capable of supporting about 100 kilograms, are mounted on all six surfaces of the room. The space is lighted, air conditioned and provided with electrical outlets and conduits for communications cables.

Capability: The room provides good free-field sound conditions from about $50 \mathrm{~Hz}$ to at least $63 \mathrm{kHz}$. Upper bounds for wide-band ambient noise are about $30 \mathrm{~dB}$ re $20 \mu \mathrm{N} / \mathrm{m}^{2}$ for $\mathrm{C}$-weighting and $23 \mathrm{~dB}$ for $\mathrm{A}$ weighting. (The actual ambient level cannot be measure with a commercial sound level meter since equivalent instrument noise exceeds the ambient acoustic noise.)

Applications: Microphone calibration, loudspeaker measurements, sound level meter calibration, noise measurement, psychoacoustic experiments, radiation and scattering experiments, general use when a quiet environment is needed.

Availability: When not otherwise in use and when staff members are available to ready the facility for the user.
Literature: J. Acoust. Soc. Amer., Vol. 52, No. 4 (Part 1), Oct. 1972, pp. 1071-1076.

Contact: Dr. E. Magrab, Sound Bldg., Room B106, Phone 301-921-3607.

\section{ACOUSTIC REVERBERATION CHAMBER}

The chamber is a vibration-isolated, shell-within-shell type structure of massive reinforced concrete construction with inside dimensions of $9.14 \times 7.62 \times$ 6.10 meters. A steel plate, double-leaf entrance door provides a clear opening to the chamber of approximately $2 \times 3$ meters. The chamber is equipped with a unique set of adjustable, variable-speed, rotating vanes to improve the diffusion of the sound field. The interior of the chamber and the surrounding onemeter-wide air envelope are lighted, air conditioned and humidity-controlled and provided with electrical outlets and conduits for communication lines. Numerous pipe-sleeve openings of various sizes also are available for other specialized uses such as conduits for hydraulic, pneumatic, fuel or exhaust lines.

Capability: Although experimental verification has not been completed, the chamber is designed to provide a highly diffuse sound field in the frequency range 100 to $4000 \mathrm{~Hz}$, and to permit reasonably accurate acoustical measurements to be made at frequencies as low as $80 \mathrm{~Hz}$ and as high as $10,000 \mathrm{~Hz}$. The wide-band ambient noise level in the chamber with the vanes stationary is about $30 \mathrm{~dB}$ re $20 \mu \mathrm{N} / \mathrm{m}^{2}$ for $\mathrm{C}$-weighting and about $36 \mathrm{~dB}$ with vanes rotating at $5 \mathrm{rpm}$. The reverberation time $T_{60}(60$ decibel decay) is approximately 25 seconds at $100 \mathrm{~Hz}$ and about 4 seconds at $4000 \mathrm{~Hz}$.

Applications: The chamber generally is used for measurement of sound power output of noise and sound sources (e.g., machinery, appliances, loudspeakers, sirens), sound absorption of architectural materials (e.g., acoustical tile, carpeting, drapery), random incidence calibration of sound level meters, microphones and noise exposure meters, and human response to noise.

Availability: When not otherwise in use and when staff members are available to prepare the facility for the user.

Literature: NBS Tech. News Bul., Vol. 52, No. 12, Dec. 1968.

Contact: Dr. I. Pallett, Sound Building, Room A155, Phone 301-921-3381. 


\section{ANTENNAS}

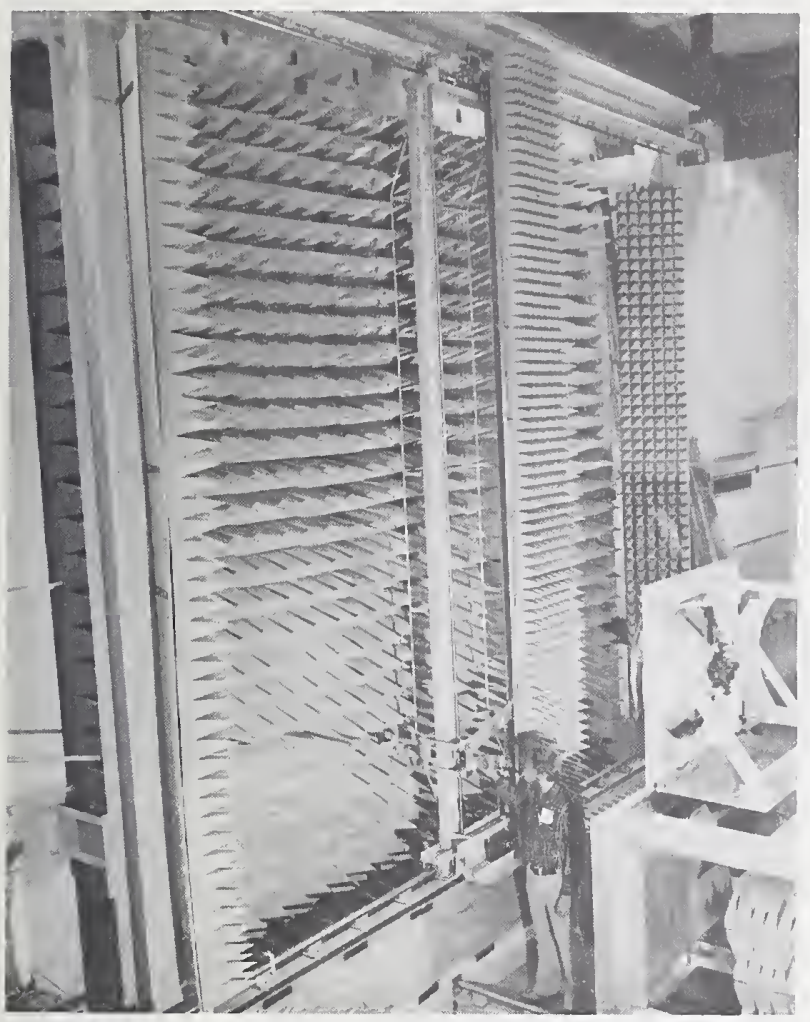

NEAR-FIELD SCANNING FACILITY for measurement of gain, pattern, and polarization characteristics of microwave antennas. The panels of pyramidal wedges prevent reflections.

\section{ANTENNA MEASUREMENT FACILITIES}

The Electromagnetic Division of the NBS Boulder Laboratories has recently perfected two new and highly accurate methods for determining antenna characteristics from measurements made at greatly reduced distances. The methods are known as the near field scanning (NFS) and extrapolation techniques and two types of unique facilities have been constructed in order to implement them.

\section{Near-Field Scanning Facility}

Capabilities: This facility is used to measure the nearfield phase and amplitude over a plane area close to the test antenna. From this information it is possible to accurately calculate the gain, pattern, and polarization characteristics at all distances from the antenna, near field as well as far field. The absolute gain can be determined to within about $\pm 0.15 \mathrm{~dB}$, the polarization axial ratio to within about $\pm 0.10 \mathrm{~dB} /$
$\mathrm{dB}$ and side lobe levels can be obtained down to -50 or $-60 \mathrm{~dB}$. The side lobe accuracy is typically about $\pm 1.0 \mathrm{~dB}$ at the $-40 \mathrm{~dB}$ level. (The exact uncertainties will depend on the frequency, type, and size of antenna, etc.) The new automated system is capable of scanning an area $15 \mathrm{ft} \times 15 \mathrm{ft}$ square and can be adapted to take data over a cylindrical or spherical surface as well.

Applications: Measurement of antenna patterns, gain, and polarization from about $750 \mathrm{MHz}$ to $75 \mathrm{GHz}$. Any other application where it is necessary to have a detailed knowledge of electromagnetic field configurations, e.g., scattering experiments.

Availability: To any qualified NBS research workers, after an initial training period with supervisor. In appropriate instances individual research workers from other Federal organizations and industry can gain access to the facility.

\section{Literature:}

[1] D. M. Kerns, "Correction of Near-Field Antenna Measurements Made with an Arbitrary But Known Measuring Antenna," Electron. Lett., 6, pp. 346-347, May 1970.

[2] R .C. Baird, A. C. Newell, P. F. Wacker, and D. M. Kerns, "Recent Experimental Results in Near-Field Antenna Measurements," Electron. Lett., 6, pp. 349-351, May 1970.

[3] A. C. Newell, and M. L. Crawford, "Planar Near-Field Measurements on High Performance Array Antennas," Report, National Bureau of Standards NBSIR 74-380, July 1974.

\section{Extrapolation Range Facilities}

Capabilities: The Electromagnetics Division operates two "extrapolation ranges," a 60-meter outdoor range and a 10-meter indoor range, for performing high accuracy measurements of gain and polarization of directive antennas. These ranges each consist of two moveable towers that roll on accurately aligned rails, enabling one to measure the signal transmitted between a pair of antennas as the separation distance between the antennas is varied. Such data are used to determine the desired far-field (infinite separation distance) gain and polarization properties of the antennas. This method is the most accurate method known for evaluating directive antennas. Above 1 $\mathrm{GHz}$, the gain accuracy is typically $\pm 0.08-0.10 \mathrm{~dB}$ and polarization axial ratio can be determined within $\pm 0.05 \mathrm{~dB} / \mathrm{dB}$. Such accuracies are normally not achievable on the best far-field antenna ranges and the dimensions of an extrapolation range are only $1 / 5$ to $1 / 10$ as large as a far-field range.

Applications: High-accuracy measurements of antenna gain and polarization above about $500 \mathrm{MHz}$ 
with no discernible upper limit. Other microwave experiments that require the precise motion of a source and/or receiver of electromagnetic energy.

Availability: To any qualified NBS research workers, after an initial training period with supervisor. In appropriate instances individual research workers from other Federal organizations and industry can gain access to the facility.

\section{Literature:}

Accurate Measurement of Antenna Gain and Polarization at Reduced Distances by an Extrapolation Technique, A. C. Newell, R. C. Baird, and P. F. Wacker, IEEE Trans. A\&P, Vol. AP-21, No. 4, July 1973, pp. 418-431.

Contact: Dr. R. C. Baird, Chief of Fields and Antennas Section, Radio Building, Room 4085, NBS Boulder, Colo. 80302, Phone 303-499-1000, ext. 3301.

\section{ROOFTOP ANTENNA TEST FACILITY}

The rooftop antenna test facility is located on the upper flat portion of the roof above Wing 6 of the Radio Building.

Capability: This test facility was built to provide a means for measuring antenna reflection and transmission coefficients. Two rigid coaxial rf cables and a multiconductor intercom and power cable connect to the automatic network analyzer in the laboratory below. The automatic network analyzer provides for the rf signal generation and detection requirements.

Applications: Complex reflection (impedance) and transmission coefficients of antennas can be measured by making use of the automatic network analyzer over the frequency range of 0.1 to $18 \mathrm{GHz}$. Antennas can be measured at frequencies below 100 $\mathrm{MHz}$ by connecting the lead-in coaxial cables to other rf sources for signal generators and components for signal detection. Although this latter equipment is not presently dedicated for use with the rooftop antenna range it is available for use from projects.

Availability: To any qualified NBS research worker, after an initial training period with supervisor. In appropriate instances individual research workers from other Federal organizations can gain access to the facility.

Contact: D. H. Russell, Program Chief, Microwave Measurement Services, Radio Building, Room 4633, NBS Boulder, Colo. 80302, Phone 303-499-1000, ext. 3811.

\section{BUILDING \\ RESEARCH FACILITIES}

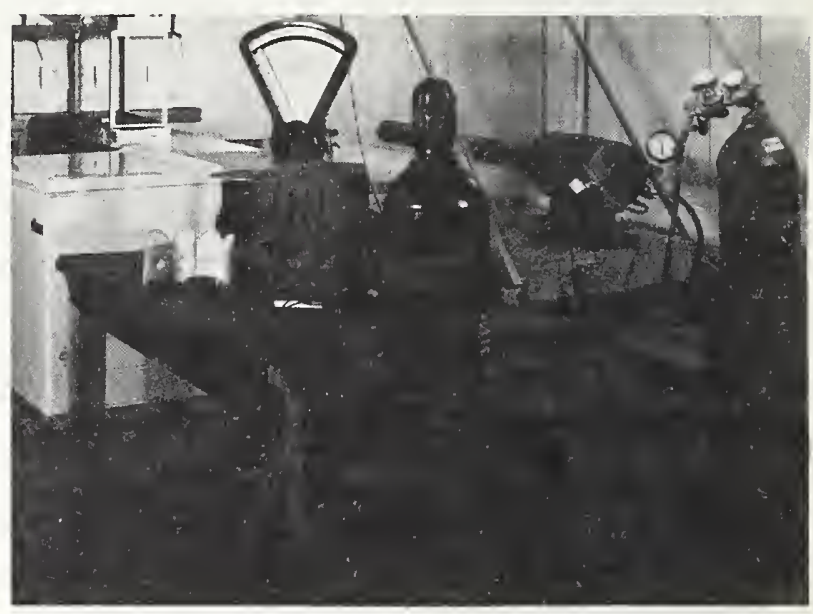

ACCELERATED WEATHERING LABORATORIES. Compressed air gun for shooting ice spheres to simulate hail damage to building materials and systems.

\section{ACCELERATED WEATHERING LABORATORIES}

The effects of sunlight, rain, hail, atmospheric contaminants, and salt spray are simulated by accelerated cycling on building materials and systems such as wall coverings and sidings, caulking, roofing, flooring, paints, and plastic coatings. Seven exposure stations throughout the United States and Puerto Rico provide a diversity of natural weathering conditions.

Capability: Radiant-energy sources of the accelerated test machines include single and twin carbon arcs, a fluorescent sunlamp/black-light unit, and both water and air-cooled xenon arcs. Monitoring is by dosimeters, radiometers, or actinometers. Some machines have temperature, humidity, and water spray controls, or light/dark cycle controls. A high-humidity chamber is used to subject samples to cycles of water condensation and drying. Flammability of roofing is tested in a small spread-of-flame apparatus. A compressed-air gun fires ice spheres up to $2 \frac{1 / 2}{2}$ inches diameter against roofing and siding specimens at measured speeds up to 145 feet per second. 
Applications: Comparative studies of structural materials, coatings, claddings, and composites; identification of relatively detrimental weathering conditions; research on mechanisms of deterioration; development of test procedures.

Availability: On contract agreement with other government agencies; when equipment is not fully utilized by NBS research programs. Members of the Section carry out the various tests.

\section{Literature:}

[1] L. W. Masters, W. C. Wolfe, W. J. Rossiter, and J. R. Shaver, State of the Art on Durability Testing of Building Components and Materials, NBSIR 73-132 (1973).

[2] L. W. Masters and W. C. Wolfe, The Use of Weather and Climatological Data in Evaluating the Durability of Building Components and Materials, NBS Tech. Note 838 (1974).

Contact: Robert G. Mathey, Assistant Chief of Materials and Composites Section, Building Research Building, Room B348, Phone 301-921-3407.

\section{PLUMBING RESEARCH LABORATORY}

With a high-speed, computerized data acquisition system and hot and cold water supplies with precisely controlled pressures and temperatures over a wide range of demands, as well as standard laboratory fluid services, this laboratory offers unique opportunities to advance the state of the art both in the design and in the evaluation of plumbing equipment and systems.

Capabilities: Tests on systems up to $45 \mathrm{ft}$, in height and up to $50 \mathrm{ft}$. in length. Water supply of up to $1000 \mathrm{gpm}$ at constant head in gravity mode; up to $300 \mathrm{gpm}$ in automatically controlled pressure mode up to $70 \mathrm{psi}$. Hot water at volumes up to $200 \mathrm{gph}$ at $180^{\circ} \mathrm{F}$.

Continuous measurements and recording of rapidly changing physical parameters such as pressure, discharge rate, water depth, and temperature, according to predetermined criteria, at up to 64 points. Data analysis through NBS central computer if desired.

Pre-programmed control of experimentation by computer if desired.

Applications: The development of improved criteria for general hydraulic design of and for prediction of loads on plumbing systems; the development of test methodology for calibration and performance evaluation of innovative plumbing equipment and systems; investigations of performance of piping mate- rials as affected by pressure, flow, and contact with hot and cold water; methodology for cost effective approaches in needed national programs to update information on plumbing loads and to develop a modern data bank on performance characteristics of innovative equipment and systems.

Availability: To qualified NBS research workers, after an initial training period. In appropriate instances the facilities can be utilized by other governmental research workers, or by university or industry workers.

Literature:

[1] UA Journal, August 1972, pp. 33-35.

[2] Building Systems Design, May 1972, pp. 5054.

[3] Commerce Today, February 21, 1975, pp. 30 31.

Contact: Dr. L. S. Galowin, Chief of the Building Service Systems, Building Research Building, Room B306, Phone 301-921-3293.

\section{STRUCTURES \\ LABORATORIES}

Static and dynamic testing is accomplished by use of a heavily reinforced tie-down floor permitting mounting of complete structural members. Hydraulic actuators provide test loads in static test while closedloop electro-hydraulic actuators provide test loads in dynamic tests. Automatic recording of up to 200 channels of sensor data is accomplished by a minicomputer-controlled data acquisition system.

Capability: The main test floor of heavily reinforced concrete and imbedded I-beams is $53 \times 47$ feet in size and is supplemented in the long direction by a 25 foot extension, 20 feet wide, for testing long beams. The 53 -foot section has a 12,000 ft-kip bending moment capacity, and its 25-foot extension has a bending moment capacity of $8,000 \mathrm{ft}-\mathrm{kips}$. The crosswise section 47 feet in length will withstand a total bending moment of $21,000 \mathrm{ft}$-kips. The floor will withstand a total horizontal shear force of 1800 kips in either direction and a vertical shear force of 2,000 kips. It is serviced by two 10-ton bridge cranes having a clear hook height of 25 feet. The ninety-nine anchorage tie-down points are designed to withstand 100 kips of either tension force or horizontal shear force. Six additional points have twice this capacity. An associated laboratory, $22 \times 75$ feet, is serviced by two 2-ton cranes and contains two universal testing machines of 60,000 -lbs, one of 200,000 -Ibs capacity, and two compression machines of 300,000 -lbs and 600,000 -Ibs capacity. The $600,000-1 b$ capacity ma- 
chine has adequate clearance for testing an 8-ft high, 4-ft wide structural member.

Application: Beams, slabs, frames or complete structures can be subjected to static loads as limited by test floor capacity or cyclic loads up to 50,000 pounds with programmed amplitude and frequency. Signals in the range of 0 to 300 volts from load cells, strain gages, pressure transducers, LVDT's, and other types of electromechanical sensors are recorded on magnetic tape and optionally printed on teletypewriters. Two mini-computer controlled data acquisition systems are available. A 200-channel portable system for either laboratory or field use provides digital recording under manual or computer control. Another 112 channels of data may be recorded in digital form by a laboratory-based system. Its channels may be accessed in sequence or at random while under computer control, and manual control is also available. Any 14 of these 112 channels may be used for recording in analog form on magnetic tape.

Software packages are available for processing data obtained by either of these systems on the central NBS computer. Processing may be controlled through the use of a laboratory-located remote terminal.

Availability: When not otherwise in use and when staff is available to prepare the facility for the user.

\section{Literature:}

[1] Achenbach, P. B., Building Research at the National Bureau of Standards, Nat. Bur. Stand. (U.S.) Bldg. Sci. Ser. No. 0 (Oct. 1970).

[2] Yokel, L. Y. and Somes, N. F., Structural Performance Evaluation of Innovative Building Systems, ibid Tech. Note 706 (Aug. 1972).

[3] Yancey, C. W. and Somes, N. F., Structural Tests of a Wood Framed Housing Module, NBSIR 73-121, NTIS: Com-73-10860, (Mar. 1973).

Contact: Dr. R. A. Crist, Chief of Structures Section, Building Research Building, Room B168, Phone 301921-3471.

\section{THERMAL ENGINEERING LABORATORIES}

This group of five laboratories permits performance testing of refrigeration and air conditioning equipment, heating systems, and insulating materials. Well controlled conditions of temperature and humidity are maintained in large test chambers. An analog and digital data logging system is available for 300 sixdigit channels for 0.1 to 1000 volt inputs.

Capabilities: The Air Cleaning Laboratory contains a test duct capable of maintaining flows of 50 to 2500 $\mathrm{cfm}$ through a $2 \mathrm{ft} \times 2 \mathrm{ft}$ device; also equipment for particle counting, dust sampling, and NBS dust spot efficiency. Air cleaners can be tested, anemometer scans checked, and field evaluation of dust problems made.

The Air Conditioner and Heat Pump Laboratory includes an indoor room $39 \mathrm{ft} \times 13 \mathrm{ft} \times 21 \mathrm{ft}$, controlled for $40^{\circ} \mathrm{F}$ to $140^{\circ} \mathrm{F}$, and $50 \%$ rh at $35^{\circ} \mathrm{F}$ to $85^{\circ} \mathrm{F}$ dewpoint at $120^{\circ} \mathrm{F}$; and an outdoor room $20 \mathrm{ft}$ $\times 13 \mathrm{ft} \times 21 \mathrm{ft}$, controlled for $-10^{\circ} \mathrm{F}$ to $150^{\circ} \mathrm{F}$. Heat pumps may be tested in either the winter or the summer mode.

The Environmental Laboratory, $49 \mathrm{ft} \times 42 \mathrm{ft} \times 31 \mathrm{ft}$, is controlled for $-46^{\circ} \mathrm{C}\left(-50^{\circ} \mathrm{F}\right)$ to $66^{\circ} \mathrm{C}\left(150^{\circ} \mathrm{F}\right)$, and $50 \%$ rh at $35^{\circ} \mathrm{F}$ to $85^{\circ} \mathrm{F}$ dewpoint at $120^{\circ} \mathrm{F}$. Supply air is furnished by ceiling diffusers; damper-controlled air ducts in all eight corners of the room permit good air distribution. The floor is earth and may be excavated. Thermal performance or heating and cooling load measurements can be made either on models or on full-scale building constructions or equipments.

The Refrigeration Laboratory, $49 \mathrm{ft} \times 20 \times 17 \mathrm{ft}$, is controlled for $-50^{\circ} \mathrm{F}$ to $150^{\circ} \mathrm{F}$, and $50 \%$ rh at $35^{\circ} \mathrm{F}$ to $85^{\circ} \mathrm{F}$ dewpoint at $120^{\circ} \mathrm{F}$. The ceiling is perforated, allowing 30,000 $\mathrm{cfm}$ of conditioned air through any or all quadrants. A large door permits access to outdoors, and the floor is concrete with a temperaturecontrolled space underneath. Long-term control of temperature, humidity, and air motion permits development of standard test methods for freezers, coolers, refrigerated spaces or vehicles, heated enclosures, air conditioning systems or large components, heating systems and large humidifying or dehumidifying equipments. A small dynamometer has a capacity of $15 \mathrm{hp}$.

The Thermal Conductivity Laboratory has a very uniform temperature control; being underground, it is effectively shielded from outdoor temperature variations. Equipment available can take measurements from $-196^{\circ} \mathrm{C}\left(-320^{\circ} \mathrm{F}\right)$ to $1200^{\circ} \mathrm{C}\left(2200^{\circ} \mathrm{F}\right)$ on glass, ceramics, pure metals or alloys, in air, vacuum, argon, or helium. The NBS Guarded Hot Plate Apparatus is the standard method of ASTM C177 for absolute determination of the thermal conductivity of dry specimens of good insulators; its range is 0.1 to 10 Btu per hour $\mathrm{ft}^{2}\left({ }^{\circ} \mathrm{F} / \mathrm{in}\right.$.), or 0.15 to 15 milliwatts per $\mathrm{cm}{ }^{\circ} \mathrm{C}$ from 0 to $130^{\circ} \mathrm{F}\left(-18\right.$ to $54^{\circ} \mathrm{C}$ ). Recently a new and more accurate hot plate apparatus based upon the Robinson Line Heat Source concept was added to the conductivity measurement facility.

Availability: To any qualified guest worker, to the extent consistent with NBS requirements; to other Government agencies on request. 
Literature:

[1] Watson, T. W. and Robinson, H. E., Trans. ASME Heat Transfer, 83C, 403 (1961).

[2] Peavy, B. A., J. Res. Nat. Bur. Stand. (U.S.), 67C, (2) 119 (1963).

[3] Hahn, M. H., Robinson, H. E., and Flynn, D. R., ASTM Spec. Tech. Publ. No. 544, $167-$ 192 (1974).

Contact: Dr. T. Kusuda, Chief of Thermal Engineering Section, Building Research Building, Room B104, Phone 301-921-3501.

\section{THERMOGRAPHIC EQUIPMENT}

Thermography portrays an object by use of the thermal energy emanating from its surface, with instrumentation resembling a closed-circuit television system. An infrared scanning camera converts invisible infrared radiation $(2-5.6 \mu \mathrm{m}$ wavelength band) into equivalent electronic video signals. These signals are amplified and transferred by interconnecting cables to one or more monitoring units. In the primary monitor they are further amplified and used to modulate the intensity of an electron beam to produce a thermal image in which the hotter areas will appear brighter and the cooler areas darker. There are two secondary monitors, one a color monitor where different temperature ranges are represented by different colors, another a profile monitor which will produce either a contour-like presentation of the thermal display, or a temperature profile across any selected scanning line.

Capabilities: The thermographic equipment displays real-time pictures of the thermal radiation from either still or moving targets. The scan rate is 16 frames per second, giving a resolving power of 140 standard lines. The object temperature range is from $-30^{\circ} \mathrm{C}$ to $+2000^{\circ} \mathrm{C}$. The minimum detectable temperature difference is less than $0.2^{\circ} \mathrm{C}$ at $+30^{\circ} \mathrm{C}$ object temperature, increasing to $2 \%$ of the temperature range at higher temperatures. Two IR lenses are available, allowing a range of focus of $0.95 \mathrm{~m}$ to infinity with a field of view of $10^{\circ} \times 10^{\circ}$ and a range of focus of $0.6 \mathrm{~m}$ to infinity with a field of view of $25^{\circ} \times 25^{\circ}$.

The equipment requires approximately 2 amperes using $115 \mathrm{~V}$ a.c. The output of the photovoltaic indium antimonide IR detector in the camera is stabilized with liquid nitrogen which also increases the sensitivity. The dewar vessel on the camera will permit 4 hours of operation without interruption.

Applications: Remote scanning of surface temperature measurements of objects in the laboratory or in the field. Excessive thermal radiation may simply indicate insufficient insulation, but more importantly, may indicate faults in the design or operation of the device or equipment being scanned. Thermography is especially useful in non-destructive evaluation of thermal equipment in operation, since unsuspected malfunctions may be responsible for large quantities of waste heat and inferior products.

Availability: Because of the complexity of the instrumentation and the procedures of operation, use of this facility is limited to qualified members of the NBS staff or other scientists, after specific training of perhaps two months. The facility may be used indirectly through cooperative or contractual research agreements.

\section{Literature:}

[1] Applied Optics, Vol. 7, No. 9, September 1968.

[2] Munis, R. H., et al; Detecting Structural Heat Losses With Mobile Infrared Thermography. Part I, Description of Technique: Nat. Tech. Info. Serv., U.S. Dept. Comm., Oct. 1974NTIS AD/A-001549.

[3] ibid-Part II, Survey of Pease Air Force Base, Portsmouth, NH, Corps of Engineers, U.S. Army, Hanover, NH, CRREL Research Report 338, June 1975.

[4] Paljik, Ivar, et al; Thermography of Buildings; Scangraf AB Stockholm, 1972.

Contact: C. W. Hurley, Mechanical Systems Section, Building Research Building, Room B126, Phone 301921-3741. 


\section{CALORIMETERS}



LOW TEMPERATURE ADIABATIC CALORIMETER. The adiabatic calorimeter with associated cryogenic and vacuum equipment.

\section{FLUORINE COMBUSTION CALORIMETER}

Solid samples may be reacted with fluorine gas in a nickel or monel $300 \mathrm{~cm}^{3}$ combustion bomb. Gas samples may be reacted in a flame (flow calorimeter) with a monel burner.

Capabilities: Fluorine or other reactive gases are stored in a special hood and are dispensed by a manifold having a pressure range from one pascal (about 1.3 micrometres of mercury) to three megapascals (about 30 atmospheres). Both the manifold and calorimeters are located in a second safety hood. Under optimum conditions, the sample sizes should be such as to cause $40 \mathrm{~kJ}$ to be liberated as heat in the reaction. Under these conditions energies or enthalpies of reaction may be determined with a precision of better than $0.02 \%$. Auxiliary equipment is available to handle and prepare samples.

The combustion vessel is located in a stirred-water isoperibol calorimeter. The temperature of the calorimeter jacket is held constant to within $0.001^{\circ} \mathrm{C}$. Calorimeter temperatures are measured by a quartzoscillator sensor with digital printout. The calorimeter is calibrated electrically. Reduction of temperaturetime data is carried out by a time-shared computer.

Application: Used to determine enthalpies of reaction at or near room temperature, for the purpose of obtaining enthalpies of formation, enthalpies of solution, and related thermodynamic properties of substances.

Availability: Because of the complexity of the instrumentation and the procedures of operation, use of this facility is limited to qualified members of the NBS staff or scientists, after specific training of perhaps two months. The facility may be used indirectly through cooperative or contractual research agreements.

\section{Literature:}

[1] R. C. King and G. T. Armstrong, Constant pressure flame calorimetry with fluorine. II The heat of formation of oxygen to fluoride. J. Res. Nat. Bur. Stand. 72A, 113 (1967).

[2] E. S. Domalski and G. T. Armstrong, The heats of combustion of polytetrafluoroethylene (Teflon) and graphite in elemental fluorine. J. Res. Nat. Bur. Stand. 71A, 105 (1967).

Contact: Dr. G. T. Armstrong, Chief of Thermochemical Measurements and Standards Section, Chemistry Building, Room B350, Phone 301-921-2131.

\section{LOW TEMPERATURE ADIABATIC CALORIMETER}

This instrument was designed and built at NBS to make high accuracy heat capacity measurement for characterization of the thermodynamic properties of materials. The instrument is automated for roundthe-clock operation.

Capability: Specimens in solid or liquid state compatible with gold plated copper cell. Temperature range, 2 to $380 \mathrm{~K}$ with $\pm 0.001 \mathrm{~K}$ accuracy (referenced to IPTS 1968). Heat capacity accurate to $0.05 \%$. A lower accuracy scanning mode is being considered for alternative operation in the future.

Applications: Low temperature thermodynamic properties; glass transition; heats of fusion and transition; comparison of glass and crystal states; zero point entropies; sensiitve measure of glass transitions using thermal drifts; detection of small effects of thermal history.

Availability: Operation under the direct supervision of Dr. S. S. Chang. Measurements of mutual interest can be arranged with NBS and other government personnel in accord with agreement. 
Literature:

[1] K. F. Sterrett et al, An adiabatic calorimeter for the range 10 to $360 \mathrm{~K}$, J. Res. Nat. Bur. Stand. (U.S.) 69C, 19 (1965).

[2] S. S. Chang and A. B. Bestul, Heat capacities of Cis-1, 4-polyisoprene from 2 to $360 \mathrm{~K}$, J. Res. Nat. Bur. Stand, 75A, 113 (1971).

Contact: Dr. Martin G. Broadhurst, Chief of the Bulk Properties Section, Polymer Building, Room B320, Phone 301-921-2748.

\section{MICROCALORIMETRY}

Capability: The facility provides the capability for measuring small thermal power (uncertainty within $\pm 10 \mu \mathrm{W}$ ) associated with (a) energies of reaction in aqueous solution at $300 \mathrm{~K}$; (b) energies of transition over the range 300 to $470 \mathrm{~K}$; and (c) energies of vaporization from 300 to $470 \mathrm{~K}$. A commercial Calvettype microcalorimeter and NBS-designed microcalorimeters are available, utilizing the basic principles of heat conduction microcalorimetry.

A thermopile is used to measure the temperature difference between the reaction vessel and a heat sink maintained at constant temperature. Measurement of the emf of the thermoelement as a function of time yields a measure of the rate of heat exchange. Resolution of the thermoelement voltage to within a few $\mathrm{nV}$ corresponds to a temperature sensitivity of a few tenths of a microdegree. Data are recorded both in analog and in digital form. For calibration purposes, electrical energy may be introduced with a precision better than $0.01 \%$.

Applications: Many applications are found in the biological sciences where heat, as a totally non-specific entity, has been found to be a useful tool for studies involving enzyme catalyzed reaction, bacterial metabolism, cellular phenomena, and immunological processes. Since nearly all reactions of biological substances are accompanied by heat effects, microcalorimetry also possesses substantial potential for analytical purposes.

Availability: Because of the complexity of the instrumentation and the procedures of operation, use of the facility is limited to qualified members of the NBS staff or other scientists, after specific training of perhaps two months. The facility may be used indirectly through cooperative or contractual research agreements.

\section{Literature:}

[1] E. Calvet and H. Prat, "Recent Progress in Microcalorimetry," translated from the
French by H. A. Skinner, The MacMillan Company, New York, 1963.

[2] "Biochemical Microcalorimetry," H. D. Brown, editor, Academic Press, New York, 1969.

[3] E. J. Prosen, R. N. Goldberg, B. R. Staples, R. N. Boyd, and G. T. Armstrong. Microcalorimetry applied to biochemical processes. pp. 253-249 "Thermal Analysis: Comparative Studies on Materials." H. Kambe and P. D. Garn, editors. (Krdansha Ltd., Tokyo, and John Wiley \& Sons, New York, 1974).

Contact: Dr. G. T. Armstrong, Chief, Thermochemical Measurements and Standards Section, Chemistry Building, Room B350, Phone 301-921-2131.

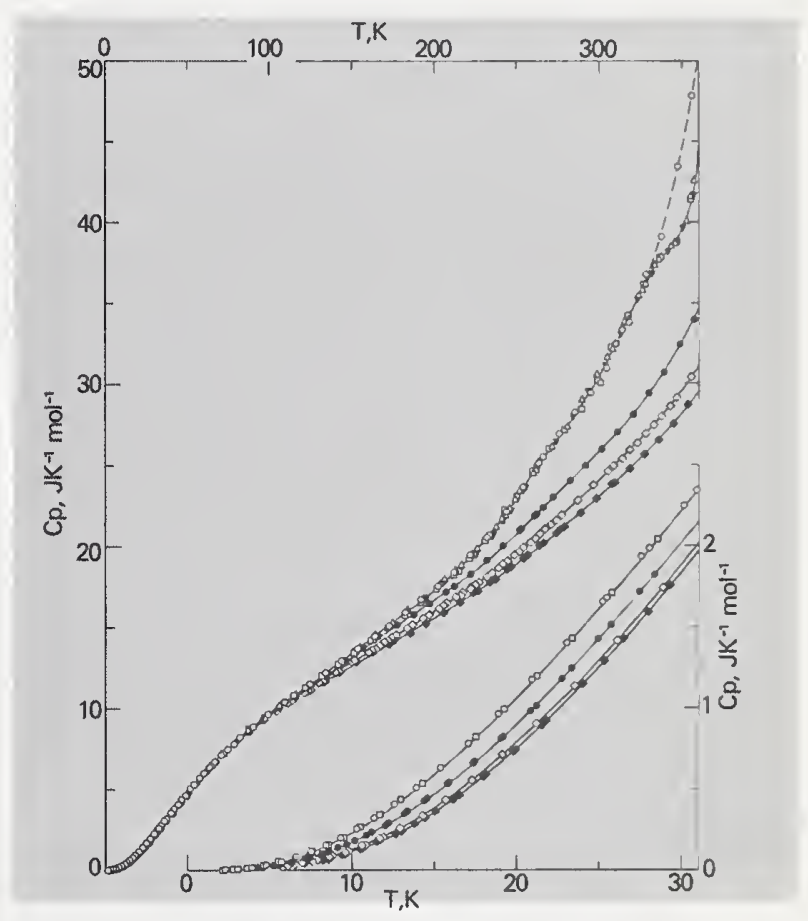

Typical specific data for different standard reference materials of polyethylene, using the LOW TEMPERATURE ADIABATIC CALORIMETER. The second-order glass transition is evident for the sample with the largest $C_{p}$ around $240 \mathrm{~K}$. 
PLATINIUM-LINED

\section{ADIABATIC SOLUTION CALORIMETER}

Capability: Liquid or crystalline samples up to 2.7 $\mathrm{cm}^{3}$ in volume are dissolved in $300 \pm 15 \mathrm{~cm}^{3}$ of any solution reactant that does not attack platinum. Minor modifications permit the introduction of gaseous samples in a flow system. For exothermic or endothermic reactions of $200 \mathrm{~J}$ or more, enthalpies of solution may be measured between 293 and $363 \mathrm{~K}$ for both rapid and slow reactions, with a precision of $0.02 \%$.

Calorimeter temperatures are measured with a quartzoscillator sensor with digital printout. The adiabatic shield temperature is controlled automatically to eliminate heat transfer to the calorimeter from its environment. The data are processed by a time-shared computer. The calorimeter is calibrated by supplying a known amount of electrical energy to the calorimeter resistance heater before and after the chemical reaction measurements.

Applications: Used to determine enthalpies of reaction at or near room temperature, for the purpose of obtaining enthalpies of formation, enthalpies of solution, and related thermodynamic properties of substances.

Availability: Because of the complexity of the instrumentation and the procedures of operation, use of the facility is limited to qualified members of the NBS staff or other scientists, after specific training of perhaps two months. The facility may be used indirectly through cooperative or contractual research agreements.

\section{Literature:}

[1] E. J. Prosen and M. V. Kilday, An adiabatic solution calorimeter and measurements of a standard reaction for solution calorimetry, J. Res. Nat. Bur. Stand. (U.S.) 77A, 179 (1973).

[2] M. V. Kilday and E. J. Prosen, The enthalpy of solution of low quartz ( $a$-quartz) in aqueous hydrofluoric acid, J. Res. Nat. Bur. Stand. (U.S.) 77A, 205 (1973).

Contact: Dr. G. T. Armstrong, Chief, Thermochemical Measurements and Standards Section, Chemistry Building, Room B350, Phone 301-921-2131.
ROTATING

PLATINUM-LINED,

ADIABATIC BOMB

CALORIMETER

Capability: Solid or liquid samples are reacted with oxygen at three megapascals (about $30 \mathrm{~atm}$ ) pressure in a $100 \mathrm{~cm}^{3}$ combustion bomb. The type of sample is limited only in that the products of the reaction must not be any chemical species that attacks platinum. A uniform concentration of aqueous products is assured by continuous rotation of the calorimeter. Amounts of sample are normally such as to cause $2500 \mathrm{~J}$ to be liberated as heat in the reaction. Under optimum conditions, the energy of reaction can be determined between $298 \mathrm{~K}$ and $323 \mathrm{~K}$ with a precision of better than $0.005 \%$. Calorimeter temperatures are measured potentiometrically with a platinum resistance thermometer as the sensor. The adiabatic shield temperature is controlled automatically to minimize heat transfer to the calorimeter from its environment. Determination of the amount and products of reaction can be determined by measurement of the amount of $\mathrm{CO}_{2}$ gas formed, and by analysis of aqueous solution constituents.

Applications: Used to determine enthalpies of reaction at or near room temperature, for the purpose of obtaining enthalpies of formation, enthalpies of solution, and related thermodynamic properties of substances.

Availability: Because of the complexity of the instrumentation and the procedures of operation, use of this facility is limited to qualified members of the NBS staff or other scientists, after specific training of perhaps two months. The facility may be used indirectly through cooperative or contractual research agreements.

\section{Literature:}

[1] W. H. Johnson and E. J. Prosen, The enthalpies of combustion and formation of the monochlorobenzoic acids, J. Res. Nat. Bur. Stand. (U.S.) 78A, 683 (1974).

Contact: Dr. G. T. Armstrong, Chief, Thermochemical Measurements and Standards Section, Chemistry Building, Room B350, Phone 301-921-2131. 


\section{COMPUTER}

\section{CENTRAL \\ COMPUTER FACILITIES}

The NBS Central Computer Facilities are available on a fee-for-service basis to support Government programs. In addition to Federal agencies, certain state and local government agencies, non-profit organizations, universities and private organizations, may qualify for use of the facilities. Service can be provided to non-Federal agencies on joint projects or for work that cannot be done effectively in the private sector. Arrangements can often be made to process work through remote terminals.

Facility Overview: The main computer in the NBS Central Facility is a UNIVAC 1108. The present operating system, EXEC 8 , is a general purpose executive designed to operate in a multiprogramming environment which provides for a variety of user options. Access to the main computer is provided to both onsite users and those at remote terminals connected via telecommunications. Software support includes FORTRAN, COBOL, ALGOL, XBASIC, MIRADS (a generalized data base management system), and OMNITAB (a computer language developed at NBS for statistical and numerical analysis).

Univac 1108: The UNIVAC 1108 includes 262,144 thirty-six-bit words of 750 nanosecond core memory. Auxiliary high-speed $(1,440,000$ characters per second) drum storage of approximately 25 -million characters capacity provides for efficient workload control and swapping of executive program files. Disk storage of approximately 925-million characters (FASTRAND mode) provides the needed capacity for on-line storage of application programs and data files. In addition, the system configuration includes eight seven-track tape drives (200, 556, $800 \mathrm{fpi})$, two nine-track NRZI tape drives (800 fpi), two nine-track PE tapedrives (1600 fpi), two printers, two card punches and two card readers. An IBM 1403-N1 printer is available off-line for printing from magnetic tapes prepared on the 1108.

Graphics Facilities: The Central Computer Facility' provides off-line plotting on a CalComp 763 ZipMode Digital Plotter, Computer Output to Microfilm (or hard copy) using a Stromberg-Carlson 4020, and extended character printing. A Graphical Display System software package is available which permits optical output to a variety of display devices including the CalComp Plotter, the SC 4020 Microfilm Recorder, or the Line Printer.
Capacity to Handle Scientific Documents: An extended character input/output subsystem, presently operating off-line to the 1108 , permits users to take full advantage of the information interchange facilities of the American National Standard Code for Information Interchange (ASCII). This provides character printing sufficient to handle documents at the normal level of complexity in notation, including half-line spacing for superscripts and subscripts, a repertory of Greek alphabetic characters and an assortment of special signs and symbols. Off-line paper tape facilities exist for entering ASCII punched paper tape as data via a 300 CPS optical scan paper tape reader.

Applications and Services: While the primary use of the central computer facility is as a laboratory tool for the technical staff of NBS and other agencies, an increasing level of support is provided to a variety of administrative and other data processing applications.

A consultant is available during working hours by phone or in the computer center for advice on details of system operation and problems owing to system and program interaction. New system development is frequently done for problem areas of general utility. Periodic training sessions are heid to acquaint users with various system capabilities (both hardware and software).

Literature: Various manuals are available to NBS users in the storeroom in the Administration Building. Other-agency users may secure manuals through the Management Assistant's office (301) 921-3364.

Use of Computer Facilities: Charges for the various computer services are on a cost-reimbursable basis and rate schedules are available.

Interested parties may contact Mr. R. A. Palladino, Management Assistant, Room A225, Administration Building, NBS, Washington, D.C. 20234 [telephone (301) 921-3364].

\section{AUTOMATION LABORATORY}

The Automation Laboratory is equipped with a computer controlled robot manipulator system with 6 degrees of freedom and a grip which allows it to pick up objects.

Capability: $750 \mathrm{~mm}$ reach; $4.5 \mathrm{~kg}$ load, $1 \mathrm{~m} / \mathrm{sec}$ tip velocity; touch, force, and proximity sensors. Controlled from a PDP-11/45 minicomputer.

Applications: Research on evaluation of sensors and computer control techniques for advanced automa- 
tion systems such as industrial robots and numerically controlled machine tools.

Availability: NBS staff, Guest Workers, Research Associates.

Contact: John M. Evans, Jr., Office of Developmental Automation Control Technology, Technology Building, Room A128, Phone 301-921-2381.

\section{ELECTRICAL \\ MEASUREMENTS FACILITIES}

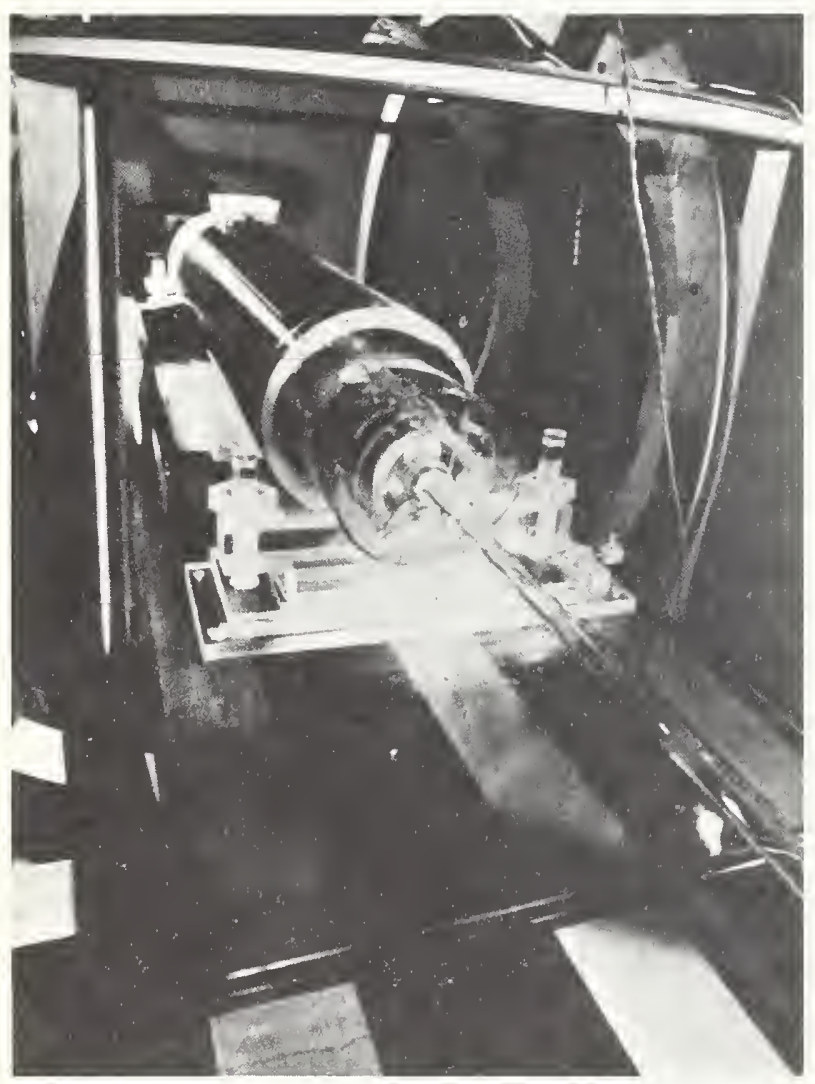

NON-MAGNETIC FACILITY. The probe shown in the foreground travels along the axis of the 1000-turn precision solenoid to locate the axial position of each turn of wire and to compare the relative area enclosed by each turn. This measurement allows calculation of the magnetic field produced by a known current.

\section{AUTOMATIC NETWORK ANALYZER}

Provides computer controlled rf stimulus for the calibration and measurement of passive quantities such as impedance, reflection coefficient, and attenuation and active quantities such as power and voltage. This is a commercially available item which has been modified into a special high accuracy system by NBS personnel.

Capability: The automatic network analyzer provides for discrete frequencies in the range of 0.1 to 18 $\mathrm{GHz}$ as an rf stimulus, applies these signals to the device under test, measures their characteristics, mathematically manipulates the data if necessary and outputs the data. The data output is available as a tabulation on a teletype or high-speed printer, a plot or diagram on an electrostatic plotter, or may be viewed as polar or rectangular plots on an oscilloscope. The measured data is in complex form and may be reflection coefficient, impedance, renormalized impedance, VSWR, attenuation, gain, or phase angle for passive quantities. Data output is in watts, volts, or fractional (decimal) parts thereof for active quantities. The connector types for connection to the automatic network analyzer may be in coaxial type such as APC-7, GR-900, type " $N$ " male or female, and in all the waveguide sizes used in the above frequency range.

These capabilities can be adjusted for either normal laboratory precision or for high accuracy standards and calibration type measurements. The NBS add-on system for high accuracy measurements and calibrations is presently undergoing evaluation.

Applications: The automatic network analyzer is intended for design, measurement, and calibration of rf and microwave components such as terminations, attenuators, thermistor mounts, crystal detectors, FIM receivers, antennas, filters, amplifiers, transistors, etc. As described previously these may be of coaxial or waveguide type usage devices.

Availability: To any qualified NBS research worker, after an initial training period with supervisor. In appropriate instances individual research workers from other Federal organizations can gain access to the facility.

Contact: D. H. Russell, Program Chief, Microwave Measurement Services, Radio Building, Room 4633, NBS Boulder, Colo. 80302, Phone 303-499-1000, ext. 3811. 
ELECTRO-OPTICAL

HIGH VOLTAGE

FIELD MAPPING SYSTEMS

State-of-the-art electrical and electro-optical measurement techniques are employed for measurement of high voltages, and for observation and probeless fringe-pattern mapping of high-intensity electric fields in insulating dielectrics. Apparatus allows operation under microsecond pulsed, and either steadystate direct or alternating voltages. Unique advantages afforded by the recently developed NBS electrooptical systems include their freedom from electromagnetic interference errors and their provision for direct visual observations (analogous to those used conventionally in photoelastic studies of mechanical stress) of electrical stress distributions.

\section{Capability, Operating Ranges, and Accuracy:}

[1] Pulsed Operation: peak voltages from 20 to $300 \mathrm{kV}$, risetimes of 0.5 to $2.0 \mu \mathrm{s}$, with durations up to $10 \mu \mathrm{s}$, repetition to 4 pulses per minute, measurement accuracy within $\pm 1 \%$.

[2] DC Operation: from 0 to $100 \mathrm{kV}$.

[3] AC Operation: from 0 to $50 \mathrm{kV} \mathrm{rms}$, from 40 to $200 \mathrm{~Hz}$.

Programs are available for automatic reduction and analysis of data, using NBS computer facility.

Applications: For calibration of HV pulse-measuring devices; for design studies with visualization of both steady-state and dynamic electrical stress distributions in selected insulating dielectrics; for visualization of the effects of space charge, suspended particles, dissolved ionic impurities and electrode composition, polish and geometry on electrical conduction in selected insulating liquids; for mapping of electric field distribution around immersed solid insulator models; for measurement of Kerr electro-optical coefficients of liquids; for dynamic and steady-state electrical breakdown studies in selected dielectrics; etc.

Availability: To qualified U.S. research workers from industry, government, and academic communities in cooperation with NBS supervisor. Scheduling is required to avoid conflict with in-house NBS research, calibration and testing programs.

\section{Literature:}

[1] NBS Tech. News Bull., Sept. 1972, Vol. 56, pp. 207-209.

[2] Rev. Sci. Instr., June 1972, Vol. 43, pp. 886893.

[3] J. Res. NBS, Vol. 73C, pp. 5-13, Jan.-June 1969.
Contact: Dr. Oskars Petersons, Chief, High Voltage Measurements Section, Metrology Building, Room B344, Phone 301-921-3121.

\section{NON-MAGNETIC FACILITY}

The non-magnetic building is located on an isolated area of the Bureau grounds, in the center of a $600-\mathrm{ft}$ square buffer zone. The building is a three-story structure (ground level plus two stories) constructed of non-magnetic materials and contains a minimum amount of electrically conducting materials. The building contains four isolation piers, one serving the ground floor and three serving the second floor level. A service building $300 \mathrm{ft}$ from the non-magnetic building provides the general laboratory equipment and support. Experiments in the non-magnetic building can be controlled and monitored from the service building.

Capability: Typical earth's magnetic field gradients are $10 \mathrm{nT} \cdot \mathrm{m}^{-1}$ in the vertical direction and $3 \mathrm{nT} \cdot \mathrm{m}^{-1}$ in the horizontal direction. Three-dimensional Helmholtz coils are available for cancelling the earth's magnetic field. Variations in the earth's field can be reduced by servo-ing to a magnetometer system in the magnetometer station located nearby. A precision solenoid is available to provide a magnetic field of $1.2 \times 10^{-3} \mathrm{~T}$ which is uniform within a $4-\mathrm{cm}$ diameter sphere and accurate to about $0.5 \mathrm{ppm}$ in terms of the NBS electrical standards. Equipment for automation and data acquisition is available.

Applications: The facilities of the non-magnetic building provide an environment where accurately known uniform magnetic fields can be applied to an experiment or where the earth's magnetic field strength and variations can be reduced a known amount. Currently the gyromagnetic ratio of the proton and the absolute ampere experiments are housed there.

Availability: The facility is available, when neither of the above two experiments are in active operation, for a compatible experiment which will not compromise the non-magnetic environment.

\section{Literature:}

[1] R. L. Driscoll and P. T. Olsen, The Review of Scientific Instruments, Vol. 42, No. 10, 1427.

[2] R. L. Driscoll and P. T. Olsen, Proc. of the International Conf. on Precision Measurement and Fundamental Constants, NBS Special Publ. 343, 117 (1970). 
[3] B. N. Taylor, D. N. Langenberg, and W. H. Parker, Scientific American, Vol. 223, No. 4, 62 (1970).

Contact: Dr. E. R. Williams, Absolute Electrical Measurements Section, Metrology Building, Room A247, Phone 301-921-3806.

\section{REACTANCE BRIDGE FOR POWER LOSS MEASUREMENT}

A typical high voltage inductor or shunt reactor on a power transmission lines has a reactive power rating of 100 megavolt-amperes and a power loss of about 200 kilowatts. Thus the power losses are of economic significance, but it is difficult if not impossible to measure them by conventional wattmeter methods because of the low power factor, i.e. the presence of very large reactive or circulating power. The shunt reactors are used to "tune out" the capacitances of transmission lines. A reactance bridge has been developed and constructed which in conjunction with readily available high-voltage standard capacitors can measure accurately such losses. Inductance and capacitance can also be measured. The instrument is designed for measurement of devices rated at moderate to extra high voltages-several hundred volts to one megavolt.

Capability: The instrument can be used at either the NBS or a commercially available high voltage laboratory. The voltage and power ranges depend principally on the capability of the power supply in the laboratory-for the NBS laboratory these are $220 \mathrm{kV}$, $200 \mathrm{kVA}$. Some commercial laboratories have capabilities of the order of $1 \mathrm{MV}$ and $100 \mathrm{MVA}$. When used in conjunction with a typical high voltage standard capacitor having a capacitance value of $100 \mathrm{pF}$, the inductance range of the specimen is from $0.12 \mathrm{H}$ to $600 \mathrm{H}$; the range for capacitors is from $100 \mathrm{pF}$ to $50 \mu \mathrm{F}$. The power losses can be measured to about one-percent accuracy; the inductance and capacitance to about 0.01 percent to 0.1 percent accuracy.

Applications: Primarily power loss measurements of large capacitors and inductors such as energy storage and power factor correction capacitors, high voltage shunt reactors (inductors); also impedance measurements of the same.

Availability: To any qualified NBS research worker or group. The High Voitage Measurements Section will provide an operator of the instrument and high voltage power supplies.
The use of the instrument is also available to outside groups in the form of calibration and test services.

Literature: NBS Tech. News Bull., April 1973, Vol. 57, No. 4, page 91.

Contact: Dr. Oskars Petersons, Chief of High Voltage Measurements Section, Metrology Building, Room B344, Phone: 301-921-3121.

\section{ELECTRON MICROSCOPES}

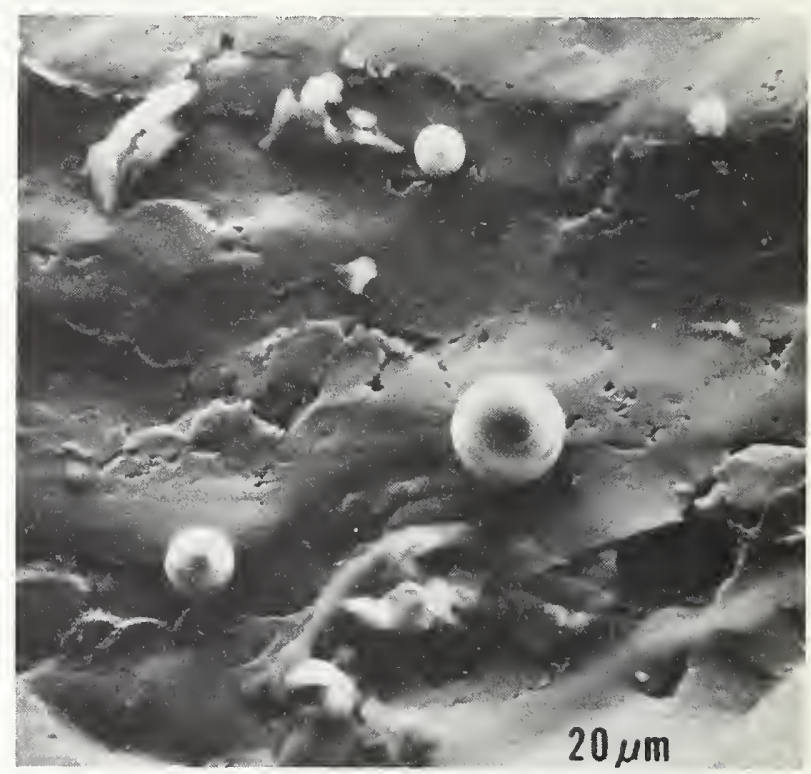

Fracture surface on worn steel specimen, including wear debris. The large depth of focus of the SCANNINC ELECTRON MICROSCOPE is demonstrated in this photomicrograph.

\section{SCANNING ELECTRON MICROSCOPE}

With resolution and depth of focus well beyond that of optical microscopes, this device uses a fine electron-beam probe to explore the minutiae of surface structure of materials such as lunar rocks, bridge structure fractures, microelectronic circuits, and dental restorations. For rough specimens, stereo-pair photography permits three-dimensional examination. Selected area electron channelling patterns can be obtained, and divergent-beam $\mathrm{x}$-ray (Kossel) patterns 
can be prepared for use in determining local stressstrain configurations.

Capability: Replica or actual specimen up to $2.5 \mathrm{~cm}$ diameter and $1 \mathrm{~cm}$ thick. Resolution of $25 \mathrm{~nm}$, and maximum magnification of 100,000x. Electron beam of about $10 \mathrm{~nm}(100 \AA)$ diameter is driven across specimen, while secondary electrons, backscattered electrons, and $\mathrm{x}$-rays are each detected and amplified to modify the brightness of a CRT raster. A data acquisition system and data reduction programs are available.

Applications: Behavior of grain boundaries in embrittled copper-palladium welds; checking of resolution using dendrites of aluminum-tungsten; identification of material in micrometeoritic lunar craters; distinguishing chrysotile from termolite; qualitative chemical analysis of microscopic particles; effect of polishing on dental materials; rusting through pinholes in enameled steel; bonding and defects in microcircuitry wafers; hydrogel coating on aortic catheters; wear of currency papers; sharpness of tungsten field-emitter tip.

Availability: To any qualified NBS research worker, after an initial training period. Over 30 NBS scientists have become competent operators. In appropriate instances individual research workers from other Federal organizations can gain access to the facility.

Literature: NBS Tech. News Bull., March 1972, Vol. 56, No. 3, pages 60-63.

Contact: Dr. Arthur W. Ruff, Jr., Chief of Microstructures Characterization Section, Materials Building, Room B118, Phone 301-921-2991.
This facilitates specimen preparation, increases foil rigidity, and reduces surface effects.

Capability: Accelerating voltages of 50, 100, 150, and $200 \mathrm{kV}$. Selected area electron diffraction and elecromagnetic beam tilting $\left( \pm 3^{\circ}\right)$ for dark field imaging. Side entry goniometer stage with: double-tilt ( $X=$ $\pm 60^{\circ}, \mathrm{Y}= \pm 45^{\circ}$ ), rotation $\left(360^{\circ}\right)$-tilt ( \pm 60 ), and heating (to $1000^{\circ} \mathrm{C}$ ) - tilt specimen holders for specimens up to $3.05 \mathrm{~mm}$ in diameter. Resolution (line) of $0.7 \mathrm{~nm}(7 \AA)$ and maximum magnification of 150,000 x. Data recorded on $3 \frac{1 / 4}{4} \times 4$ inch glass photographic plates. Dispersive $x$-ray energy analysis.

Applications: Examination of the surface regions of various ceramic materials after abrasive, smoothsliding and erosive wear; analysis of deformation and fracture mechanisms in ceramics as a function of temperature; analysis of cracks and crack healing processes in ceramics; microstructure characterization of cemented carbides; determination of stacking fault energy as a function of temperature in $\mathrm{Ag}-\mathrm{Sn}$ and $\mathrm{Au}-\mathrm{Sn}$ alloys; analysis of deformation modes in superplastic Al-base alloys; study of deformation and corrosion in $\mathrm{Cu}-, \mathrm{Fe}-$, and $\mathrm{Ni}$-base alloys.

Availability: To experienced electron microscopists having research applications which require high voltage electron microscopy.

Contact: Dr. Bernard J. Hockey, Physical Properties Section, Materials Building, Room A355, Phone 301921-2901.

\section{TRANSMISSION}

\section{ELECTRON MICROSCOPE, $200 \mathrm{kV}$}

This instrument allows high resolution examination of surface replicas and actual, thin-foil specimens of metals, ceramics, and polymers. Analysis of microstructure and lattice defects in crystalline materials can be made by electron diffraction contrast and selected area electron diffraction. The instrument is also equipped with a dispersive $x$-ray energy analysis system for elemental analysis. Compared to conventional transmission electron microscopes (100 kV), specimens which are $70 \%$ thicker can be examined. 


\section{ENVIRONMENTAL FACILITIES}

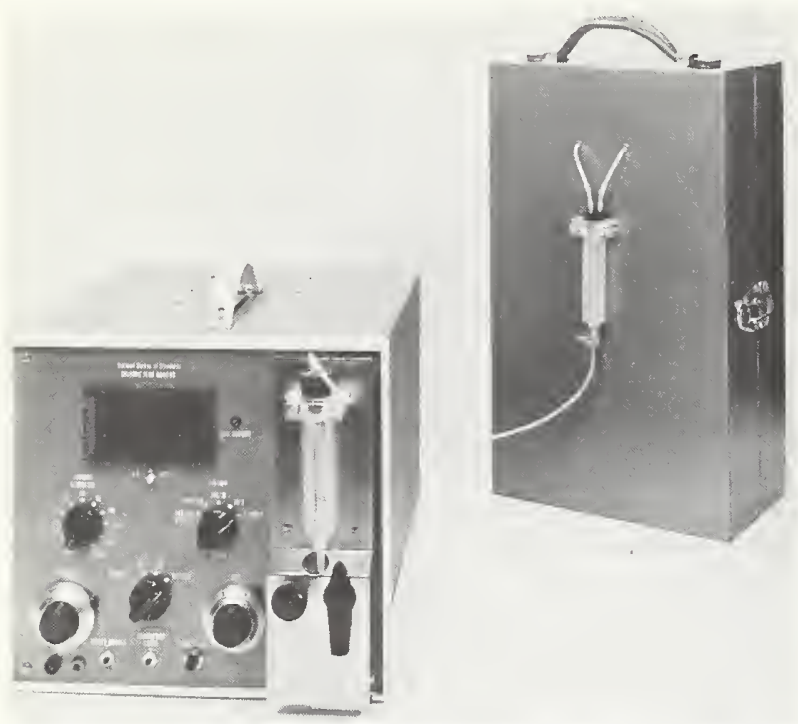

Portable system for field testing of chlorine-polluted water. Detection and calibration unit of CHLORINE FLUX MONI$T O R$ at left, reagent supply unit at right.

\section{CHLORINE FLUX MONITOR}

This newly developed electrochemical system for measuring traces of chlorine in water is based on the well-known principle that chlorine, chloramines, and hypochlorites will oxidize an iodide to iodine at the proper $\mathrm{pH}$. A motor-driven pump supplies the water sample to the iodine detector cell at a constant flow rate. The cell contains a platinum microelectrode and a reference electrode with a microammeter connected across them. The ammeter reading resulting from the oxidation reaction is displayed or recorded continuously as the monitored signal. A novel feature is the calibration of the amperometric signal, which is accomplished internally by supplying an accurately known amount of iodine generated coulometrically.

Capability: The newly developed chlorine flux monitor is capable of measuring chlorine concentrations from 20 parts per million (or higher, but higher concentrations were not tested) down to a fraction of a part per billion. The response is linear over this wide range (four orders of magnitude) with very few possible interferences, such as ozone, $\mathrm{MnO}_{\overline{4}}, \mathrm{Cr}_{2} \mathrm{O}_{7}=$, $\mathrm{Br}_{2}$, and $\mathrm{I}_{2}$.
Applications: Measurement of total residual chlorine concentrations in waste water, reactor coolant water, power plants, potable water, etc.

Availability: To any qualified researcher whose interests in chlorine measurements parallel those of Dr. George Marinenko and who is willing to collaborate.

\section{Literature:}

[1] Dimensions NBS, 58, No. 9, 208-209 (1974).

[2] Patent Application No. 610711.

[3] G. Marinenko, Fisheries Research Board of Canada (in press).

Contact: Dr. George Marinenko, Research Chemist, Analytical Chemistry Division, Chemistry Building, Room A225, Phone 301-921-2883.

\section{PRECISION HUMIDITY MEASUREMENT}

This facility comprises two precision humidity generators and a gravimetric hygrometer that can be used separately or in combination for calibration, testing, and development of instruments, sensors and devices and for research on the properties of moist gases. The generators produce continuous gas flows of constant moisture content whereas the hygrometer makes accurate humidity measurements.

Capability: Gas flows up to 150 cubic decimetres per minute. Ambient temperatures from +65 to $-75^{\circ} \mathrm{C}$. Mixing ratios from about 150 to $1 \times 50^{-5} \mathrm{~g} / \mathrm{kg}(1.5$ $X 10^{5}$ to $\left.0.01 \mathrm{ppm}\right)$. Dew point of $+65^{\circ} \mathrm{C}$ to frost point of $-100^{\circ} \mathrm{C}$. Ambient pressures from atmospheric to $50 \mathrm{mb}$. Generated moisture contents known to 0.5 percent or better over most of range and to 2 percent at extremes. Measurement accuracy 0.1 percent. New equipment soon operational will provide improved accuracy over wider ranges. Limited capability for response time testing. Data acquisition system available.

Applications: Calibration of dew-point hygrometers, psychrometers, electric hygrometers, infra-red hygrometers, dewcels, coulometric hygrometers; evaluation and testing of such sensors as carbon film, aluminum oxide, crystal array, lithium chloride, barium floride; enhancement of water vapor in air with pressure.

Availability: Facility available for use on tests, research or programs of NBS divisions, other Government agencies, and industrial or scientific laboratories.

\section{Literature:}

[1] J. Res. NBS 40, 479 (1948)

[2] NBS Monograph 73 (1964)

[3] ISA Trans. 7 (No. 4), 356-362 (1969) 
Contact: Arnold Wexler, Chief, Humidity Section. Physics Building, Room B356, Phone 301-921-2794.

\section{FIRE RESEARCH}

\section{FIRE RESEARCH LABORATORY}

A special laboratory building for large scale fire experiments has just been completed.

Capability: A major feature of the building is a $60 \mathrm{ft}$ $X 120 \mathrm{ft}$ test floor with a $32 \mathrm{ft}$ ceiling height. The test floor is equipped with smoke abatement equipment to meet air pollution regulations, water supplies and floor drains, making it suitable for a variety of fire experiments. A shop for the fabrication of test structures, a conditioning room for the storage of materials and test structures prior to test, an instrument room, and office and service areas complete the building.

The only permanent experimental facility on the test floor is the Fire Research Test Furnace described in detail below. Other test structures and apparatus are erected as needed for specific programs, providing maximum flexibility in space utilization.

The facilities are: $A$ room and corridor facility. This consists of a corridor approximately $50 \mathrm{ft}$ long with two $8 \mathrm{ft}$ by $8 \mathrm{ft}$ rooms opening onto the side wall. Provisions are made for varying the wall and ceiling spacings and controlling draft conditions. The facility can be used for study of the spread of fire through corridors, the movement of smoke and gas through room-corridor systems, the effect of surface finishing materials on fire spread, and related purposes.

A burn room and smoke movement facility. This is a two story masonry structure with controlled ventilation and communication between floors. It can be used to conduct studies of the burning of room furnishings or to study the spread of smoke, gas, and fire through a multi-compartment structure.

$A$ rate of heat release calorimeter. This instrument measures the rate of heat release and the total heat release from a large sample of material when exposed to a controlled energy flux. It is used to measure the energy contribution of materials involved in a building fire.

A research test furnace. This is a medium-sized unit providing conformity with the temperature-time exposure specification of ASTM E119, plus extension to
$150 \%$. It will accommodate 30 -ton walls or partitions 10 feet long by 8 feet high, 20-ton columns 8 feet high, or 20 -ton floor-ceiling assemblies 8 feet by 10 feet. Furnace pressure is controllable between -0.05 and $+0.15 \mathrm{in}$. water to permit study of the effect on fire performance. The furnace can be used for fire endurance tests on structural components such as ducts, dampers, doors, and plumbing systems, on innovative constructions such as double modular walls, and on joints in wall-floor assemblies.

Applications: The Fire Research Laboratory provides a location where large scale fire experiments can be carried out under controlled conditions. Space is available for the construction of a variety of experimental installations.

Availability: Available upon request for research experiments for other Government agencies and industrial groups. Available for research programs of industrial Research Associates. Availability of specific facilities is dependent on workload.

\section{Literature:}

[1] Francis C. W. Fung, Miles R. Suchomel and Philip L. Oglesby, The NBS Program on Corridor Fires, Fire Journal 67, pages 41-48 (May 1973).

[2] W. J. Parker and M. E. Long, Development of a Heat Release Rate Calorimeter at NBS, ASTM STP 502, pages 135-151 (1972).

Contact: Mr. J. A. Benjamin, Fire Technology Division, Technology Building, Room B64, Phone 301-9213255.

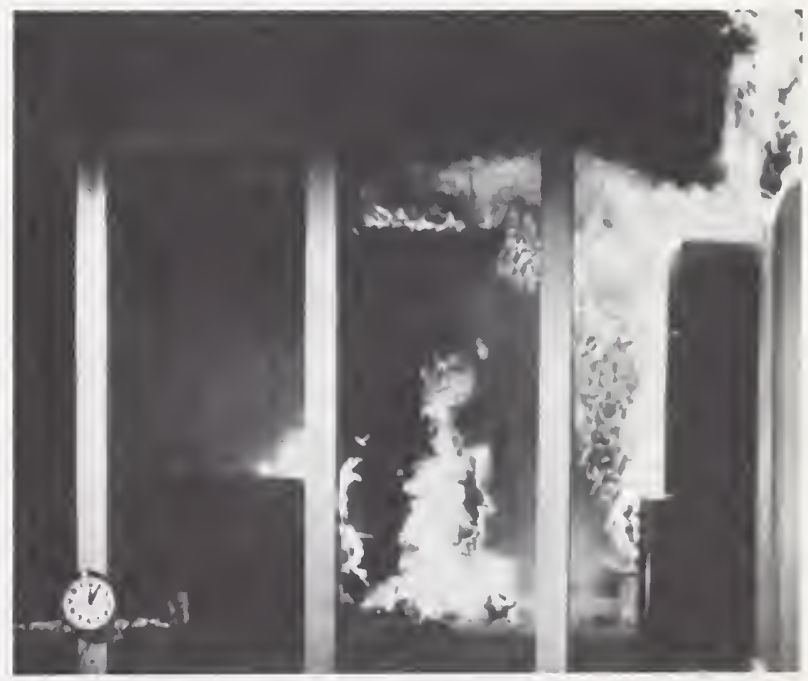

A room fire test in the FIRE RESEARCH LABORATORY. 


\section{HIGH PRESSURE FACILITIES}

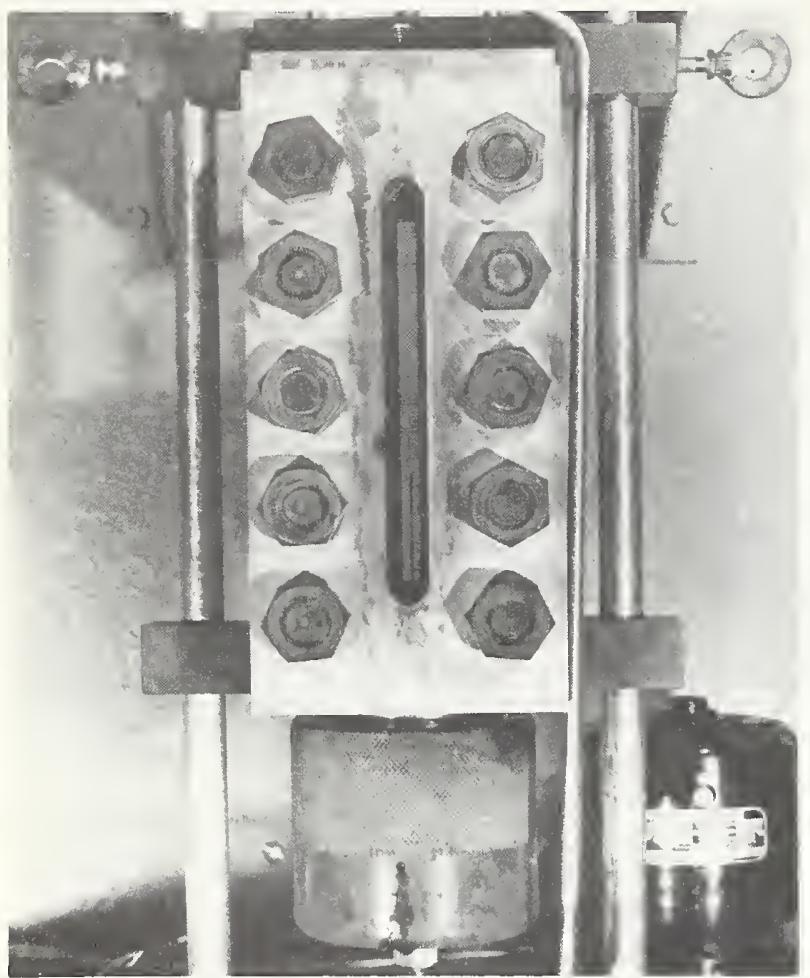

HIGH PRESSURE PVT DILATOMETER. The mercury column is seen in the capillary inside the pressure chamber.

\section{HIGH PRESSURE GENERATORS}

Two systems for generating high pressures have been developed for the measurement of electrical, mechanical and pressure/volume properties of liquids and solids.

\begin{tabular}{|c|c|c|}
\hline \multicolumn{3}{|l|}{ Capability } \\
\hline & System I & System II \\
\hline $\begin{array}{l}\text { MAXIMUM } \\
\text { PRESSURE }\end{array}$ & $\begin{array}{c}26 \mathrm{kbar} \\
2600 \text { (MPa) }\end{array}$ & $\begin{array}{c}40 \text { kbar } \\
(4000 \mathrm{Mpa})\end{array}$ \\
\hline $\begin{array}{l}\text { USABLE } \\
\text { VOLUME }\end{array}$ & $\begin{array}{l}19 \mathrm{~mm} \text { diameter } \\
\times 100 \mathrm{~mm} \text { length }\end{array}$ & $\begin{array}{c}10 \mathrm{~mm} \text { diameter } \\
\times 10 \mathrm{~mm} \text { diameter }\end{array}$ \\
\hline $\begin{array}{l}\text { ELECTRICAL } \\
\text { LEADS }\end{array}$ & 4 & 1 \\
\hline $\begin{array}{l}\text { PRESSURE } \\
\text { GAGE }\end{array}$ & manganin & ram force \\
\hline $\begin{array}{l}\text { TRANSMITTING } \\
\text { FLUID }\end{array}$ & pentane mixtures & $\begin{array}{l}\text { pentane mixtures, } \\
\text { also soft solids }\end{array}$ \\
\hline
\end{tabular}

Application: System 1 has been used for ultrasonic measurements on solids and liquids, for electrical resistance measurements, for measurements of crack propagation in glasses and for the study of phase transition. Apparatus requiring electrical leads can be plugged into a receptacle at the inside bottom of the pressure vessel. A total of four leads are available.

System II has been used for ultrasonic measurements in liquids and in solids under either hydrostatic or non-hydrostatic conditions. Transducers to detect shear or longitudinal mode properties are mounted on the outside; they use a back plate as acoustic buffer. A back plate with one electrical lead is also available.

Availability: The equipment is available to qualified researchers after an initial training period or with assistance from Section personnel.

Literature: D. L. Decker et al, High-Pressure Calibration, A Critical Review, J. Phys. \& Chem. Ref. Data, 1, no. 3, pp. 173-836, 1972.

Contact: Dr. Peter L. M. Heydemann, Chief, Pressure and Vacuum Section, Metrology Building, Room A149, phone 301-921-2121.

\section{HIGH PRESSURE OPTICAL \\ FLUORESCENCE SYSTEM}

The optical system measures the pressure-dependent shift of the sharp fluorescent $R_{1}$-line of ruby which has been calibrated against the compression of $\mathrm{NaCl}$ as the primary standard. The system was developed to measure pressure in the diamond-anvil high pressure cell, but with minor modification can be used in any pressure vessel which has optical access.

Capability: Quantitative pressure determinations are made to 300 kbar with an accuracy in the range of 5 percent; qualitative measurements up to the realizable limit of about 500 kbar. Temperature capability to $300^{\circ} \mathrm{C}$ is also available, but the accuracy in the pressure measurement is significantly reduced at this temperature.

Applications: Characterization of phenomena induced by pressure-such as phase transitions in solids, freezing pressures of liquids, glass transition pressures in vitrified materials, compressibility measurements (in conjunction with x-ray measurement), and pressure distribution in various pressure transmitting media.

Availability: On a selective basis when not required for Crystallography Section programs. The system 
must be operated by Section personnel and only work of mutual interest can be unde taken.

\section{Literature:}

[1] G. J. Piermarini, S. Block, J. D. Barnett, and R. A. Forman, J. Appl. Phys. 46, 2774 (1975).

[2] G. J. Piermarini and S. Block, Rev. Sci. Instr. 46, 33 (1975).

Contact: Dr. G. J. Piermarini, Materials Building, Room B224, Phone 301-921-2950.

\section{HIGH PRESSURE PVT DILATOMETER}

This PVT (pressure-volume-temperature) apparatus is used to measure the density of liquids and solids (including polymers) with varying temperature and pressure. The method employs pressurized dilatometry in which a dilatometer is placed in a pressure chamber with glass windows. This chamber is, in turn, placed in a liquid thermostat with glass windows which is controlled by a refrigerator and electric heaters. The pressure is generated by a hand pump and may be determined by a bourdon or dead weight piston gage. The sample volume is determined in terms of the relative height of the mercury column of the dilatometer, using a cathetometer.

Capability: Temperature range, -40 to $200^{\circ} \mathrm{C}$. Constant heating and cooling rates may be selected as low as $.05^{\circ} / \mathrm{hr}$; pressure range, 800 bar. (This range may be extended to 2 kbar by using a suitable pressure chamber.) A dead weight piston gage is available to maintain constant pressure during, for example, isobaric heating and cooling, and volume creep measurements.

Applications: Ordinary equilibrium PVT measurements, including phase changes. Non-equilibrium measurements may include influence of temperature and pressure on glass transition and crystal growth mechanisms, glasses formed at constant volume, and volume creep and stress (pressure) relaxation. The densification of polymer glasses at elevated formation pressures gives a higher refractive index which suggests their use as optical lenses.

Availability: By research workers on problems of mutual interest with those of the Bulk Properties Section. Initial instruction will be given by the Section staff.

\section{Literature:}

[1] J. E. McKinney and R. W. Penn, Rev. Sci. Instr. 43, 1212;

[2] J. E. McKinney and M. Goldstein, J. Res.,
Nat. Bur. Stand. (U.S.) 78A, no. 3, 331-353 (May-June 1974).

Contact: John E. McKinney, Bulk Properties Section, Polymer Building, Room B330, Phone 301-921-2116.

\section{HIGH TEMPERATURE FACILITIES}

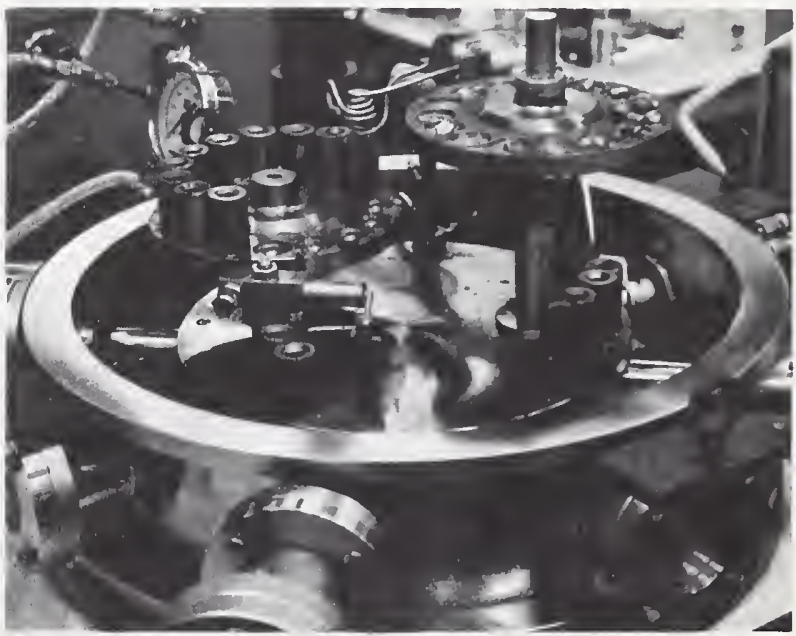

Levitation vacuum melting equipment for preparation of high-purity materials in the ALLOY PREPARATION LABORATORY

\section{ALLOY PREPARATION LABORATORY}

Research grade samples of metals and alloys are prepared when such samples are not readily available commercially, or when accurate details are required concerning the purity of the constituents and the melting and fabricating history.

Capability: Vacuum-induction melting and casting; arc furnace; levitation melting furnace; electronbeam zone refiner; electron-beam button melter; electron-beam evaporator; induction and resistance melting and casting furnaces; heat-treating furnaces; cold-working equipment for rolling, swaging, and drawing; apparatus for producing metallic hydrides under hydrogen pressures up to $6900 \mathrm{kN} / \mathrm{m}^{2}$ (1000 psi).

Applications: High purity iron ingot with 1.194 $\pm 0.004 \%$ carbon; homogeneous ingot of magnesium-zinc; 200-mesh lead-indium powders; devices for hydrogen storage. 
Literature: NBS Tech. News. Bull. Vol. 56 No. 8, p. 182-183 (Aug. 1972).

Contact: H. C. Burnett, Scientific Assistant, Metallurgy Division, Materials Building, Room B260, Phone 301921-2813.

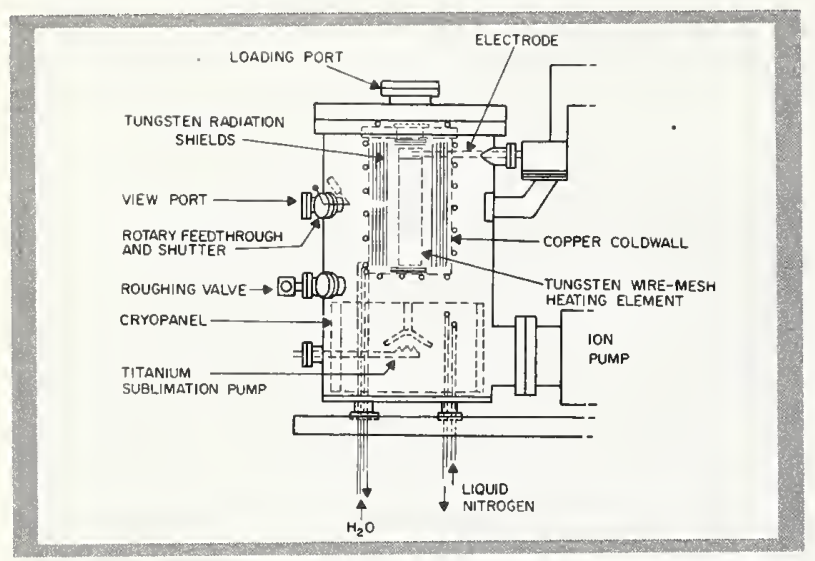

Schematic of the HIGH TEMPERATURE . CONTROLLEDATMOSPHERE FURNACE, designed for testing thermocouples in high temperature gas environments.

\section{HIGH-TEMPERATURE CONTROLLED-ATMOSPHERE FURNACE}

The furnace provides the facility for establishing heated environments at a temperature in the range between $1000^{\circ} \mathrm{C}$ and $2750^{\circ} \mathrm{C}$ in vacuum. If high conductivity gas environments are required the upper temperature range is about $2500^{\circ} \mathrm{C}$.

Capability: The furnace has a tungsten-mesh heating element $6.4 \mathrm{~cm}$ in diameter by $30.5 \mathrm{~cm}$ long, oriented with its central axis vertical. The heating element is surrounded by tungsten radiation shields formed from $0.125 \mathrm{~mm}$ thick tungsten sheet; these are enclosed within a water-cooled copper assembly. A 10$\mathrm{cm}$ diameter port at the top of the vacuum chamber provides complete access to the interior of the heating element for installing materials and experimental devices for test. A viewing port on the side of the vacuum chamber is part of the optical path that extends to within the heater coil. At ambient temperatures, base pressures of less than $5 \times 10^{-11}$ torr (6.66 $\mathrm{n} \mathrm{Nm}^{-2}$ ) may be achieved within 20 hours and the furnace is designed to produce hot zone temperatures to $3000 \mathrm{~K}$ while maintaining the pressure in the $10^{-8}$ torr (1333 $\mathrm{nNm}^{-2}$ ) range. Equipment conven- tionally used with the furnace includes a residual gas analyzer and a photoelectric pyrometer.

Applications: Thus far the furnace has been used for investigating the behavior-stability and emf characteristics-of tungsten/rhenium alloy thermocouples.

Availability: To any qualified NBS research worker, after making availability arrangements and receiving training from Mr. George Burns, phone 301-921-2069. In appropriate instances arrangements might be made for individual research workers from other Federal organizations to gain access to the facility. The furnace is currently in use for research over extended periods of time.

Literature: J. Res. Nat. Bur. Stand. (U.S.) Vol. 75C, No. 2, April-June 1971.

Contact: Dr. J. F. Schooley, Chief, Temperature Section, Physics Building, Room B222, Phone 301-9212801.

\section{HIGH TEMPERATURE VAPORIZATION LABORATORY}

This laboratory contains extensive facilities for the study of high-temperature vaporization equilibria and gas phase chemical reactions.

Capabilities: The laboratory is equipped to carry out measurements of vaporization equilibria at temperatures up to $3200 \mathrm{~K}$ using both Langmuir and Knudsen methods. The laboratory is equipped for mass spectrometry, torsion effusion, and gravimetric (including vacuum microbalance) methods. A unique mass spectrometric sampling system has been developed to permit molecular beam sampling from high temperature gaseous or gas-solid systems at pressures exceeding one atmosphere, and other mass spectrometers are available for the study of heterogeneous reactions of solids with reactive gases at high temperatures.

Applications: The facilities of the laboratory have been or are being applied to investigation of a number of diverse high-temperature problems. These include measurements of vapor pressures and vanorization thermodynamics for metals, oxides, carbides, and other materials, as well as vapor-solid reaction studies related to the corrosion of refractories in aggressive environments. Investigations involving sampling of specific regions of flames are carried out to define basic flame chemistry and to study effects of flame extinguishants and retardants at the molecular level. 
Other applications include investigations of laserinduced chemical phenomena in the gas phase.

Availability: Because of the complexity of the instrumentation and prior programmatic commitments, direct use of the facility is limited to qualified members of the Section staff. The facility may be used indirectly through collaborative research agreements with other qualified NBS or guest scientists.

Literature: NBS Tech. News Bull. 56, 11, 271, January 1972.

Contact: Dr. T. D. Coyle, Chief, Inorganic Chemistry Section, Materials Building, Room A329, Phone 301921-2847.

\section{INORGANIC GLASSES: PREPARATION AND VISCOSITY}

This laboratory has facilities for the melting of experimental glasses at temperatures to $1600^{\circ} \mathrm{C}$ and for measuring the viscosity of glasses over the range from $10^{2}$ to $10^{15}$ poises ( 10 to $10^{14} \mathrm{~Pa} \cdot \mathrm{s}$ ) at temperatures 1430 to $520^{\circ} \mathrm{C}$.

Capabilities: A batch of $1000 \mathrm{~g}$ of an experimental glass can be made using starting materials of known purity and doped with known amounts of trace elements. The melts are normally made in platinum crucibles heated in an electric furnace with silicon carbide elements, and stirred with platinum-10\% rhodium stirrers to produce glasses having a high degree of homogeneity. Melts may also be made in ceramic crucibles if the glass composition is not compatible with platinum. After fining the molten glass is poured into a metal mold to form a test block, which is then placed in a muffle furnace to cool to room temperature in about 18 hours. From this block samples may be cut for property measurements. Specimens may also be cast into various shapes or drawn into rods, tubes, or fibers.

Viscosities in the range of $10^{2}$ to $10^{10}$ poises (10 to $10^{9} \mathrm{~Pa} \cdot \mathrm{s}$ ) corresponding to a temperature range for soda-lime-silica glass from 1430 to $630^{\circ} \mathrm{C}$, are measured by a rotating concentric cylinder apparatus. Higher viscosities, up to $10^{15}$ poises $\left(10^{14} \mathrm{~Pa} \cdot \mathrm{s}\right)$ at temperatures down to about $520^{\circ} \mathrm{C}$ for the sodalime-silica glass, are measured primarily by fiber elongation procedures.

Applications: Production of small lots of optical glass. Synthesis of the glassy coal slag produced in magneto-hydrodynamic power cells, and measurement of its properties. Studies of softening, annealing, and strain points needed for control of viscosity in auto- matic machinery used to manufacture glass containers.

Availability: Because of the experience required, the use of the laboratory is limited to (a) permanent members of the Section and (b) qualified individuals working directly under the supervision of Inorganic Glass Section personnel. The facility may be used indirectly through cooperative or contractual research agreements.

\section{Literature:}

[1] Given W. Cleek and Edgar Hamilton, Properties of Barium Titanium Silicate Glasses, J. Res. Nat. Bur. Stand. (U.S.) 57 [6] 317 (1956).

[2] Albert Napolitano and Earl G. Hawkins, Viscosity of a Standard Soda-Lime-Silica Glass, J. Res. Nat. Bur. Stand. (U.S.) 68A [5] 439 (1964).

[3] Albert Napolitano, Pedro B. Macedo, and Earl G. Hawkins, A Wide-Range (up to $10^{10} \mathrm{P}$ ) Rotating Cylinder Viscometer, J. Res. Nat. Bur. Stand. (U.S.) 69A [5] 449 (1965).

Contact: Dr. W. Haller, Chief of Inorganic Glass Section, Inorganic Materials Division, Materials Building, Room B328, Phone 301-921-2819.

\section{LASER MATERIALS FACILITY}

This well-characterized, high-power laser of neodymium-doped glass is used to produce data on the damage thresholds for laser materials.

Capability: The neodyminum-doped glass laser consists of an oscillator and two amplifiers. The temporal and spatial properties of the laser beam are well controlled and characterized with precision. The oscillator operates in the TEM $\mathrm{TO}_{00}$ mode with an aperture of about $2.5 \mathrm{~mm}$ in diameter. The spatial beam profile at $5 \mathrm{~m}$ from the output energy approximates a Gaussian distribution. The output energy is reproducible to within $\pm 2 \%$. The facility with one amplifier produces a minimum energy of $650 \mathrm{~m}$ ). The facility with both amplifiers produces approximately 3 J with some deterioration of the beam quality.

The operating pulse width at half the maximum power and the wavelength are respectively $25 \mathrm{~ns}$ and $1060 \mathrm{~nm}$. A frequency doubler is available to produce a $530 \mathrm{~nm}$ wavelength. A laser-triggered spark gap and Pockels cell are available for producing pulse widths as small as $2.5 \mathrm{~ns}$. A dye cell is available for mode-locking. 
Applications: This facility is used to measure extrinsic and intrinsic bulk damage thresholds and surface damage thresholds. Whenever intrinsic damage arises from self-focusing, procedures exist for the identification of the dominant mechanisms, such as the thermal effect, electrorestrictive effect, and Kerr effect. The facility also may be used to investigate twophoton absorption processes.

Availability: The availability of this facility depends upon mutual interest, the time required to make the measurements, and whether there are other commitments for its use. Because this facility is complex, its use requires the presence and guidance of permanent members of the laboratory. A requesting party, who is qualified, may assist in taking the data.

\section{Literature:}

[1] A. Feldman et al., ARPA-NBS Program of Research on High Temperature and Laser Materials, NBS Technical Note 703 (Dec. 1971).

[2] A. Feldman et al., "Mechanisms for SelfFocusing in Optical Glasses," IEEE Journal of Quantum Electronics (Nov. 1973).

Contact: Dr. Herbert S. Bennett, Chief of the Solid State Materials Section, Room A259, Materials Building, Phone 301-921-2415.

\section{MILLISECOND HIGH-TEMPERATURE THERMOPHYSICAL MEASUREMENTS}

This facility, which is unique of its kind in the world, allows the accurate measurement of selected thermophysical and related properties of electrically conducting solid substances at high temperatures (above $1500 \mathrm{~K})$ in experiments of subsecond duration.

Capability: The method is based on rapid resistive self-heating of the specimen from room temperature to any desired high temperature (up to the melting point) in less than one second by the passage through it of electrical currents of several thousand amperes. Measurement and recording of experimental quantities are made automatically every 0.4 millisecond, with a full-scale signal resolution of one part in 8000 . A high-speed pyrometer and a digital data acquisition system are employed.

Applications: The facility provides the capability of measuring, either simultaneously or consecutively, the following properties: specific heat, electrical resistivity, hemispherical total emittance, normal spec- tral emittance (at $650 \mathrm{~nm}$ ), and melting point, in the temperature range from $1500 \mathrm{~K}$ to the melting point of the specimen. The facility, after some modifications, has the potential of measuring other thermodynamic and transport properties and extending the measurements to the liquid phase.

Availability: Because of the complexity of instrumentation, the direct use of this facility is limited to: (a) permanent members of the laboratory, and (b) qualified full-time guest scientists with appointments exceeding six months. The facility may be used indirectly through cooperative research agreements.

\section{Literature:}

[1] A. Cezairliyan, M. S. Morse, H. A. Berman, and C. W. Beckett, J. Res. Nat. Bur. Stand. (U.S.), 74A, 65 (1970).

[2] A. Cezairliyan, J. Res. Nat. Bur. Stand. (U.S.), 75C, 7 (1971).

Contact: Dr. Ared Cezairliyan, High-Speed Thermophysics Laboratory, Hazards Building, Room 124, Phone 301-921-3687.

\section{LOW PRESSURE FACILITY}

\section{MERCURY MANOMETER}

For this design of low-pressure manometer, end length standards are used to measure the height of the column of mercury that is supported by gas pressure. The locations of the large mercury menisci are reproduced by reestablishing the capacitance between the crowns and carefully located capacitance electrodes.

Capability: Optimum relative accuracy of a single pressure measurement within $2 \times 10^{-6}$ for pressures between $5 \times 10^{3}$ and $1.3 \times 10^{5} \mathrm{~Pa}(4 \mathrm{~cm}$ to $1 \mathrm{~m} \mathrm{Hg})$, and for ratios of pressures that are in the same range. The relative error for lower pressures does not exceed $5 \times 10^{-6}$ for pressures down to $5 \times 10^{2} \mathrm{~Pa}(0.4 \mathrm{~cm}$ $\mathrm{Hg}$ ). Both absolute and differential pressures can be measured.

Applications: Determination of the pressure of fixed points for "benchmark" purposes; realization of a standard atmosphere; calibration of highest quality deadweight gages operating in the range of 1 atmosphere; calibration of ultraprecise manometers (such as ultrasonic mercury manometers, and perhaps diaphragm or quartz devices). 
Availability: On a selective basis when not being used for gas thermometry. It is desired to make use of the facility so far as possible whenever the exceptional accuracy obtainable is essential. The instrument must be operated by project personnel.

\section{Literature:}

[1] Metrologia 6, 1 (1970).

[2] NBS Tech. News Bull., March 1971, Vol. 55, No. 3, pages 73-75.

[3] Experimental Thermodynamics, v. II, Ch. 4., pt 1, 115-131 (1975).

Contact: Dr. Leslie A. Guildner, Project Leader, Gas Thermometry, Room A05, Physics Building, Phone 301-921-2076.

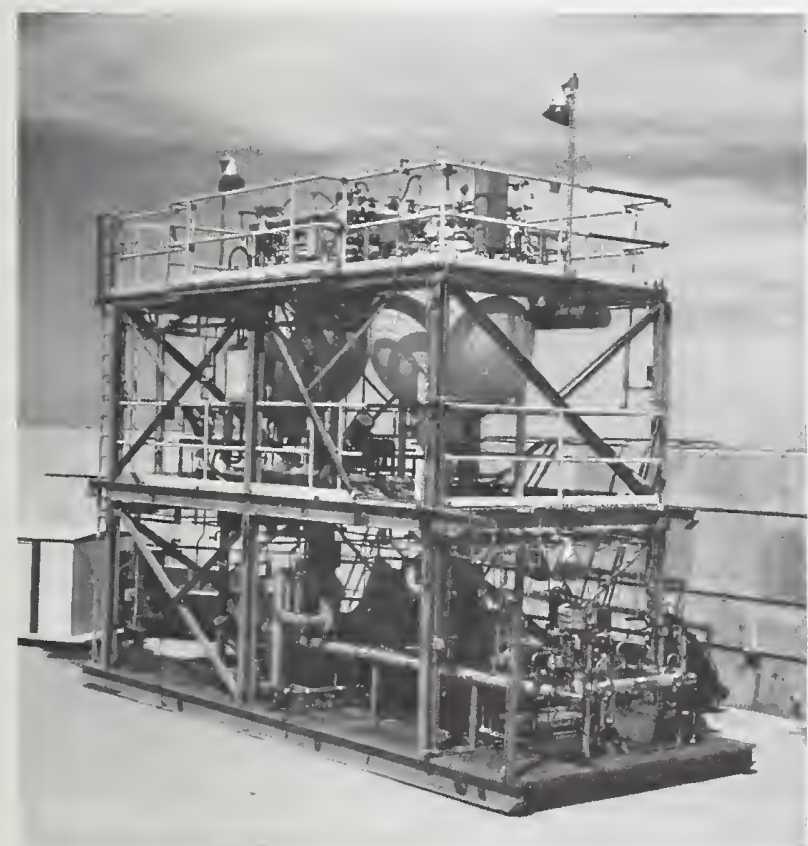

LIQUEFIED NATURAL CAS FLOW FACILITY. Insulated tanks with pumps, weighing system, and instrumentation for liquefied natural gas.

\section{LOW TEMPERATURE FACILITIES}

\section{ACOUSTICAL THERMOMETER}

The instrument is a standing wave ultrasonic interferometer that operates at principally 1 megahertz. It is employed to determine values of temperature be- tween 2 and 27 kelvins on the NBS P2-20 (1965) scale.

Capability: The instrument employs highly reproducible germanium resistance thermometers for indicating the constancy and reproducibility of temperatures. Isotherms of the speed of sound versus the pressure of ${ }^{4} \mathrm{He}$ gas have indicated a reproducibility of data points that is within \pm 2 millikelvins. The facility has operated at temperatures between $2.3 \mathrm{~K}$ and $27 \mathrm{~K}$. A laser interferometer has been installed to permit the measurement of acoustical wavelengths. Auxiliary equipment permits the potentiometric measurement and calibration of the resistance of germanium resistance thermometers.

Applications: Determination of absolute temperature values at low temperatures.

Availability: This facility is available at times when it is not being employed for the Temperature Section's research program.

\section{Literature:}

[1] Metrologia, Vol. 2, No. 4, 18 (1966).

[2] Cataland, G. and Plumb, H. H., Nat. Bur. Stand. (U.S.), Tech. Note 765, 23p (May 1973).

Contact: Dr. J. F. Schooley, Chief, Temperature Section, Physics Building, Room B222, Phone 301-9212801.

\section{CRYOGENIC FLOW RESEARCH FACILITY}

Facility provides continuous flow of liquid nitrogen with the ability to control flow rate, temperature, and pressure over wide ranges.

Capability: Flow rate is continuously variable for 1.3 to $13 \mathrm{l} / \mathrm{s}$ (20 to $200 \mathrm{gpm}$ ). Normal temperature range is 72 to $90 \mathrm{~K}\left(129.6\right.$ to $\left.162^{\circ} \mathrm{R}\right)$ which can be extended to $115 \mathrm{~K}\left(207^{\circ} \mathrm{R}\right)$. Normal pressure range is 0.22 to $0.77 \mathrm{MPa}$ (32 to $112 \mathrm{psia}$ ) which can be extended to $2.15 \mathrm{MPa}$ (312 psia). Temperature and pressure combinations are limited to the compressed liquid region for accurate flow rate determinations.

Applications: Flow measurement; heat transfer measurements in flowing fluids at cryogenic temperatures; calibration of flowmeters and transfer devices.

Availability: To qualified NBS and other Federal Government personnel. Facility operators will be provided.

\section{Literature:}

[1] J. A. Brennan, et al., Tech. Note 624, "And Evaluation of Several Cryogenic Turbine 
Flowmeters," Nat. Bur. Stand. (U.S.), Oct. 1972.

[2] ). A. Brennan, et al, "An Evaluation of Selected Angular Momentum, Vortex Shedding and Orifice Cryogenic Flowmeters," NBS Technical Note 650 (March 1974).

[3] J. A. Brennan, et al, "NBS-CGA Cryogenic Flow Measurement Program," ISA preprint 74-612, ISA Annual Meeting, Oct. 28-31, 1974.

Contact: R. S. Collier, Chief, Cryogenic Metrology Section, Cryogenics Building, Room 1108, NBS Boulder, Colo. 80302, Phone 303-499-1000 ext. 3178.

\section{HYDROGEN LIQUEFACTION FACILITY}

The NBS hydrogen liquefier was first operated in March 1952. Since that time it has been used extensively as a liquefier and as a general facility for relatively large-scale low-temperature experiments requiring quantities of high pressure gas and purification equipment.

Capabilities: The facility contains compressors, vacuum pumps, gas holders, liquid nitrogen temperature silica gel purifiers and a liquefier containing an ortho to para hydrogen catalyst. The unit is capable of producing liquid hydrogen at the rate of 250 liters per hour. The gas flow rate is 750 standard cubic feet per minute $\left(1300 \mathrm{~m}^{3} / \mathrm{h}\right)$ at approximately $2000 \mathrm{psi}$ $\left(13.6 \times 10^{6} \mathrm{~Pa}\right)$. The purifiers and the liquefier proper are contained in stainless steel high-vacuum insulated dewars 30 inches diameter by 93 inches long $(0.76 \mathrm{~m}$ $\times 2.4 \mathrm{~m}$ ).

Applications: The facility is applicable to large scale experiments requiring low temperatures combined with a gas flow and purification capability. Safety equipment allows the use of hydrogen. It is also possible to use gases such as helium and nitrogen.

Availability: Available to all NBS employees. Facility must be operated by qualified Cryogenics Division staff. Three months advance notice is necessary because of large number of on-going experiments in the building.

Literature: NBS Technical News Bulletin October 1953, Vol. 37, No. 10, pages 152-158.

Contact: Dr. R. H. Kropschot, Chief, Cryogenics Division, Cryogenics Building, Room 2006, NBS Boulder, Colo. 80302. Phone 303-499-1000 ext. 4108.

\section{LIQUEFIED NATURAL GAS FLOW FACILITY}

The Flow Facility is located behind a protective barrier at the Mesa Test Site, Boulder, Colorado. This research facility allows the development of methodology for measurement of pressure, temperature, flow, density, and state of LNG. It also provides the opportunity to develop new methods of measurement for LNG where the unique characteristics of this fluid require advances in the state of the art.

Capability: The system consists of two vacuum-powder insulated tanks, vacuum insulated lines, valves, pump, pumping system, weigh system and gas analyzer.

Flow rates can be varied from 2.5 to 13 liters per second with pressures up to $0.69 \mathrm{MPa}(100 \mathrm{psi})$. Tank gauging measurements can be made in the two insulated tanks. Gas analysis on both liquid and vapor can be performed.

Applications: Flow measurements; temperature and pressure measurements; liquid level measurements; calorimetric analysis of delivered gas mixtures.

Availability: To qualified NBS and other Federal Government personnel. Facility operators will be provided.

Literature: American Gas Association Pipeline Research Summary, 1970 , pages $13-14 ; 1971$, pages $12-$ $13 ; 1972$, pages $15-16 ; 1973$, page $35 ; 1974$, pages 33-34.

Contact: R. S. Collier, Chief, Cryogenic Metrology Section, Cryogenics Building, Room 1108, NBS Boulder, Colo. 80302, Phone 303-499-1000 ext. 3178.

\section{MACHINE TOOLS, NUMERICALLY CONTROLLED}

Numerically controlled machine tools are finding wide application in industry, both on the production line with long runs and in the job shop on single intricate pieces. The units located in the National 
Bureau of Standards Instrument Shops Division are primarily used for the short-run or single-piece application. Computer-assisted programming speeds the preparation of tapes while providing capability for the generation of irregular, elliptic, and hyperbolic curves. On the machining center, the generation of patterns and their rotation and/or translation are easily accomplished.

Machining Center: This unit is a numerically controlled bed-type milling machine with an eight-station turret in which tools are mounted. Selection of these tools, as well as "on," "off," speeds, feeds, positioning, end and side milling, drilling, tapping, and boring cycles, are controlled through punched paper tape. Selection of inch/metric operation, mirror image, and EIA or ASCII(ISO) tape codes are accomplished by manual switches. Table travel of this machine is 20 inches by 40 inches. Vertical capacity of the machine is from 0 inch to 22 inches with 10 inches of this travel under tape control. The table offers linear and circular interpolation while the vertical travel is point-to-point. Instrument Shops Division at the Boulder Laboratories has a similar machining center and a single spindle machining center.

Lathe: The lathe is of the slant-bed type with an eight-station turret in which tools are mounted. It is a two-axis machine offering linear and circular interpolation. It has capability for turning, drilling, boring, threading, grooving, and knurling. All above features, as well as speeds and feeds, are controlled by punched paper tape. Inch/metric operation and EIA or ASCII tape code formats are selected by manual switches. Capacity of this machine is $10 \frac{1}{2}$ inches over the cross slide and longitudinal travel is 26 inches.

Coordinate Measuring Machine: A three-axis machine interfaced with a digital readout system, computer, and a Teletype unit. Measuring range of the machine is 30 inches by 26 inches horizontal and 16 inches vertical. Accuracy within any horiozntal plane is \pm 0.0002 inch. Vertical axis accuracy is \pm 0.0002 inch. A right-angle probe holder permits measuring details of vertical planes. Optical viewing screens and microscopes are available for non-contacting measurements.

Contact: Robert E. Lach, Shops Building, Room 136, Phone 301-921-2349.

\section{MECHANICAL MEASUREMENT FACILITIES}

\section{DEADWEIGHT FORCE CALIBRATION MACHINES}

These seven machines are the NBS standards for the calibration of precise force-measuring instruments such as proving rings, load cells, and other similar devices. The machines are not used for testing the strength of materials or for calibrating scales and other weighing equipment.

Capability: The machines apply specific calibration loads of high accuracy in the engineering units of the pound-force and in some cases, as noted in the table below, in units of the kilogram-force. The accuracy is better than 0.002 percent of load. The characteristics of the machines are as follows:

$\begin{array}{cc}\text { Maximum load } & \text { Minimum load } \\ 500 \mathrm{lbf} & 10 \mathrm{lbf} \\ 6100 \mathrm{lbf} & 200 \mathrm{lbf} \\ (3050 \mathrm{kgf}) & (100 \mathrm{kgf}) \\ 25,300 \mathrm{lbf} & 400 \mathrm{lbf} \\ (11,500 \mathrm{kgf}) & (500 \mathrm{kgf}) \\ 112,00 \mathrm{lbf} & 300 \mathrm{lbf} \\ 300,000 \mathrm{lbf} & 10,000 \mathrm{lbf} \\ 1,000,000 \mathrm{lbf} & 50,000 \mathrm{lbf}\end{array}$

Units of intermediate loads $5 \mathrm{lbf}$ $100 \mathrm{lbf}$ (50 kgf) $100 \mathrm{lbf}$ (500 kgf) $1000 \mathrm{lbf}$ (note 1) $50,000 \mathrm{lbf}$ Note 1-Intermediate loads vary, 10,000 Ibf, 20,000 Ibf, and 30,000 lbf depending on range.

Availability: The machines are not available for shared use and are operated only by personnel of the Engineering Mechanics Section. Arrangements for the calibration of specific instruments on a fee basis can be made and scheduled according to current work loads.

Literature: "Research and Testing Facilities of the Engineering Mechanics Section, National Bureau of Standards, Washington, D.C." D. J. Chwirut, Nat. Bur. Stand. (U.S.) Spec. Pub. 370 (Jan. 1973).

Contact: Roscoe L. Bloss, Chief, Engineering Mechanics Section, Engineering Mechanics Building, Room 219, Phone 301-921-2621. 


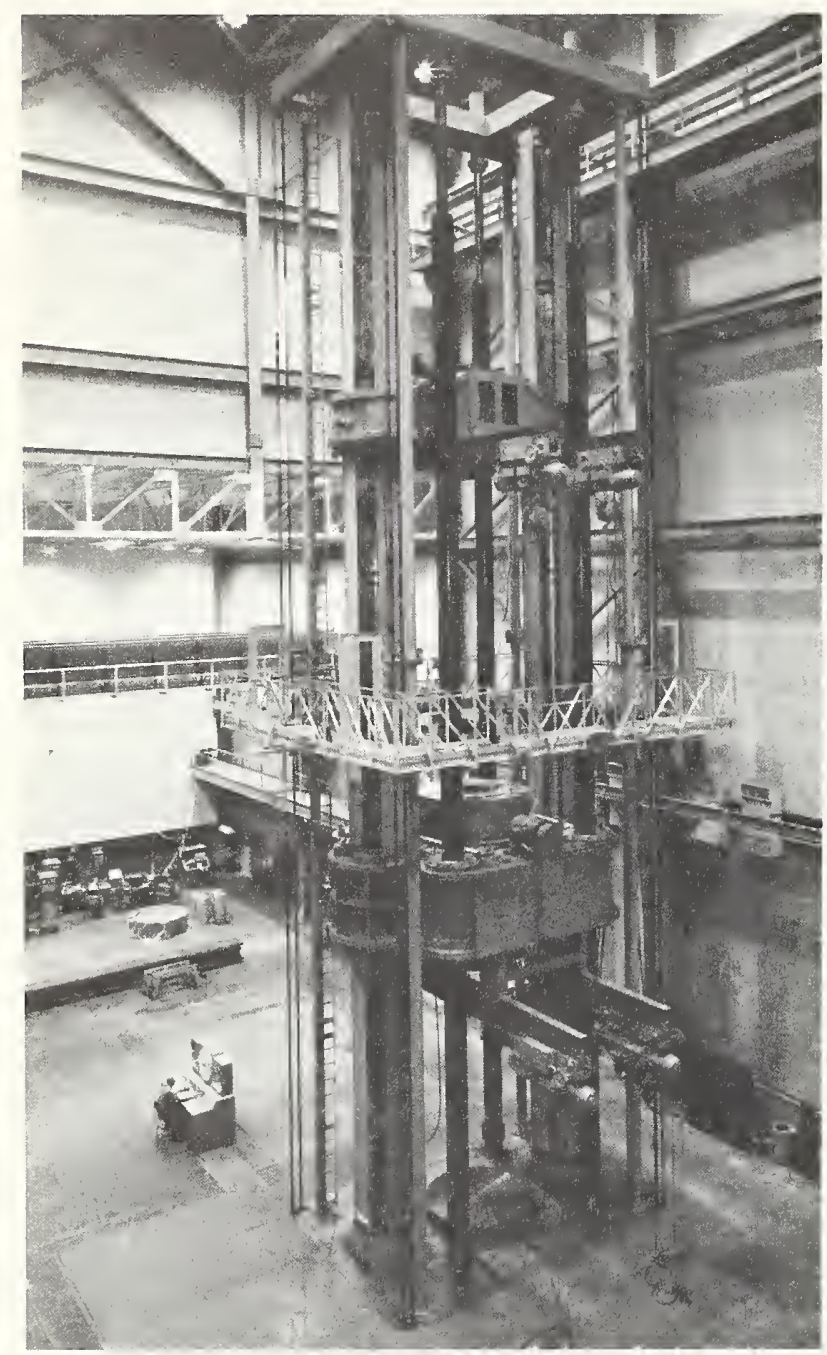

UNIVERSAL TESTING MACHINE, TWELVE MILLION POUND-FORCE.

\section{FLUID FLOW MEASUREMENT}

Laboratory techniques provide precise measurement of the flux of fluid in a closed system, to permit calibration of meters for fluid quantity and flowrate, using air, water, and certain liquid hydrocarbons.

Capabilities: A liquid flowmeter calibrator is used for flow measurement of filtered and dried air supplied from a compressor at rates up to $2700 \mathrm{scfm}$ (cu $\mathrm{ft} / \mathrm{min}$ at 14.69 psia and $70^{\circ} \mathrm{F}$ ). Air is fed through sonic nozzles in 2, 3, 4 or 6-inch meter runs at pressures up to $110 \mathrm{psig}\left(758 \mathrm{kNm}^{-2}\right)$ through a special three-way ball valve to a tank of known volume. The mass rate of flow is computed from measurements of the collection time and of pressure and temperature after the air is accumulated in the known volume. Smaller flows, from $50 \mathrm{~cm}^{3} \mathrm{~min}^{-1}$ up to $50 \mathrm{scfm}$, are measured with piston-type or bell-type provers. Flowrate of a liquid is measured by static or dynamic weighing the quantity accumulated during a known time interval. Rotation of the diverter valve controls fluid collection in a weigh tank, with a switching error less than $10 \mathrm{~ms}$. Net weights are measured to within \pm 0.01 percent on commercial lever balances or weighing scales. The countertimer is accurate to one part in $10^{6}$.

Calibration reports are based (usually) on ten separate observations taken in groups of five successive runs on each of two separate days. These reported values have an estimated overall uncertainty from \pm 0.13 to \pm 0.25 percent, depending on the sensitivity and repeatability of the system under test.

Applications: Calibration of flowmeters of either fixed restriction or moving element types, at rates from 0.03 to 10,000 gallons per minute $\left(1.9 \times 10^{-6}\right.$ to $6.3 \times 10^{-1} \mathrm{~m}^{3} / \mathrm{s}$ ) for water, and from 0.03 to 1000 gallons per minute for liquids such as aircraft fuels. Calibration of critical-flow nozzles and other types of meters for gaseous flow, over the range from $50 \mathrm{~cm}^{3}$ $\mathrm{min}^{-1}$ to $2700 \mathrm{scfm}(1.5 \mathrm{~kg} / \mathrm{s})$.

Availability: Calibration services for Federal agencies, and for industrial or commercial laboratories in USA or abroad.

\section{Literature:}

[1] F. W. Ruegg and M. R. Shafer, Flow Measurement: Procedures and Facilities at National Bureau of Standards, ASHRAE Symposium, San Francisco, CA, Jan. 19-22, 1970.

[2] Lief Olsen and G. P. Baumgarten, Gas Flow Measurement by Collection Time and Density in a Constant Volume, First Symposium on Flow, Pittsburgh, PA, 1971.

Contact: F. W. Ruegg, Chief of Fluid Meters Section, Fluid Mechanics Building, Room 111, Phone 301-9213681.

\section{THREE=DIMENSIONAL PRECISION MEASUREMENT}

In a numerically controlled machine tool, the cutters are positioned precisely by the digits on a punched paper tape, or often by direct computer control. The workpiece, instead of being removed from the machine for checking a single measurement, is inspected 
as a finished piece for the accuracy of all its dimensions and angles. This automated metrology facility is designed to meet the needs of such automated production.

Capability: A 3-axis measuring machine built to stateof-the-art specifications will be housed in a stabilized environment, and can be operated either manually or under full control from a programmed computer. It has a working volume of $48 \times 24 \times 12$ inches with a 16-inch clearance under the bridge, and can detect a difference in length of $0.250 \mathrm{~nm}$ (10 micro-inches), using a non-contacting sensor. Bulk disc storage of computer programs is provided, and a line printer capable of graphic presentation is available. Reference to the SI metre will eventually be provided by a stabilized laser interferometer.

Applications: Provides digital data on probe position in three dimensions, or two-dimensional graphic projection of complex three-dimensional shapes. Substitutes for the skilled handling of gage blocks, micrometer calipers, height gages, sine bars, straight edges, polygons, plug and ring gages, master gears, and thread wires.

Availability: To any NBS worker after minimal training. In appropriate instances, individual workers from other Federal organizations may gain access to the facility.

Literature: Simpson, J. A., Use of a microscope as a non-contacting microdisplacement device, Rev. Sci. Instr. 42, 1378 (1971).

Contact: Dr. J. A. Simpson, Acting Chief, Mechanics Division, Metrology Building, Room B322, Phone 301-921-2171.

\section{UNIVERSAL TESTING MACHINE, TWELVE MILLION POUND-FORCE}

This hydraulically operated machine of 12-million pounds-force capacity, believed to be the largest in the world, was designed to test large structural components and to apply the forces needed to calibrate force measuring devices of large capacity.

Capability: The machine can apply axial force of $12,000,000 \mathrm{lbf}$ in compression $6,000,000 \mathrm{lbf}$ in tension, and a transverse force of $4,000,000 \mathrm{lbf}$ to a flexural member. Working space between the screw columns is 8 feet 4 inches, and the working surface of the main platen is 8 feet 4 inches by 15 feet. The reinforced concrete foundation includes a tie-down floor system with the following working strength values:

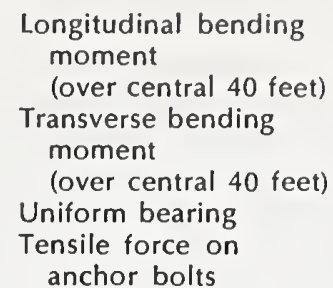

$12,500,000 \mathrm{lbf}-\mathrm{ft}$
$20,000,000 \mathrm{lbf}-\mathrm{ft}$

$467,000 \mathrm{lbf}-\mathrm{ft} / \mathrm{ft}$ of width $940 \mathrm{lbf} / \mathrm{in}^{2}$

$150,000 \mathrm{lbf} / \mathrm{bolt}$ $750,000 \mathrm{lbf}-\mathrm{ft} / \mathrm{ft}$ of width

There are two hydraulic capsules in the sensitive crosshead, one providing the force measuring function and the other for preloading. Pressure transducers in a constant temperature oven on the crosshead provide signals to analog readout for force, strain, and displacement, and also to a digital readout calibrated to within \pm 0.5 percent of the applied load. Both coarse and fine adjustment of power cylinder motion ( 5 feet max.) are provided from the control console.

Applications: Axial forces of 12,000,000 lbf can be applied to column sections or fabricated members with lengths up to 58 feet, or to elastic devices such as the load cells used to measure rocket thrust or rolling mill forces. To apply the full $6,000,000 \mathrm{lbf}$ tension to eye bars, drill rod for undersea operations, large diameter wire rope, and the like, both threaded couplings and clevis fixtures are provided to take specimens up to 53 feet long. Transverse or flexural tests under $4,000,000 \mathrm{lbf}$ load can be made on beams and similar structures with lengths up to 90 feet.

Availability: To be negotiated, for prearranged schedule not interfering with the work of the Section or with Government priorities. Other requestors must attest no competition with non-Government agencies.

Literature: A. F. Kirstein, Universal Testing Machine of 12-Million-Ibf Capacity, Nat. Bur. Stand. (U.S.) Spec. Publ. 355 (Sept. 1971); NBS Tech. News Bull. 55, No. 11, p. 174-5 (Nov. 1971).

Contact: Roscoe L. Bloss, Chief of Engineering Mechanics Section, Engineering Mechanics Building, Room 219, Phone 301-921-2621.

\section{WIND TUNNEL FOR UNSTEADY FLOWS}

This facility is designed for the study of unsteady conditions in low-speed aerodynamics.

Capabilities: In two test sections, 4.5 feet square by 16 feet in length, each fitted with a set of continuously rotating shutters, oscillatory flows of air can be generated at mean speeds from nearly zero up to 45 feet per second. Provision is also made for simu- 
lating gusts and lulls of adjustable amplitude and frontal duration and for varying the intensity and scale of the free-stream turbulence. One set of rotating shutters lags the other by a quarter-turn to give more uniform loading on the fan. The flow can be oscillated sinusoidally at frequencies from $0.1 \mathrm{~Hz}$ to $25 \mathrm{~Hz}$. The amplitude is limited to about $5 \mathrm{fps}$ at 10 $\mathrm{Hz}$ but can be increased to $45 \mathrm{fps}$ at $0.1 \mathrm{~Hz}$. The "time-constant" for the overall facility is approximately 0.2 seconds.

Applications: Such important problems in unsteady aerodynamics as the dynamic response of various types of wind-speed instruments, the effect of wind loading on buildings and other structures under the action of a variable wind, unsteady heat transfer phenomena, and unsteady boundary layers may be investigated in this facility.

Availability: The direct use of this facility is limited to staff members of the Aerodynamics Section or qualified guest scientists. However, it may be used indirectly through cooperative or contractual research arrangements with other Government agencies or with private industrial organizations.

Contact: Philip S. Klebanoff, Chief of Aerodynamics Section, Fluid Mechanics Building, Room 105, Phone 301-921-3684.

\section{NUCLEAR REACTOR AND ASSOCIATED FACILITIES}

\section{NUCLEAR REACTOR}

The NBS research reactor is a high-flux reactor designed for materials research and analysis. It operates around the clock at a power level of $10 \mathrm{MW}$, generating neutron fluxes averaging $10^{14}$ neutrons per square centimeter per second.

Capability: The intense neutron flux makes possible a wide variety of experiments and investigations such as crystal structure determination, lattice dynamics measurements, phase transition studies, trace element analysis, radioisotope production, and radiation effects studies. The neutrons are made available through beam ports, pneumatic tubes, and in-core irradiation thimbles. The reactor facilities can be seen

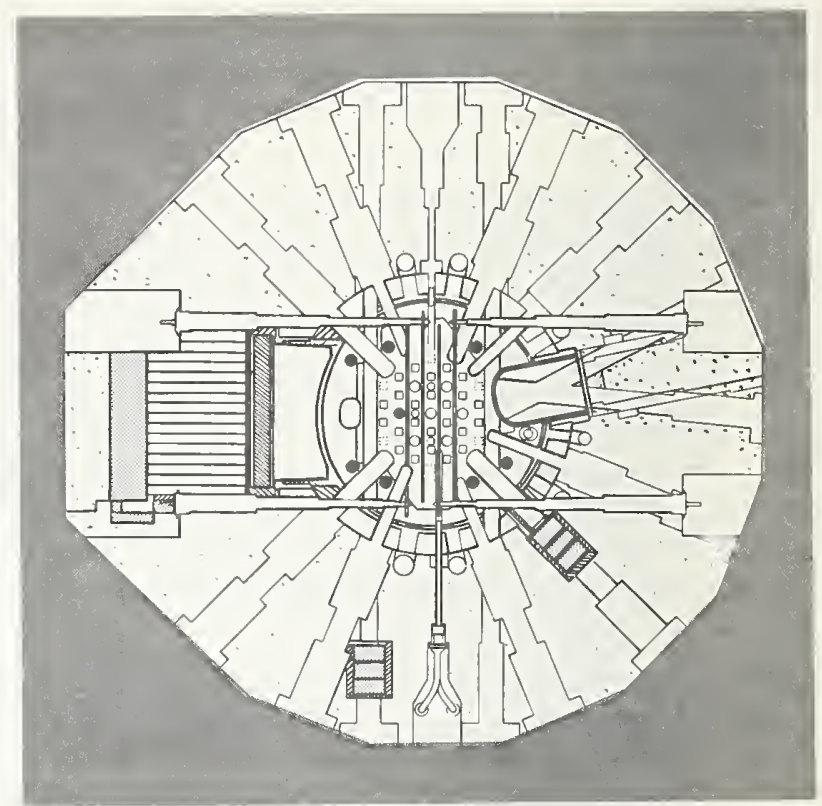

NUCLEAR REACTOR. Plan view of the NBS reactor showing beam ports, pneumatic tubes, and vertical thimbles.

in the diagram and include:

9 radial beam ports

2 through beam ports

2 cold-source beam ports

1 thermal column

4 pneumatic tubes

7 vertical thimbles in the reflector

10 vertical thimbles in the core

Availability: All but one of the beam ports and several of the vertical thimbles already have experimental equipments installed. These facilities and their availability are described in the following pages. The remaining facilities listed above are available for suitable programs.

Literature: W. F. Sheely, The NBS Reactor: Its Description and a Guide to Use by Experimenters, NBS Rept. 9081 (1966).

Contact: Dr. Robert S. Carter, Chief of the Reactor Radiation Division, Reactor Building, Room A106, Phone (301) 921-2421.

\section{FILTERED}

\section{NEUTRON BEAMS}

Nearly monoenergetic nertrons with energies above $\sim 100 \mathrm{keV}$ can be readily produced with adequate yields in positive-ion accelerators, but there are no convenient accelerator sources of monoenergetic 
neutrons with energies below $100 \mathrm{keV}$. Much of the neutron dose, however, comes from neutrons in this energy range, and dosimetry development is severely hampered by the lack of test facilities.

Capability: Thick scandium, iron, or silicon filters placed in a through tube of the NBS reactor result in monoenergetic neutron beams of $2 \mathrm{keV}, 25 \mathrm{keV}$, or $144 \mathrm{keV}$, respectively. Calculated intensities are in the range of $10^{6} \mathrm{n} / \mathrm{cm}^{2} \cdot \mathrm{s}$, with very low gammaray background.

ENERGY: 2,25 and $144 \mathrm{keV}$

ENERGY SPREAD: $10 \%$

INTENSITY: $10^{6} \mathrm{n} / \mathrm{cm}^{2} \cdot \mathrm{s}$ (continuous beam)

EXPERIMENTAL LOCATIONS: two

GAMMA RAY BACKGROUND: very small owing to filter's atomic absorption

Applications: The NBS filtered beams will constitute a primary neutron source facility for neutrons of 2 $\mathrm{keV}, 25 \mathrm{keV}$, and $144 \mathrm{keV}$. This facility is to function as the point of reference for the development and maintenance of secondary source capabilities at satellite locations, as well as providing means for the evaluation and calibration of new types of dosimeters.

The filtered beams will also be used for cross section measurements, and fission physics measurements, which require a high-intensity, monoenergetic, "clean," continuous neutron beam.

Availability: Beam time is available to NBS staff, other agency and university users, industrial users, and guest workers. Operation only by qualified $\mathrm{Di}$ vision personnel under the direction of $\mathrm{Dr}$. A. R. Schwartz or Dr. I. Schroder.

\section{Literature:}

NBS Reactor: Summary of Activities, Oct. 1971Sept. 1972, Nat. Bur. Stand. (U.S.) Tech. Note 759 (Mar. 1973).

Contact: Dr. Charles D. Bowman, Chief, Neutron Standards Section, Radiation Physics Building, Room B117, phone 301-921-2234.

\section{INTERMEDIATE-ENERGY STANDARD NEUTRON FIELD (ISNF)}

This facility provides a primary standard neutron field with a smoothly varying energy spectrum that may be accurately calculated. The energy range of the neutron spectrum- $95 \%$ of the spectrum is between 2 $\mathrm{keV}$ and $5 \mathrm{MeV}$-is just that of core neutrons in presently conceived U.S. fast breeder reactors. The system, which is operated in the thermal column of the NBS rector, is one of several energy-distributed, fast-neutron fields developed by the NBS Neutron Standards Program.

Capabilities: The ISNF arrangement is fundamentally simple: a spherical cavity in graphite, a thin shell of ${ }^{10} \mathrm{~B}$ mounted at the center, and fission source disks of ${ }^{235} \mathrm{U}$ placed around the periphery of the cavity. Fission neutrons returning from the graphite give rise to the ISNF field at the center of the cavity:

Total flux intensity $\sim 10^{9} \mathrm{n} / \mathrm{cm}^{2} \cdot \mathrm{s}$

Total fluence for 24 hour irradiation $\sim 10^{14} \mathrm{n} / \mathrm{cm}^{2}$ Uniformity of the field $<2 \%$ variation over $4 \mathrm{~cm}$ Initial accuracy of flux and spectrum $\pm 5 \%$

Applications: Two general kinds of applications are planned for the ISNF: (1) measurement of absolute and relative integral reaction rates for breeder reactor development; (2) calibration of various types of neutron detectors important for nuclear technology.

Availability: The ISNF facility will be operational late in 1974. Experiments by outside users will be an essential feature of the ISNF measurements program but they will require careful coordination and scheduling.

\section{Literature:}

NBS Reactor: Summary of activities, Oct. 1971Sept. 1972, Nat. Bur. Stand. (U.S.) Tech. Note 758 (Mar. 1973).

Contact: Dr. James A. Grundl, Neutron Standards Section, Reactor Building, Room A-120, phone (301) 921 2421.

\section{ISOTOPE SEPARATOR LABORATORY}

Isotopic separations are produced by the combined action of an electric and a magnetic field on a stream of ions, which is transmitted through an electrostatic lens system and a $90^{\circ}$-sector magnet to a dispersion and target chamber.

Capability: Potentials up to 90 kilovolts produce ion beam currents up to 100 microamperes. Sector electromagnet of 150-centimeter radius. Mass dispersion sufficient to separate all known isotopes. Target with temperature control. Collimating aperture and lens system adjusts shape of beam.

Applications: Preparation of isotopically pure substances, irradiation of materials, studies of nuclear structure, ion implantation in semiconductors, precise chemical sectioning of foils. Source material may vary from gaseous substance to metallic oxide, with 
contamination-free transport from radio-chemistry laboratory.

Availability: By prior arrangement.

\section{Literature:}

[1] Nuclear Orientation of ${ }^{82} \mathrm{Br}$ in Iron. A. T. Hirshfeld, D. D. Hoppes, W. B. Mann, and F. J. Schima. Hyperfine Interactions in Excited Nuclei. Vol. 1, p. 335 (1971). Proceedings of International Conference at Rehovot, Israel, Sept. 6-11, 1970. (Gordon and Breach Sci. Publishers, New York.)

[2] The L/K Electron Capture Ratio in First-Forbidden ${ }^{81 g \mathrm{Kr}}$ Decay. W. M. Chew, A. C. Xenoulis, R. W. Fink, F. J. Schima and W. B. Mann. Nucl. Phys. A229, 79 (1974).

[3]. Implantation of ${ }^{14} \mathrm{~N}^{+}$into Monocrystalline GaN Films. A. N. Saxena, L. R. Weisberg, W. B. Mann and F. J. Schima. Int. J. Appl. Rad. Isotopes, 1, 33 (1975).

Contact: Dr. W. B. Mann, Deputy Chief, Applied Radiation Division, Radiation Physics Building, Room C118, Phone 301-921-2668.
All data are collected by computer control, and basic reduction is also performed by the computer.

Applications: Two-axis diffractometers are used in studies of the structure of crystals, glasses, and simple liquids. They are particularly suitable for studies of compounds containing hydrogen, compounds with atoms having very similar or widely different atomic numbers, and magnetic materials. Three-axis spectrometers are used in studies of crystal and molecular vibrations, and molecular reorientation and hydrogen diffusion in solids.

Availability: Instrument time can be scheduled for appropriate experiments or projects of NBS staff after the proposed measurements are reviewed by the Users Committee for these facilities. Outside users can also be accommodated, depending on the type of measurements and the available resources.

\section{Literature:}

NBS Reactor: Summary of Activities, Oct. 1971Sept. 1972, Nat. Bur. Stand. (U.S.) Tech. Note 758 (Mar. 1973).

Contact: Dr. John J. Rush, Chief of Neutron Solid State Physics Section, Reactor Building, Room A126, Phone 301-921-3634.

\section{NEUTRON \\ DIFFRACTOMETERS}

These facilities at the NBS reactor include 4 two-axis neutron diffractometers for elastic scattering and crystal structure studies, and 3 three-axis neutron diffractometers for inelastic scattering studies. All instruments are computer controlled, and software is available for a wide variety of experimental procedures.

Capability: Two of the two-axis diffractometers are equipped with full-circle goniometers for collecting three-dimensional neutron diffraction data from single crystals. Incident wavelengths are from 1.0 to $1.25 \AA$, and the limiting scattering angle is from $100^{\circ}$ to $110^{\circ}$. The other two are suitable for diffraction measurements from polycrystalline or amorphous solids, liquids, and single crystals when the necessary information can be derived from measurements in a single zone. Incident wavelengths are variable from $0.9 \AA$ to $2.5 \AA$, and the limiting scattering angles are up to $120^{\circ}$. The three-axis diffractometers can measure both quasielastically and inelastically scattered neutrons. The incident energy can be varied from 4 to $100 \mathrm{meV}$, and energy changes can be measured from $0.5 \mathrm{meV}$ to $100 \mathrm{meV}$. Cryostats are available to provide sample temperatures from $4 \mathrm{~K}$ to $300 \mathrm{~K}$. Some high-temperature sample furnaces are also available.

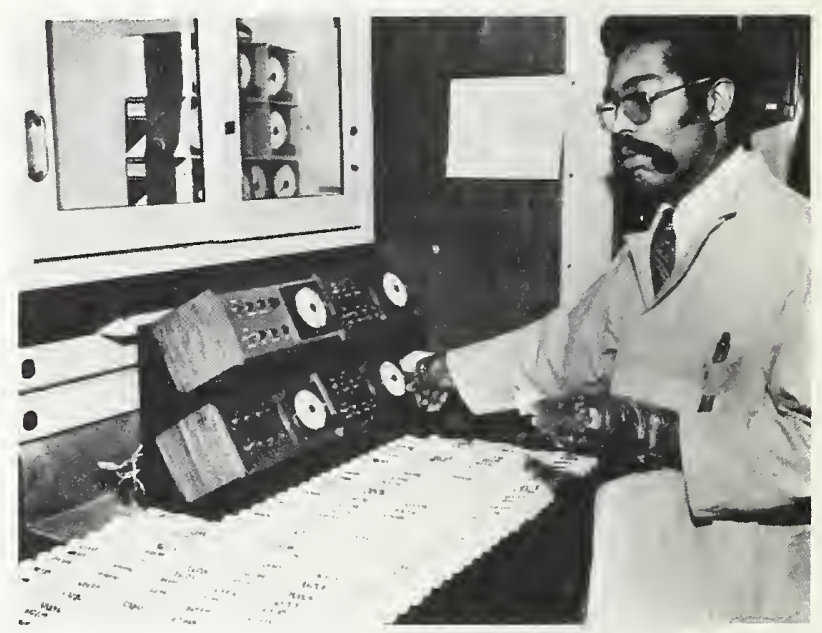

NUCLEAR IRRADIATION FACILITIES. Samples are loaded into pneumatic tubes for transport into the reactor. 


\section{NEUTRON RADIOGRAPHY FACILITY}

Neutron radiography may display contrasts unobtainable by x-radiography because of the varying attenuation characteristics for the elements, the differences in neutron attenuation between isotopes, and the capability of neutron detection in high gammaray intensities.

Capability: A well-moderated neutron beam has been extracted from the reactor thermal column for neutron radiographic use. The beam covers a detector area of $12.5 \mathrm{~cm}$ diameter with a thermal neutron intensity that can be varied from $5 \times 10^{5} \mathrm{n} / \mathrm{cm}^{2} \cdot \mathrm{s}$ to $2 \times 10^{7} \mathrm{n} / \mathrm{cm}^{2} \cdot \mathrm{s}$, with a cadmium ratio $[0.5 \mathrm{~mm}$ cadmium cover on gold] of about 600 . The beam divergence characteristics can be changed quickly to provide L/D (length to neutron aperture diameter) ratios from about 180 (at the lower neutron intensity) to about 30 . The gamma radiation intensity in the beam is in the order of 2 röntgen per hour, sufficiently low that direct film techniques can be used for detection. Detectors available with this facility include direct methods (convertors include gadolinium metal and scintillators) with films that provide radiographs with total exposures from $5 \times 10^{5} \mathrm{n} / \mathrm{cm}^{2}$ to $10^{11} \mathrm{n} / \mathrm{cm}^{2}$, activation transfer detectors (indium, dysprosium, gold), track-etch plastics, and a neutron image intensifier-television system. The latter system provides images at a rate of 30 frames per second and permits object motion to be followed. The best spatial resolution of the radiographs is in the order of $10 \mu \mathrm{m}$ for high contrast objects. A darkroom for processing radiographs is available at the Reactor.

Applications: With neutrons one can readily observe materials containing hydrogen, lithium, boron, cadmium or several rare earths in combination with other materials, even dense metals. Therefore, examinations of adhesives, fluids, explosives, plastics, or hydriding in metals becomes feasible, as does examination of items such as boron filament composites or cadmium plating. Isotopic sensitivity permits, as examples, differentiation between hydrogen and deuterium, ${ }^{235} \mathrm{U}$ and ${ }^{238} \mathrm{U}$, or between ${ }^{113} \mathrm{Cd}$ and other cadmium isotopes. In addition, the fact that neutron images can be made by gamma-ray insensitive techniques leads to inspection capability for radioactive materials.

Availability: Instrument time can be scheduled for appropriate experiments or projects of NBS staff after the proposed measurements are reviewed by the User's Committee for these facilities. Outside users can also be accommodated depending on the type of measurements and available resources.
Literature:

[1] NBS Reactor: Summary of Activities, Oct. 1971-Sept. 1972, Nat. Bur. Stand. (U.S.) Tech. Note 758 (Mar. 1973).

[2] Dimensions/NBS, 59, 106 (May 1975).

Contact: Mr. Harold Berger, Reactor Radiation Division, Reactor Building, Room A-128, phone 301-9213634.

\section{NEUTRON SCATTERING SPECTROMETER}

A double-crystal small-angle scattering spectrometer is available at the NBS reactor to measure the neutron scattering from inhomogeneities in materials.

Capability: Using nearly perfect silicon crystals, the range of angular observation ( 3 seconds to 6 degrees of arc) allows measurement of diffraction from "particles" of sizes ranging from about 10 to $10,000 \AA$. Exploiting this high angular resolution is most appropriate when the correlations persist over distances of micrometres; for shorter-range correlations the resolution can be broadened by substituting matched pairs of crystals with larger mosaic spread, thereby greatly enhancing the beam intensity. The wavelength of neutrons used in this spectrometer can be varied from $1.5 \AA$ to $4.0 \AA$ in order to optimize the resolution with the sample attentuation characteristics.

Applications: This spectrometer has applications in the determination of shape, size and interaction of macromolecules as well as similar properties of defects in materials, magnetic correlations at extended distances, and density fluctuations near the critical point of phase transitions. Neutron small-angle scattering has particular application to submicroscopic particles of low population densities, where light and $\mathrm{x}$-ray scattering suffer from absorption and poor resolution.

Availability: Instrument time can be scheduled for appropriate experiments of projects of NBS staff, after the proposed measurements are reviewed by the Users Committee for these facilities. Outside users can also be accommodated depending on the type of measurements and the available resources.

\section{Literature:}

NBS Reactor: Summary of Activities, Oct. 1971Sept. 1972, Nat. Bur. Stand. (U.S.) Tech. Note 758 (Mar. 1973). 
Contact: Dr. Robert Carter, Chief, Reactor Radiation Division, Reactor Building, Room A106, phone 301921-2421.

\section{NUCLEAR IRRADIATION FACILITIES}

Capability: An extensive number of well-characterized irradiation facilities offer a wide range of neutron and/or gamma environments to levels exceeding $10^{14}$ neutrons per square centimeter per second. These include five distinct pneumatic facilities, eleven in-core vertical thimbles with inside diameters up to $3 \frac{1}{2}$ inches, and seven vertical reflector thimbles with $4 \frac{1}{2}$ inch openings. These facilities are used simultaneously and can accommodate tens of thousands of samples a year.

Applications: Most common use is in neutron activation analysis for detection of trace elements in parts per million, billion, or trillion. Other uses include preparation of isotopes for tracer work, preparation of isotopes for medicine, production of gamma and positron sources, studies of radiation damage, and the characterization of standard reference materials.

Availability: All facilities are available to qualified scientists. Each sample to be irradiated must be accompanied by an irradiation proposal form for safety review. The packaging of each sample must be approved by the staff of the Reactor Operations Section, who can also provide guidance in the preparation of the irradiation proposals.

Literature: W. F. Sheely, The NBS Reactor: Its Description and a Guide to Its Use by Experimenters, NBS Rept. 9081 (1966).

Contact: Tawfik M. Raby, Deputy Chief, Reactor Radiation Division, Reactor Building, Room A148, phone 301-921-2523.

\section{TIME-OF-FLIGHT NEUTRON SPECTROMETERS}

This instrumentation utilizes either crystal monochromators or phased-choppers to select monoenergetic neutrons, which are scattered by a sample and detected 2.5 to 3.8 metres away by multiple neutron detectors at scattering angles between $10^{\circ}$ and $105^{\circ}$. The energy of the scattered neutrons is determined by time-of-flight analysis.

Capability: The spectrometers provide incident neutron beams ranging in energy between $3 \mathrm{meV}(25$ $\left.\mathrm{cm}^{-1}\right)$ and $100 \mathrm{meV}\left(800 \mathrm{~cm}^{-1}\right)$ and cover a spectral range for inelastic scattering of $0.5 \mathrm{meV}$ to $100 \mathrm{meV}$ ( 4 to $800 \mathrm{~cm}^{-1}$ ). The available resolution varies from $0.2 \mathrm{meV}$ (at the lowest energies) to $5 \mathrm{meV}$. The range of momentum transfers (Q) for elastic scattering is from $0.2 \AA^{-1}$ to $10 \AA^{-1}$. The time-of-flight data collection is automatic, utilizing either a multichannel analyzer or a small computer. The spectrum is continuously observable on a scope and the data can be printed out on paper tape or on a typewriter. A specially designed sample cryostat is available for spectrum measurements on solid and liquid samples between 5 and $300 \mathrm{~K}$.

Applications: The spectrometers can be used widely in the study of the dynamics of liquids and solids. Some applications include the study of crystal and molecular dynamics of solids, vibrational spectra of glasses, hydrogen diffusion in metals, orientational disorder and relaxation processes in polymers and molecular crystals, and the dynamics of liquids.

Availability: Instrument time can be scheduled for appropriate experiments or projects of NBS staff after the proposed measurements are reviewed by the Users Committee for these facilities. Outside users can also be accommodated depending on the type of measurements and available resources.

\section{Literature:}

NBS Reactor: Summary of Activities, Oct. 1971Sept. 1972, Nat. Bur. Stand. (U.S.) Tech. Note 758 (Mar. 1973).

Contact: Dr. R. S. Carter, Chief, Reactor Radiation Division, Reactor Building, Room A106, Phone 301921-2421. 


\section{RADIOACTIVE SOURCE}

\section{COBALT-60 \\ IRRADIATION \\ FACILITY}

Capabilities: The facility consists of twelve rods containing ${ }^{60} \mathrm{Co}$ mounted in a circle on a plate at the bottom of a water pool 10 feet deep. The dose rates available range from about $2 \times 10^{6} \mathrm{rad} / \mathrm{h}$ (in carbon) at the center of the source array to about $2 \times 10^{3}$ $\mathrm{rad} / \mathrm{h}$ near the edge of the mounting plate as of February 1974; these values decrease by about $10 \%$ per year. Samples as large as $5 \mathrm{~cm}$ high by $5 \mathrm{~cm}$ in diameter can be given reasonably uniform doses at the center position of the source array. Samples may be irradiated under various atmospheric conditions and over a wide range of temperatures.

Applications: This facility may be used to study the effects of gamma radiation on various materials such as polymers and electronic components. It may also be used as a standard calibration source for calibrating different types of radiation dosimeters such as thin polymer dye films.

Availability: Generally available to NBS personnel or qualified guest scientists on a scheduled basis.

Contact: J. C. Humphreys, Applied Radiation Division, Room C216, Radiation Physics Building, phone 301921-2201.

\section{RADIO STATIONS}

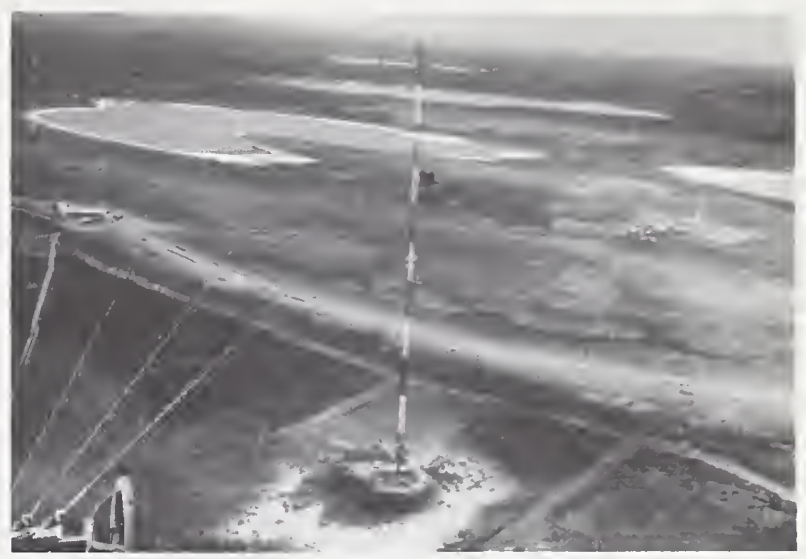

Transmitter buildings and antennas of WWVL, WWVB, and WWV at Fort Collins, Colorado.

\section{WWVL VLF \\ BROADCAST STATION}

WWVL is an experimental very-low-frequency (VLF) radio station located on the same Ft. Collins, Colorado, site as radio stations $W W V$ and WWVB. Prior to July 1, 1972, it was operated by the Time and Frequency Division on a regularly scheduled basis to provide stable and accurate frequencies and timing information referenced to the NBS primary standards. Various combinations of 1-3 timeshared carrier frequencies were transmitted in the region of $20 \mathrm{kHz}$. Regular scheduled broadcasts were terminated as of July 1, 1972.

Capability: Approximately $2 \mathrm{~kW}$ radiated power; multiple carrier frequencies (timeshared) in the region of $20 \mathrm{kHz}$; carrier frequencies and phases can be controlled relative to NBS primary standards.

Applications: Propagation research at VLF; frequency and time dissemination via multiple VLF carriers.

Availability: Operation of the WWVL facility is the responsibility of the full-time Ft. Collins field site staff. Installation, maintenance, and monitoring of any special equipment involved in special experiments by other government agencies must be arranged with R. E. Beehler or the Engineer in Charge at Ft. Collins, Mr. J. Milton.

Contact: R. E. Beehler, Chief, Time and Frequency Services Section, Radio Building, Room 4039, NBS Boulder, Colo. 80302. Phone 303-499-1000 ext 3282. 


\section{ANNOUNCEMENTS \\ ON WWV/ WWVH}

Radio stations WWV in Ft. Collins, Colorado, and WWVH in Kekaha, Kauai, Hawaii, are operated by the Time and Frequency Division of NBS for the dissemination of standard frequency and time information. Transmissions are on a continuous basis, simultaneously on $2.5,5,10,15$, and $20 \mathrm{MHz}$ from both stations. In addition, WWV also transmits at $25 \mathrm{MHz}$. Essentially worldwide coverage is achieved.

Capability: In addition to the primary time and frequency information provided, the WWV and WWVH formats include 45 -second segments every other minute, most of which can be made available on a subscription basis to other government agencies for dissemination of official and public service information. Each prerecorded voice announcement will be repeated once per hour and will appear on all transmitted frequencies. A wide variety of commercial receivers are readily available that provide adequate reception.

Applications: Presently, voice announcements have been arranged for marine weather advisories by NOAA, geoalert messages by NOAA, radio propagation forecasts by the Office of Telecommunications, and Skylab-related information by NOAA. Decisions regarding suitability of proposed announcements for inclusion in the WWV/WWVH format will be the responsibility of NBS.

Availability: All segments except those reserved for NBS use, the semi-silent period, and those presently in use by other agencies are available. The content of all announcements accepted for inclusion in the broadcast formats will be the responsibility of the sponsoring agency and must be transmitted to the Ft. Collins or Hawaii sites by teletype or other suitable means. The permanent station staff will be responsible for prerecording the information supplied (if necessary) and for arranging for broadcast of the information at the proper times. Provisions can be made for a reasonable frequency of updating of the material broadcast.

Literature: NBS Frequency and Time Broadcast Services, Viezbicke, P.P., Nat. Bur. Stand. (U.S.) Spec. Publ. 236 (March 1974)。

Contact: R. E. Beehler, Chief, Time and Frequency Services Section, Radio Building, Room 4039, NBS Boulder, Colo. 80302. Phone-303-499-1000 ext 3282.

\section{SPECTROSCOPY FACILITIES}

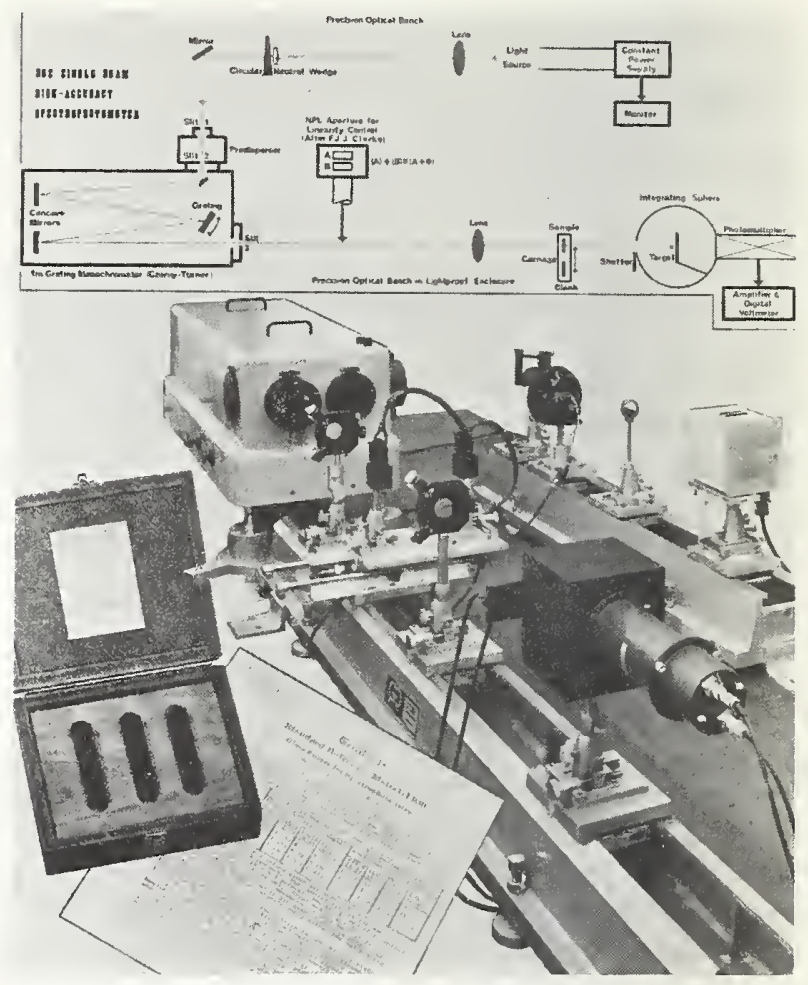

ANALYTICAL SPECTROPHOTOMETER.

\section{ANALYTICAL SPECTROPHOTOMETER}

This high-accuracy spectrophotometer, with good sensitivity and linearity, will check the photometric scale accuracy of the transmittance of either solid or liquid filters used in commercial spectrophotometers.

Capability: The single-beam spectrophotometer is capable of measuring transmittance (T) values on solid and liquid materials to within an uncertainty of one part in $10^{4} \mathrm{~T}$ units. It consists of a constant radiation source (stability 7 parts in $10^{5}$ ), a double monochromator, adequate sample holders (one being automated through computer interfacing), and an averaging sphere with photomultiplier tube assembly. The latter is connected to a digital voltmeter; data acquisition and presentation is performed in a computer.

Applications: Spectrophotometric (colorimetric) anal$y$ sis is the predominant technique for bioclinical ex- 
amination of various body fluids and solids, and for other measurements involving health problems. This instrument is used to certify colored glass filters (SRM 930) between 300 and $700 \mathrm{~nm}$, at three transmittance levels to within an uncertainty of one part in $10^{4} \mathrm{~T}$ units. Ampoules containing solutions (SRM 931) are particularly designed to be used in conjunction with flow-type spectrophotometers in both visible and ultraviolet regions. These SRM's were developed to meet the particular needs expressed by clinical chemists organizations. The technique is also widely used for environmental studies of smog, stack emissions, stream pollutants, and atmospheric contaminants.

Availability: Only limited time is presently available for other agencies, because of the SRM certification program, research on stable materials, reproducible methods for transmittance measurements, spectral bandwidth and stray light determinations.

\section{Literature:}

[1] R. Mavrodineanu, NBS J. Res. 76A, No. 5, 405-425 (Sept.-Oct. 1972); NBS Tech. News Bull. 56, No. 7, pages 166-167 (July 1972).

[2] R. Mavrodineau, Spectrophotometry Instrument Development, NBS Tech. Note 584, pp. 9-21, (June 1971).

[3] R. N. Rand, Practical Photometric Standards, Clinical Chemistry 15, 839-863 (September 1969).

Contact: Dr. R. Mavrodineanu, Special Analytical Instrumentation Section, Room A205, Chemistry Building, phone 301-921-2861.

\section{CONCAVE GRATING SPECTROGRAPHS, $10.7 \mathrm{~m}$}

The Spectroscopy Section has three 10.7-m concave grating spectrographs for use in different portions of the photographic region:

1. About 2000 to $12000 \AA$-air region, normal incidence

2. About 450 to $2500 \AA$-vacuum ultraviolet region, normal incidence

3. About 75 to $600 \AA$-vacuum ultraviolet region, grazing incidence at $10^{\circ}$.

These instruments can be used for the photographic recording of all types of atomic and molecular spectra.

Capability: The $10.7-\mathrm{m}$ concave gratings with 1200 grooves/mm give resolving powers of over 150,000 and plate factors of about $0.77 \AA / \mathrm{mm}$ in the first spectral order of the normal incidence instruments. The plate factor of the grazing incidence spectrograph varies from $0.17 \AA / \mathrm{mm}$ at $70 \AA$ to $0.32 \AA / \mathrm{mm}$ at $600 \AA$.

Applications: These spectrographs have been used in conjunction with mild discharge light sources for the photographic recording of the spectra of neutral and single ionized spectra of a wide variety of elements, and in conjunction with spark discharges for the similar acquisition of highly-ionized spectra.

Availability: To any qualified research worker. In the immediate past, guests from Kitt Peak, Naval Research Laboratory, Canada, The Netherlands, and France, have used the spectrographs.

Contact: Dr. William C. Martin, Jr., Chief of Spectroscopy Section, Physics Building, Room A167, Phone 301-921-2011.

\section{CZERNY-TURNER HIGH DISPERSION SPECTROGRAPH}

This is a high resolution, high dispersion, stigmatic, plane grating spectrograph. The grating is $220 \times$ $135-\mathrm{mm}$, has 300 grooves $/ \mathrm{mm}$, and is blazed at $63^{\circ} 26^{\prime}(6 \mu \mathrm{m})$. It is used in the fifth to the thirtieth order. A predisperser used in conjunction with this spectrograph separates or eliminates overlapping orders.

Capability: The resolving power of the instrument is about 700,000 at $4000 \AA$ (fifteenth order). The plate factor is about $3.6 / \mathrm{n} \AA / \mathrm{mm}$ ( $\mathrm{n}=$ order number). The instrument can be used from 2000 to $12000 \AA$.

Applications: This instrument has been used for a wide variety of atomic and molecular spectroscopic studies for which high resolution was necessary. The stigmatic property of the spectrograph is useful for spectral separation in types of discharges where different ions are excited in different areas. It can be used for cross-dispersion with interferometers.

Availability: To any qualified research worker. In the immediate past, guests from Kitt Peak, Naval Research Laboratory, Canada, The Netherlands, and France, have used the spectrograph.

Literature:

[1] J. Reader, L. C. Marquet, and S. P. Davis, Predisperser for high-resolution grating spectrographs, Appl. Optics, 2, 963 (Sept. 1963).

[2] J. Reader, Optimizing Czerny-Turner Spectro- 
graphs, J. Opt. Soc. Amer. 59, no. 9, 1189 1196 (Sept. 1969).

Contact: Dr. William C. Martin, Jr., Chief of Spectroscopy Section, Physics Building, Room A167, Phone 301-921-2011.

\section{ELECTRON ENERGY LOSS SPECTROMETERS FOR GASES}

Three state-of-the-art electron energy loss spectrometers allow measurements of the energy loss spectra of gases with an energy resolution of 15 to 50 milli-electron volt with incident energies from threshold to several hundred electron volts.

Capabilities: Energy loss spectra of gases. Excitation functions near threshold. Analysis of gas mixtures. The spectrometers are controlled and data taken by an Interdata 70 computer. Computer programs for gas analysis and for plotting of data are available.

Availability: Because of the complexity of instrumentation, the direct use of these spectrometers is limited to: (a) permanent members of the laboratory; and (b) qualified full-time guest scientists with appointments exceeding six months. The spectrometers may be used indirectly through cooperative or contractual research agreements.

Literature:

[1] R. Celotta, S. R. Mielczarek, and C. E. Kuyatt, NBS Report 10915 (September 1972).

[2] N. Swanson, C. E. Kuyatt, J. W. Cooper and M. Krauss, Phys. Rev. Letters 28, 948 (1972).

[3] G. E. Chamberlain, S. R. Mielczarek and C. E. Kuyatt, Phys. Rev. A 2, 1905 (1970).

Contact: Dr. Chris E. Kuyatt, Chief, Surface and Electron Physics Section, Metrology Building, Room B214, Phone 301-921-2051.

\section{FAR INFRARED SPECTROSCOPY}

Far infrared spectroscopy studies the absorption, transmission or reflection of long wavelength, $1000 \mu$ to $10 \mu\left(10^{6}-10^{4} \mathrm{~nm}\right)$, electromagnetic radiation which is caused by vibrations, rotations, and translations which modulate the dipole moment of the atoms and molecules in the sample. It is a useful tool for the identification of molecular or ionic species in the liquid, solid, and gaseous states.
Capability: The techniques of Fourier transform spectroscopy are applied in the far infrared instrument. The range of $10-1000 \mathrm{~cm}^{-1}$ can be measured with a resolution of $0.5 \mathrm{~cm}^{-1}$. The radiation detector is a triglycine sulfate (TCS) pyroelectric crystal. The Michelson interferometer employs a high precision air bearing translator, and a He-Ne laser is used for distance measurement. Data output is typically graphical and is processed by an on-line computer which also serves to control the instrument throughout the experiment. Specimens can be studied by transmission or reflection as is necessary. Facilities are provided for sample temperature variation between $10 \mathrm{~K}$ and $300 \mathrm{~K}$ and for matrix isolation.

Applications: Molecular and crystal dynamics as displayed by translational, rotational, librational and vibrational degrees of freedom are measured as a function of parameters such as temperature, pressure, stoichiometric relations, electric or magnetic fields, concentration and phase. Typical applications involve the spectra of matrix isolated free radicals and molecules, lattice and molecular dynamics of polymers, phase transitions in solids (including melting), studies of isomerism, vibrational and rotational studies in gases, investigation of stoichiometry in crystals and disordered solids, and measurements of chemical reaction products.

Availability: The instrument is available to qualified research workers, following a training period in its use. Proposed research projects require the approval of the instrument manager, or in special cases, of the users committee.

\section{Literature:}

[1] G. Horlick, Appl. Spectrosc. 22, 617 (1968).

[2] P. R. Griffiths, C. T. Foskett, and R. Curbelo, Appl. Spectrosc. Revs. 6, 31 (1972).

Contact: Dr. Marilyn E. Jacox, Acting Chief of Environmental Chemical Processes Section, Chemistry Building, Room A243, Phone 301-921-2754.

\section{FLAME EMISSION SPECTROMETER WITH REPETITIVE OPTICAL SCANNING}

Repetitive optical scanning for flame emission spectrometry provides a unique way of minimizing spectral interferences in matrices and flame gases. By measuring the second derivative of the output intensity, a small signal from an atomic emission line can be readily discerned from a very large continuum. This is especially useful when dealing with the high 
temperature flames and plasmas which are needed to excite the more refractory elements. At the same time this technique requires a minimum of sample.

Capabilities: The instrument provides the capability of quantitative measurements at the parts per million level or less for thirty elements in a large variety of matrices with a precision of 0.2 to 5 percent. For many of these analyses only $50 \mu \mathrm{l}$ of solution is necessary per analysis.

Application: This instrument is presently being used to characterize many of the trace elements in Standard Reference Materials and other related materials. Typical examples include $\mathrm{Li}, \mathrm{Na}, \mathrm{K}$ and $\mathrm{Ca}$ in serum, liver, orchard leaves, fertilizer and clays; $\mathrm{Ca}, \mathrm{Sr}$ and $\mathrm{Ba}$ in steels; $\mathrm{Al}$ in high purity steel and phosphate rock; $\mathrm{Li}$ in both fresh and sea water; $\mathrm{Zr}$, La and $\mathrm{Sr}$ in optical quality glass; $\mathrm{Ni}$ and $\mathrm{Co}$ in steels and ores; $\mathrm{Gd}$ in calcium fluoride; $\mathrm{Pd}$ and $\mathrm{Ru}$ in alloys and $\mathrm{Tl}$ in organic compounds.

Availability: To any qualified research worker, but because of the complexity of the instrument and safety in the handling of high temperature flames and plasmas, the operation of the facility is limited to permanent members of the Analytical Spectrometry Section.

\section{Literature:}

[1] W. Snelleman, T. C. Rains, K. W. Yee, H. D. Cook, and O. Menis, Flame emission spectrometry with repetitive optical scanning in the derivative mode, Anal. Chem., 42, 394 (1970).

[2] O. Menis, editor, Flame emission and atomic absorption spectrometry, NBS Technical Note 504 (1969), pp. 1-8.

[3] O. Menis and J. I. Shultz, editors, Analytical flame spectroscopy, NBS Technical Note 544, (1970), pp. 58-86.

Contact: Theodore C. Rains, Analytical Spectrometry Section, Chemistry Building, Room B222, Phone 301921-2142.

\section{FLASH PHOTOLYSIS RESONANCE FLUORESCENCE APPARATUS}

Fluorescence measuring techniques have proven to be quite sensitive and versatile for the detection and monitoring of many short-lived species. The existing
NBS facility for the production and subsequent kinetic detection of reactive atomic and free radical species incorporates such fluorescence techniques and is the precursor of several similar pieces of apparatus in chemical laboratories throughout the world.

Capability: Gas mixtures of an atom or free-radical source compound, reactant substrate, and inert diluent (from 1 torr to $1 \mathrm{~atm}$ in total pressure) are subjected to a flash pulse (electrical discharge or laser). The atoms or free radicals photolytically produced are subjected to the $\mathrm{cw}$ radiation of a microwave resonance flow lamp or the delayed pulsed radiation of a suitable laser. The scattered radiation is subsesequently monitored as a function of time to obtain the kinetic history of the reactive species. Experiments can be conducted at temperatures ranging from 200 to $500 \mathrm{~K}$.

Applicability: The technique is presently suited for the study of chemical dynamics of systems involving $\mathrm{H}, \mathrm{O}, \mathrm{N}, \mathrm{S}, \mathrm{Cl}, \mathrm{C}$, and $\mathrm{Br}$ atoms as well as $\mathrm{OH}$ radicals. With suitable resonance lamp development, the technique can be extended to numerous other reactive species. The range of experimental conditions overlaps those desired for investigations involving air pollution, combustion processes, planetary atmosphere, chemical laser systems, etc.

Availability: The apparatus is presently being used full-time for chemical kinetics studies of atmospheric interest and for laser induced chemical processes. Outside use is consequently restricted to short-term problems suitable for study on a cooperative basis.

\section{Literature:}

[1] E. L. Baardsen and R. W. Terhune, Appl. Phys. Lett. 21, 209, (1972).

[2] M. J. Kurylo, J. Phys. Chem. 76, 3518 (1972).

[3] F. Stuhl and H. Niki, J. Chem. Phys. 57, 3671 and 3677 (1972).

Contact: Dr. Michael J. Kurylo, Environmental Chemical Processes Section, Chemistry Building, Room A253, Phone 301-921-2080.

\section{FOURIER TRANSFORM NUCLEAR MAGNETIC RESONANCE SPECTROMETER}

This high-resolution instrument utilizes the magnetic moment of ${ }^{13} \mathrm{C}$ nuclei to probe the molecular dynamics and structure of polymeric materials. 
Capability: Requires sample concentration of at least 0.05 mole in $2 \mathrm{~m} \ell$ of solution. Magnetic field operates at $1.4 \mathrm{~T}$, corresponding to a resonance frequency of $15.08 \mathrm{MHz}$. Spinning resolution of $0.5 \mathrm{~Hz}$ over $10 \mathrm{~mm}$ sample tube; $90^{\circ}$ rotation of magnetization requires pulse of $<5 \mu$ s duration and pulse programmer allows $180^{\circ}-\tau-90^{\circ}$ pulse sequence to be performed. A computer with 8000 words is available for accumulation and processing of data.

Applications: Identification of monomers and polymers in solution; identification of molecular rotational isomers; determination of polymer tacticity, cross-link and branches; determination of polymer chain dynamics in solution and in the solid state; determination of molecular conformation and structure of biopolymers and proteins.

Availability: The use of this instrument by NBS research workers on problems of mutual interest can be arranged. It must be operated only under the direct supervision of the scientist in charge of the instrument.

Contact: Dr. Darrell H. Reneker, Chief of Structural Analysis and Standards Section, Polymer Building, Room A209, Phone 301-921-3344.

\section{GAS CHROMATOGRAPH- MASS SPECTROMETER SYSTEM}

The gas chromatograph-mass spectrometer-computer system is designed for organic chemical applications, particularly trace organic analysis and structural identification. The system uses a quadrupole spectrometer and includes both electron impact and chemical ionization sources.

Capability: The gas chromatograph-mass spectrometer system is capable of measuring mass spectra with unit mass resolution from $\mathrm{m} / \mathrm{e} 2$ to 650 at a maximum scan speed of $325 \mathrm{amu} / \mathrm{s}$. The gas chromatograph is equipped with linear temperature programming, dual column operation, thermal conductivity, flame ionization, and electron capture detectors. The mass spectrometer is controlled by a $16 \mathrm{~K}$ word, 16 bit data acquisition and control system. The data system includes two 1.2 million word discs, programmable read-only memory, and an interactive display terminal. Both glass jet and membrane separators are available for the GC-MS interface.

Applications: Mass spectrometric analyses of gas chromatographic effluents from samples of biological and environmental origin are the predominant current applications. Other work in progress includes isotope dilution mass spectrometry, precision of quantitation for both electron impact and chemical ionization, and spectrometric measurement and identification of impurities in Standard Reference Materials.

Availability: A limited amount of time is available for other groups and agencies. Laboratories with challenging analytical problems are encouraged to enter into collaborative programs with the Section, particularly in the areas of biological materials, clinical analysis, and trace organic analyses in the environment.

Contact: Dr. Robert Schaffer, Chief of the Bio-organic Standards Section, Chemistry Building, Room A367, Phone 301-921-2866.

\section{HIGH PRESSURE PHOTOIONIZATION MASS SPECTROMETER}

This instrument combines a photoionization and reaction chamber with a mass spectrometer in order to investigate the interactions of positive and negative ions with neutral molecules in the vapor phase.

Capability: Ionization of pure samples or mixtures may be induced by photoabsorption at $8.4,10.0,11.7$, 16.7 , or $21.2 \mathrm{eV}$ over the pressure range $10^{-4}$ to approximately 3 torr. Accurate rate constants are obtained between 200 and $350 \mathrm{~K}$ for bimolecular and relatively fast termolecular reactions involving ionneutral collision processes. The kinetics of higher order processes including collisional stabilization and ionic solvation reactions may also be easily defined.

Applications: Determination of accurate rate constants for ion-molecule reactions; effect of internal energy and pressure on reaction rates; elucidation of ionic polymerization mechanisms; analysis of trace components using chemical ionization techniques; laboratory simulation of planetary ionospheres; determination of ionic fragmentation patterns for correlation with photoelectron spectroscopy.

Availability: Contingent upon contract commitments and direction of in-house program. In appropriate instances qualified scientists from NBS, other federal organizations, and private institutions may collaborate on problems of mutual interest to ihe operators.

\section{Literature:}

[1] J. Am. Chem. Soc. 91, 7627 (1969). 
[2] J. Chem. Phys. 53, 794 (1970).

[3] J. Am. Chem. Soc. 92, 2937 (1970).

Contact: Dr. Wayne Sieck, Environmental Chemical Processes Section, Chemistry Building, Room A255, Phone 301-921-2783.

\section{HIGH RESOLUTION INFRARED SPECTROMETER}

This facility consists of a high resolution vacuum spectrometer with associated hardware and software to cover the infrared region from $5.5 \mu \mathrm{m}$ to $1.5 \mu \mathrm{m}$. The instrument is available for measuring high resolution spectra of molecules in the gas phase.

Capability: This instrument operates in the spectral range from $1850 \mathrm{~cm}^{-1}$ to $6000 \mathrm{~cm}^{-1}$ with a resolution of about $0.03 \mathrm{~cm}^{-1}$, a precision of measurement of $\pm 0.002 \mathrm{~cm}^{-1}$, and an accuracy of measurement of about $\pm 0.006 \mathrm{~cm}^{-1}$. The entire optical path can be evacuated to eliminate absorption due to atmospheric constituents. Facilities are available for making measurements on gas samples in the temperature range from $-76^{\circ} \mathrm{C}$ to $+1200^{\circ} \mathrm{C}$. A variable long path absorption cell is also available, providing absorption paths up to 39 meters. The spectrometer output is recorded directly on magnetic tape, and software is available for processing the output on a digital computer to automatically provide an atlas listing the frequencies and intensities of absorption lines.

Applications: Fields of applications for these measurements are: air pollution, terrestrial and planetary atmospheric measurements, measurements on cool stars, molecular structure, studies of reaction intermediates and reaction products, flames and high temperature studies, thermodynamics, mechanisms of laser action, properties of chemical bonds, energy transfer mechanisms, and many more.

Availability: Instrument time is available for any projects which properly utilize the unique high resolution capabilities of this instrument.

Contact: Dr. Arthur Maki, Chief of Molecular Spectroscopy Section, Physics Building, Room B268, Phone 301-921-2021.

\section{ISOTOPE RATIO MASS SPECTROMETERS}

The laboratory contains all the necessary chemical and mass spectrometric equipment for the determination of isotopic ratios at the "state of the art" ac- curacy level for all elements that will ionize by either surface or thermal methods.

Capability: The range of available equipment is such that almost any size sample down to $10^{-14}$ grams can be handled, for both absolute isotopic abundance ratio determinations or the determination of trace element concentration by isotope dilution.

Applications: Current applications include the determination of the absolute isotopic abundance ratios and atomic weights of the polynuclidic elements, the determination and certification of the absolute isotopic abundance ratios for standards of interest to the nuclear energy industry and the geochemist, the geochemical age determinations ( $\mathrm{Pb}-\mathrm{U}-\mathrm{Th}, \mathrm{Rb}-\mathrm{Sr}$ ) on lunar materials, and the determination of trace concentrations of a wide variety of elements in almost any conceivable matrix.

Availability: The facility is available to any qualified guest worker interested in high-accuracy analysis, but does require a three to six months training period.

\section{Literature:}

[1] NBS Technical Note, 456, Nov. 1968, pp 1-47.

[2] NBS Technical Note, 506, May 1970, pp 1-48.

[3] NBS Technical Note, 546, Nov. 1970, pp 1-110.

Contact: Dr. I. L. Barnes, Analytical Spectrometry Section, Physics Building, Room A25, Phone 301-9213674 .

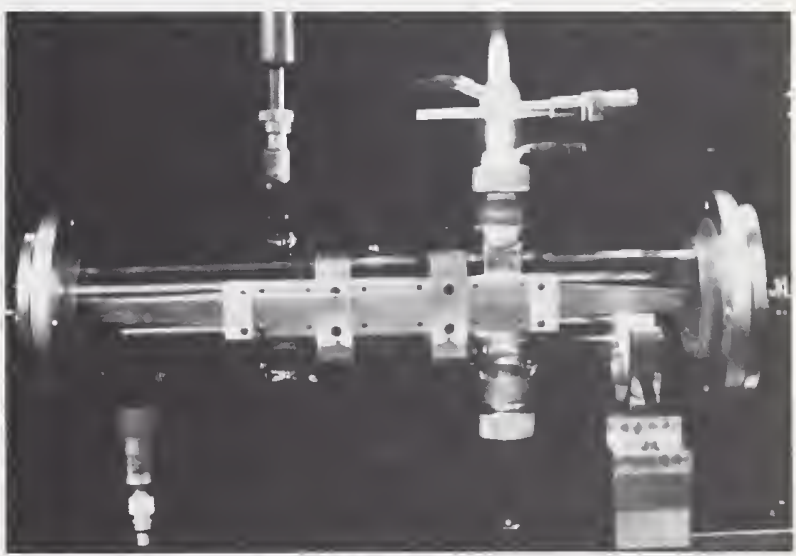

MICROWAVE SPECTROSCOPY FACILITY. Millimeter-wave parallel plate absorption cell with discharge production system.

\section{MICROWAVE SPECTROSCOPY FACILITY}

The microwave spectroscopy laboratory at the $\mathrm{Na}$ tional Bureau of Standards has had a long history of 
research into problems involving extensive development of microwave instrumentation. Pioneering efforts in the study of transient and high temperature molecules have led to designs and techniques which affect spectrometer performance in many ways. Operational flexibility and sensitivity have been significantly extended in both the high and low frequency extremes of the traditional microwave region.

Capability: Two separate spectrometer systems are available with klystron sources and requisite hardware to cover the complete ránge from 2 to $132 \mathrm{GHz}$. Harmonic generation equipment extends the operation further into the millimetre region. Conventional septum-type waveguide absorption cells, used for studies of static systems, include a $12 \mathrm{ft}$ gold-plated cell (3.3 GHz cutoff), $15 \mathrm{ft}$ brass cell ( $8 \mathrm{GHz}$ cutoff), and $4 \mathrm{ft}$ all-stainless and Teflon cell for special handling of reactive gases ( $12 \mathrm{GHz}$ cutoff). All three conventional cells can be cooled to dry ice and the special stainless cell may be heated to $300^{\circ} \mathrm{C}$. Several parallel plate cells are available complete with discharge and pyrolysis sample generating apparatus and fast-continuous-flow vacuum systems. Special ovens will allow operating temperatures to $1000^{\circ} \mathrm{C}$ for certain experiments.

Applications: Analyses of rotational spectra of polar gas-phase molecules yielding structural parameters, electric dipole moments, quadrupole coupling constants and spectroscopic details such as vibrationrotation interactions, etc. Stable molecules with vapor pressures of a few micrometres of $\mathrm{Hg}$ at temperatures below $1000^{\circ} \mathrm{C}$ are readily accessible. A variety of small transient molecules with lifetimes of the order of $10 \mathrm{~ms}$ have been successfully studied in the flow systems. Certain laser-microwave double resonance and laser pumped reaction systems are also within the range of capabilities.

Availability: To qualified research workers on a collaborative basis with NBS staff or in special cases where background and experience is adequate on a guest worker basis. It should be emphasized that these spectrometer systems are hand-built, state-ofthe-art devices and require extended experience for competent operation.

Contact: Dr. Donald R. Johnson, Molecular Spectroscopy Section, Physics Building, Room B268, Phone 301-921-2021.

\section{MÖSSBAUER SPECTROSCOPY OF METALS}

Mössbauer effect utilizes the nuclear properties of various isotopes to probe the local chemical, magnetic and electronic environment of an atom embedded in a solid material. By detecting the conversion electrons that emanate from a sample, very thin. surface layers can be studied. Differences between the surface and bulk can be observed by also detecting the primary Mössbauer effect gamma rays.

Capability: Solid specimens of irregular shapes with outside dimensions up to $30 \mathrm{~cm}$ can be utilized. Minimum size is about $0.5 \mathrm{~cm}$ diameter and $5 \mu \mathrm{m}$ thickness. Transmission spectra can be obtained (on powders or foils) as a function of temperature in applied magnetic fields up to $50 \mathrm{kG}$. On selected specimens, time delayed perturbed angular correlation or positron lifetime studies can also be made.

Applications: Measurements of isomer shifts, magnetic hyperfine fields and electric field gradients permit studies of phase composition, magnetic properties, electronic structure and diffusion. Applications to corrosion studies, surface effects, and other metallurgical problems.

Availability: To any qualified NBS research worker. In appropriate instances, researchers from other organizations can gain access to the facility. Scientists from U.S. universities, federal agencies and industries, and from abroad have qualified to use this equipment in the past.

\section{Literature:}

[1] Nuclear Resonances in Metals: NMR and Mössbauer Effect by I. D. Weisman, L. J. Swartzendruber and L. H. Bennett in Measurement of Physical Properties, E. Passaglia and R. F. Bunshah, Editors. (Wiley-Interscience, New York), V. 6(2), 1973.

[2] Mössbauer Spectrometer Calibration Using TiFe, Nat. Bur. Stand. (U.S.) Tech. News Bull. 54, No. 10, page 239 (1970).

Contact: Dr. L. H. Bennett, Chief of Alloy Physics Section, Materials Building, Room B150, Phone 301921-2982.

\section{MULTICHANNEL FLAME SPECTROMETER}

This flexible system was designed and assembled at NBS to perform precise spectral measurements in the emission and atomic absorption modes using flames or similar high temperature "thermostates." The spectrometer used to detect the radiations originating from the excitation source is a conventional 1-m grating instrument, arranged to focus on a photographic plate, a variable exit slit, or a metal plate with eight exit slits. 
Capability: Operable as a spectrograph, a scanning monochromator, or a multichannel instrument. Measures in emission and atomic absorption modes for one element at a time, or up to 8 chemical species simultaneously. The output is either analog or digital.

Applications: Analysis for alkali and earth alkali metals in body fluids, agricultural products, soils, air, and water samples; for elements from the I to VIII groups in alloys; for trace elements such as $\mathrm{Pb}, \mathrm{Cd}$, $\mathrm{Hg}, \mathrm{Cu}, \mathrm{Cr}, \mathrm{Ni}$.

Availability: To any qualified NBS research worker, after an initial training period by R. Mavrodineanu.

\section{Literature:}

[1] R. Mavrodineanu, Discussion of some experimental and fundamental flame spectroscopy, Revue GAMS, 1971, no. 3, 39-60.

[2] R. Mavrodineanu and H. Boiteux, Flame Spectroscopy, John Wiley and Sons, 1965, pp. 721.

Contact: Dr. R. Mavrodineanu, Assistant Chief, Special Analytical Instrumentation Section, Chemistry Building, Room A205, Phone 301-921-2861.

\section{NUCLEAR MAGNETIC RESONANCE SPECTROSCOPY}

The NMR method makes use of the magnetic and electric moments of atomic nuclei to probe the local environment about selected nuclei in materials. Appropriate nuclei of virtually any chemical element can be used, but considerations such as isotopic abundance, sensitivity and atomic motion restrict studies to preselected problems.

Capability: Metallic specimens generally should be in the form of -325 mesh powder, but other forms including single crystals are possible. Wide-line NMR spectroscopy with laboratory electromagnet and high-power pulsed NMR spectroscopy with superconducting magnet. Data acquisition system used for sensitivity enhancement. Ferromagnetic NMR spectroscopy also available. Temperature and pressure variations possible.

Applications: Measurements of Knight shifts, relaxation times, electric quadrupole interactions and lineshapes permit studies of electronic structure, defect structure and diffusion. These have been important primarily in the study of metals, alloys, and intermetallic compounds but occasional attention has been given to practical problems outside of metallurgy such as detecting cancer in live mice utilizing NMR.
Availability: To any qualified NBS research worker. In appropriate instances, researchers from other organizations can gain access to the facility. Scientists from U.S. universities, federal agencies and industries, and from abroad have qualified to use this equipment in the past.

Literature: Nuclear Resonances in Metals: NMR and Mössbauer Effect by I. D. Weisman, L. J. Swartzendruber and L. H. Bennett in Measurement of Physical Properties, E. Passaglia and R. F. Bunshah, Editors. (Wiley-Interscience, New York, V. 6(2), 1973.

Contact: Dr. Lawrence $\mathrm{H}$. Bennett, Chief of Alloy Physics Section, Materials Building, Room B150, Phone 301-921-2982.

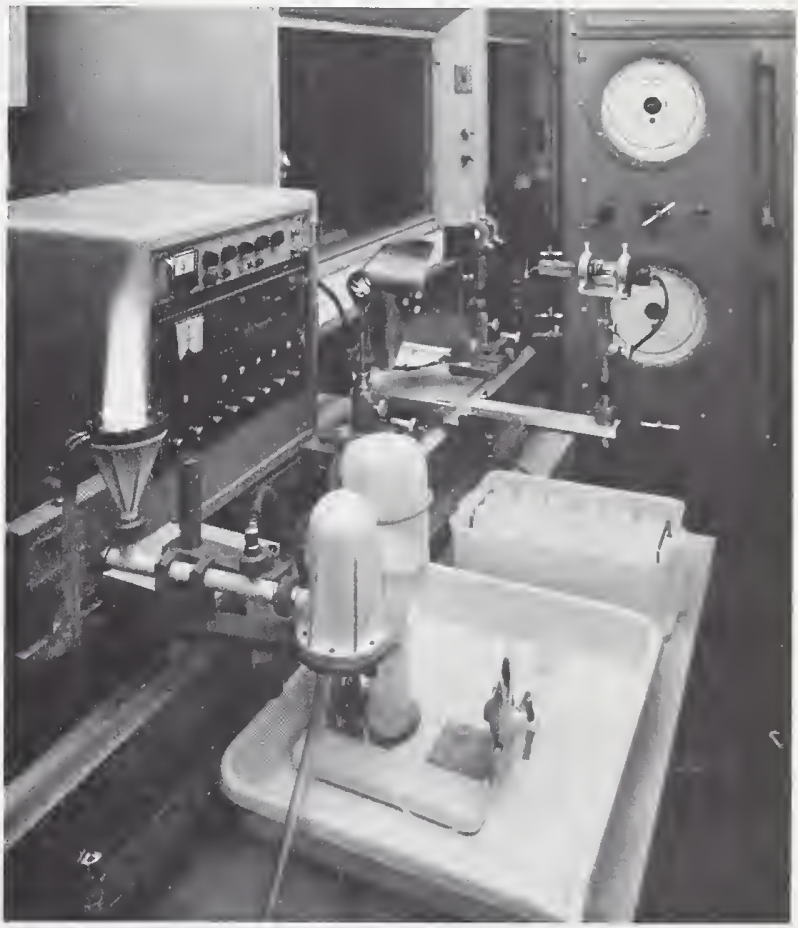

MULTICHANNEL FLAME SPECTROMETER.

\section{PHOTOIONIZATION MASS SPECTROMETRY}

The photoionization laboratory operates and maintains two major equipment items for use in basic studies of photoionization processes in low pressure gases and vapors. This is a powerful technique for the accurate determination of ionization thresholds for molecular, dissociative, and ion-pair processes as well as the study of the spectroscopy of ions.

Capability: Each unit consists of a windowless vacuum ultraviolet monochromator combined with a 
magnetic mass spectrometer for the detection and identification of photoions. The best optical resolution available at present is $0.012 \mathrm{~nm}$ in the first order over the wavelength region of 130 to $60 \mathrm{~nm}$. Included in the apparatus is a step-controlled grating drive, digitized photon detector, and the programmed control of wavelength, ion and photon recording and the print-out of data. Automatic computation of ion yield and the plotting of original or smoothed data is a present capability. The ion source of the mass spectrometer can be cooled to $115 \mathrm{~K}$ or heated to $500 \mathrm{~K}$ to enable the identification of effects due to thermal excitation of molecules under study.

Applications: A continuing program of research on molecular ionization, dissociative ionization, and ionpair processes in diatomic and polyatomic molecules has included the study of autoionization and predissociation phenomena, identification of Rydberg series and progressions, the determination of FranckCondon factors for direct ionization, accurate ionization threshold values and the derivation of bond dissociation energies, electron affinities and heats of formation of ions and molecules.

Availability: The instruments are available at NBS to qualified research workers following a short training period. Proposed research projects require the approval of the Section Chief.

\section{Literature:}

[1] V. H. Dibeler, et al, Int. J. Mass Spectrometry and Ion Phys. 11, 49 (1973).

[2] J. Chem. Phys. 44, 1271 (1966).

[3] K. E. McCulloh, J. Chem. Phy. 59, Oct. 1973.

Contact: Dr. Henry M. Rosenstock, Chief, Chemical Dynamics Section, Chemistry Building, Room A145, Phone 301-921-2792.

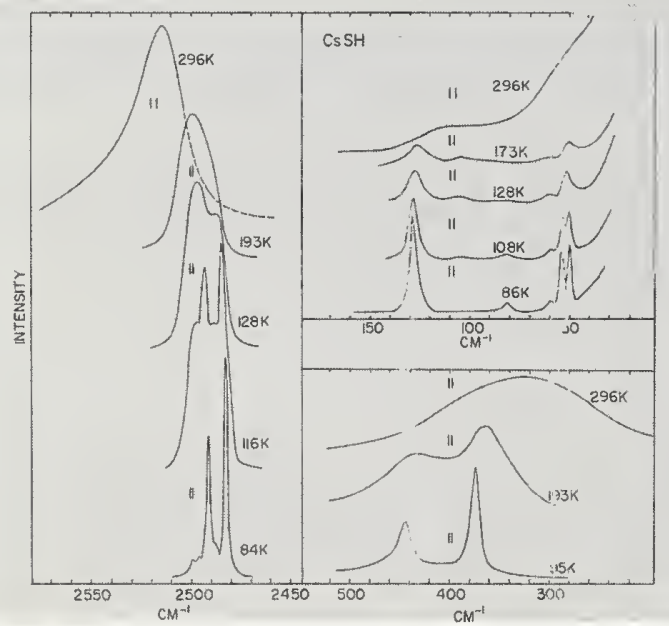

RAMAN SPECTROSCOPY. Raman spectra showing changes associated with order-disorder phase transitions (at ca. $205 \mathrm{~K}$ and $\mathrm{ca} .113 \mathrm{~K}$ ) in $\mathrm{CsSH}$, lattice translations (30-200 $\left.\mathrm{cm}^{-1}\right)$, lattice librations (200-600 $\left.\mathrm{cm}^{-1}\right)$ and $\mathrm{SH}$ - stretching modes (ca. $2500 \mathrm{~cm}^{-1}$ ).

\section{RAMAN SPECTROSCOPY}

The spectral features observed in Raman and infrared spectroscopy allow qualitative and quantitative identification of species and can be used to establish structure and measure dynamical interactions in molecular compounds and crystalline bodies. Raman spectroscopy routinely studies the molecular motions in the range 0 to $5000 \mathrm{~cm}^{-1}$. It investigates the scattering of electromagnetic waves (typically 400 to 700 $\mathrm{nm}$ ) caused by the modulation of the optical polarizability of atoms and molecules created by their internal vibrations, rotations, translations and a variety of electronic processes (magnons, plasmons).

Capability: Laser sources are used in conjunction with a double monochromator for spectral analysis of the scattered light. The photoelectrically detected signal is processed by either $\mathrm{dc}$ or photon rate techniques. The spectrometer covers the range from 30,000 to $10,000 \mathrm{~cm}^{-1}$ with a resolution of $0.25 \mathrm{~cm}^{-1}$. The lasers available are a He-Ne laser operating at $632.8 \mathrm{~nm}$, $60 \mathrm{~mW}$ power, and an $\mathrm{Ar}^{+}$ion laser operating principally at 488.0 or $514.5 \mathrm{~nm}$, powers up to 5 watts. The $\mathrm{Ar}^{+}$ion laser (which can produce over 1 watt in the UV lines) can be used in conjunction with a jetstream dye laser to produce a continuously tunable laser source covering the range from 400.0 to 700.0 $\mathrm{nm}$. The instrument is equipped with a versatile sample chamber which allows a great variety of sample types and scattering geometries to be selected. Equipment for temperature variation and matrix isolation is provided. The Raman laboratory is equipped with a dedicated minicomputer and associated peripheral equipment which allows automated data acquisition and "on-line" processing of Raman spectral data.

Applications: Raman spectroscopy is a useful tool for the identification of molecular or ionic species. Structures and force constants can be determined for liquids, solids, and gases. Typical applications involve the spectra of matrix isolated free radicals and molecules, lattice and molecular dynamics of polymers, phase transitions in solids (including melting), studies of isomerism, vibrational and rotational studies in gases, investigation of stoichiometry in crystals and disordered solids, and measurements of chemical reaction products.

Availability: The instrument is available to qualifie. research workers at NBS, following a training period in its use. Proposed research projects require the approval of the instrument manager, or in special cases by a users committee.

Contact: Dr. Gregory J. Rosasco, Physicist, Solid State Materials Section, Materials Building, Room A165, Phone 301-921-2780. 
SURFACE

PROPERTIES

FACILITIES

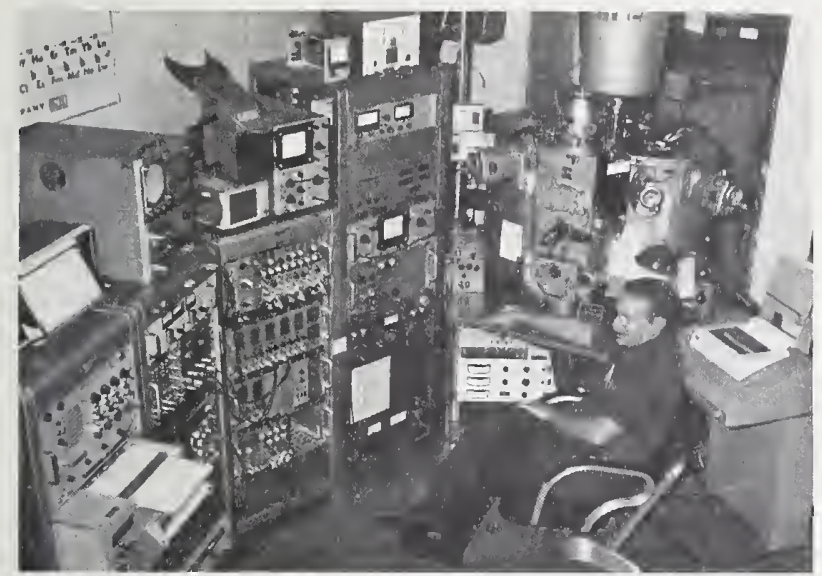

ELECTRON PROBE MICROANALYZER.

\section{ELECTRON PROBE MICROANALYZER}

The electron probe microanalyzer has the unique function of qualitatively and quantitatively analyzing microscopic regions of specimens, of $1-3 \mu \mathrm{m}$ diameter, with regard to elemental composition. This is achieved by focusing a beam of electrons upon the specimen surface, and analyzing the characteristic $x$-radiation emitted from the bombarded spot on the specimen.

The function of localized analysis is complemented by capabilities for area- and line-scanning, which permit the simultaneous exploration of a microscopic region.

The electron probe has been used for a wide range of specimens, including lunar and terrestrial rocks, alloys, ceramics, paper, and biological materials.

Operational Characteristics: Specimens of up to 2.54 $\mathrm{cm}$ (1 inch) diameter can be analyzed. For quantitative analysis, specimens must be flat and electric insulators must be coated with a film of carbon or metal. Facilities for specimen preparation are available. All elements of atomic number above 4 can be detected, and quantitative analysis is possible for elements of atomic number above 10. Limits of detection are typically in the order of $0.01 \%$; the total sample mass analyzed is typically $10^{-11} \mathrm{~g}$. Accuracy of quantitative analysis for major constituents is typically $2-3 \%$ relative.

Typical Applications: Study of inclusions, of corrosion products on alloys of coating and paint layers, of particulate corrosion or pollution products, altered coins, failures of solid-state microelectronics, manufacturing techniques of archaeological objects, distribution of elements in biological tissue (plant or animal).

Availability: To trained operators only. Service using our own operators is available.

Contact: Dr. Kurt F. J. Heinrich, Chief, Microanalysis Section, Chemistry Building, Room A121, Phone 301921-2871.

\section{ION PROBE MICROANALYZER}

The ion probe microanalyzer is a tool for qualitative and semiquantitative elemental analysis of microscopic regions of solid specimens. The technique of ion probe microanalysis is based on the formation of a focused beam of ions which bombards a microscopic region of the specimen. The area of impact of the primary beam is eroded by it, and secondary ions of the elements present in the specimen are emitted. These ions are analyzed in a mass analyzer; the mass numbers of the ions indicate which elements are present, and the intensities of emission are related to the concentrations of the elements forming secondary ions.

The capabilities of this instrument include trace analysis, isotope ratio measurement, and the detection and analysis for elements of low atomic number, including hdyrogen. All these measurements can be taken from a region a few micrometeres wide and a few tens of angstroms deep.

Operational Characteristics: Specimens of up to 2.54 $\mathrm{cm}$ ( 1 inch) diameter can be analyzed. The specimens must be flat. Facilities for specimen preparation are available. All elements can be detected and analyzed semiquantitatively. The sensitivity is highest for elements of Groups I and II (e.g., sodium) where it is in the ppm range. The accuracy of isotope ratio measurements for major components is typically 2 to $3 \%$.

Typical Applications: This is a novel instrument, and present experience is limited. Lunar rocks, distribution of impurities in semiconductors, surface impurities on irradiated materials, and trace element distributions in glasses have been investigated. Preliminary investigations of biological materials are very encouraging. 
Availability: In view of the expense and complexity of this instrument, access is given to trained operators only. Service by the NBS operator is available.

Contact: Dr. Kurt F. J. Heinrich, Chief of Surface Microanalysis Section, Chemistry Building, Room A121, Phone 301-921-2871.

\section{MOLECULAR BEAM- FIELD EMISSION MICROSCOPE}

A molecular beam machine is combined with a field emission microscope, capable of operation down to $4.2 \mathrm{~K}$, to observe deposition, surface migration, adsorption, displacement effects and catalysis in almost molecular detail.

Capability: Surface studies may be made on any metal or semiconductor capable of being used as a field electron emission source. Included are such metals as tungsten, molybdenum, rhenium, rhodium, nickel, niobium, ruthenium, and many others. The specific features of the apparatus are excellent control and quantitative measure of the deposition of gases on surfaces, the facile switching of gases in the beam, and the ease of control of the beam temperature. The temperature range available for the emitter tip is from $4.2 \mathrm{~K}$ to the melting point of the metal or semiconductor.

Applications: Fundamental studies and observations of catalytic surfaces, or adsorption, of sticking probabilities, of adsorption-displacement, and of surface reactions are possible with the apparatus.

Availability: To qualified research personnel on a cooperative basis. Prior arrangements must be made, and only short term (one to two weeks) experiments will be considered.

\section{Literature:}

[1] "Preparation of Contiguous Chemisorbed Adlayers by Sequential Deposition and Surface Migration" Ralph Klein, Surface Science, 29, No. 1, pp. 309-316, January, 1972.

[2] "Second Layer Migration with Trapping on First Layer Sites: Hydrogen, Nitrogen, and Carbon Monoxide on Tungsten" Mordecai Folman and Ralph Klein, Surface Science, 11, pp. 430-442, 1968.

[3] "The Deposition of Hydrogen Beams on Tungsten" Ralph Klein, Surface Science, 11, pp. 227-241, 1968.
Contact: Dr. Ralph Klein, Senior Scientist, Physical Chemistry Division, Chemistry Building, Room B248, Phone 301-921-2161.

\section{MOLECULAR BEAM MACHINE}

An ultrahigh vacuum, differentially pumped molecular beam machine for high precision work. At present it uses alkali or alkali halide beams with surface ionization detection.

Capability: Source is a resistively heated effusion cell. Detector can probe $6.5 \mu \mathrm{m}$ perpendicular to the beam axis, with a resolution of $0.02 \mu \mathrm{m}$. Ultimate vacuum is $10^{-11}$ torr.

Application: Primarily as a research tool for investigation of gas-surface interactions.

Availability: This equipment is being used presently on a longrange program concerned specifically with measurement of van der Waal's forces. Availability is limited to very short-range problems of mutual interest in that field, with operation by Section staff.

Contact: Dr. Ralph Klein, Senior Scientist, Physical Chemistry Division, Chemistry Building, Room B248, Phone 301-921-2161. 


\section{SURFACE ANALYSIS FACILITY}

ESCA and Auger spectrometers are available for the quantitative or semiquantitative chemical analysis of surfaces and surface layers. Both spectrometers have a sensitivity of a small fraction of a monolayer to most elements. In the case of ESCA, the presence of a chemical shift is often used to determine the valence state of surface species.

Capability: Ambient pressure is $10^{-10}$ torr. Sample size abnut $1 \mathrm{~cm}^{2}$. Depth sensitivity is of the order of $10 \AA$. Depth profile measurement using $\mathrm{Ar}$ ion sputtering is possible.

Application: Wherever chemical analysis of surface layers is desirable. In most cases, special sample handling procedures are of importance to reduce contamination effects.

Availability: These instruments are research tools being used extensively in ongoing research programs. They are generally not available for analyses of samples. However, in certain situations, where our staff might become involved in a research problem, the instrument could be made available. Special training is necessary for operation of either instrument.

Contact: Dr. John T. Yates, Jr., Acting Chief, Surface Process and Catalysis Section, Chemistry Building, Room B250, Phone 301-921-2188.

\section{Literature:}

[1] S. H. and D. M. Hercules, Surface Characterization by Electron Spectroscopy for Chemical Analysis (ESCA), p. 307 in book Characterization of Solid Surfaces, Kane \& Larrabee, Plenum Pr., New York, 1974.

[2] C. C. Chang, Chemical Analysis by Auger Electron Spectroscopy, ibid, p. 509.

[3] E. N. Sickafus, J. Vac. Sci. \& Tech. 11, 299 (1974).

\section{SURFACE AREA ANALYZER}

The Surface Area Analyzer provides a complete system for preconditioning and measuring both low and high values of surface area by the classic BrunauerEmmett-Teller technique, employing krypton and nitrogen as the absorbates in a metal system. In addition, pore size distribution can be obtained from complete adsorption or desorption isotherms. Calculations can be made manually or with available computer programs.
Capability: The system is capable of measuring active surface areas as low as $100 \mathrm{~cm}^{2} / \mathrm{g}$. The reproducibility of the system using krypton is \pm 3 percent for materials with surface areas of $200 \mathrm{~cm}^{2} / \mathrm{g}$ or greater, having a total sample area of $500 \mathrm{~cm}^{2}$ or greater. Using nitrogen, the reproducibility is \pm 3 percent for a total sample area of $5 \mathrm{~m}^{2}$ or greater. Special sample holders are available, capable of accepting planar materials having dimensions $1.5 \times 1.5 \times .05 \mathrm{~cm}$.

Applications: The surface area and/or pore size distribution of materials such as catalysts, gasket material, paper, plastics, foams, etc., may be determined. The special sample holders for planar materials enable determination of surface properties and physical tests on the same specimen.

Availability: To an qualified research worker after an initial training period with Dr. E. L. Graminski. A good knowledge of vacuum systems is necessary to operate the apparatus.

Contact: Dr. E. L. Graminski, Polymer Stability and Reactivity Section, Polymer Building, Room A369, Phone 301-921-2923.

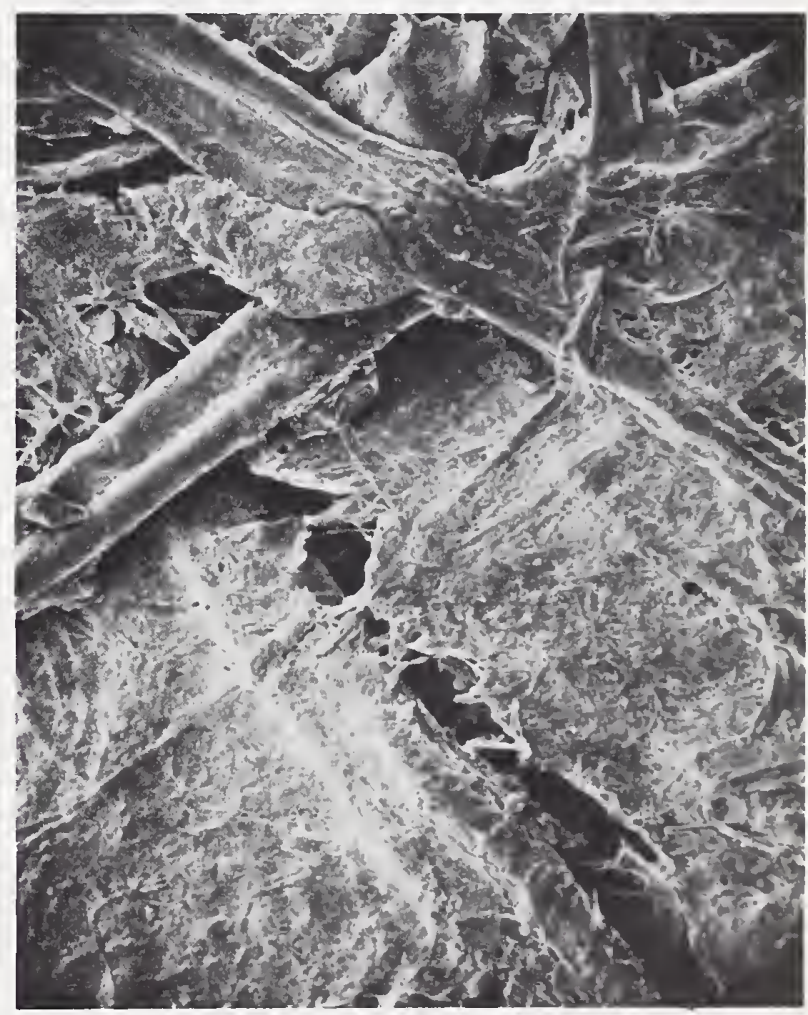

Scanning electron photomicrograph shows broken fibers and other characteristics of a paper specimen which affect the surface area of the specimen. A typical specimen measured by the SURFACE AREA ANALYZER. 


\section{FACILITIES}

\section{ROTATING \\ X-RAY ANODE \\ DIFFRACTION UNIT}

Stationary anode X-ray tubes have been used for most conventional X-ray diffraction generators. However, since a large amount of heat energy is generated by the electron beam bombardment on the anode, the $\mathrm{X}$-ray intensity is limited. The rotating anode tube can give higher intensity $\mathrm{X}$-rays because the water-cooled anode is rotated at a high speed to distribute the heat energy over the circumferential surface of the anode.

Capability: The maximum operating conditions for this unit are $60 \mathrm{kV}$ and $100 \mathrm{~mA}$. This produces $\mathrm{X}$-rays whose brilliance is 10 to 20 times greater than that of the normal sealed X-ray tubes. This makes it possible to reduce the exposure time dramatically in the photographic method, to scan rapidly with a counter, or to study dynamic changes or transformations in the crystal structure.

Applications: Measurement of the long period in chain-folded polymer crystals. Crystallographic studies of paraffins; observations of phase changes in polymer and paraffin crystals; $X$-ray diffraction patterns from wet collagen; detection of small amounts of crystalline impurities.

Availability: The use of this instrument by NBS research workers on problems of mutual interest can be arranged. It must be operated only under the direct supervision of the scientist in charge of the instrument.

Contact: Dr. Darreli H. Reneker, Chief of Structural Analysis and Standards Section, Polymer Building, Room A209, Phone 301-921-3344.



SOFT X-RAY SPECTROMETER. A comparison of the soft $x$-ray $M_{3}$ spectrum (SXS) of $C u$ with ultraviolet (UPS) and $x$-ray (XPS) photoemission and ion neutralization (INS) spectra.

\section{SOFT X-RAY SPECTROMETER}

This spectrometer is a 2-meter, grazing incidence instrument with a ruled glass grating, 30,000 lines per inch. It is equipped with an electron multiplier detector and magnetic tape output for digital computer processing. Programs are available for data reduction and plotting of spectra. A spectral range of approximately 2.5 to $80 \mathrm{~nm}$ can be covered but as presently set, the grating cut-off is at about $4 \mathrm{~nm}$.

Capability: Optimum specimen shape is a rod about $1 / 4$ " dia. $\times 3$ " long but variations from this can be used. Electron excitation of 2500 volts is used which causes some heating of the specimen. The temperature can be controlled within limits and can be continuously monitored with a thermocouple on the specimen. The maximum effective skin depth of material being analyzed is of the order of 4 to $100 \mathrm{~nm}$, depending on atomic number. 
Applications: Chemical analysis for the light elements down to lithium in atomic number (except oxygen and nitrogen with the spectrometer as presently set); this application would be particularly useful when associated with surface and shallow skin depth phenomena, such as the identification of boride, carbide, and sulfide precipitates on a fracture surface, for example. Application to other types of metallurgical phenomena such as detection of dezincification in brass and the reduction of iron oxide in the aluminizing of steel sheet; in the case of the higher atomic number elements, transitions between outer electron levels, and transitions from the valence band to outer levels are observed. Valence band spectra as a function of the state of chemical combination; the bulk of the work that has been done on this instrument has been the study of valence band structure to obtain a better understanding of the principles of intermetallic compound formation and the electronic basis for their physical properties.

Availability: To any qualified NBS research worker. Also, in appropriate situations the facility can be made available to researchers from other government, education and industrial organizations.

\section{Literature:}

[1] A Soft X-Ray Spectrometer with Improved Drive, J. R. Cuthill, Rev. Sci. Inst. 41, 422 (1970).

[2] Improved Drive for Soft X-Ray Spectrometer, NBS Tech. News Bull., October 1970, Vol. 54, No. 10, Page 231.

Contact: Dr. John R. Cuthill, Assistant Chief, Alloy Physics Section, Materials Building, Room B-148, Phone 301-921-2913.

\section{THREE-CIRCLE}

\section{X-RAY DIFFRACTOMETER}

Operating completely under computer control, the instrument orients a single crystal in the $x$-ray beam and records the diffracted intensity for each of several thousand reflections.

Capability: Data are collected at rates up to 1000 reflections per day. Accuracy is indicated by the final $R$ value obtained after least squares refinement. Typical values are in the range 3 to $5 \%$.

Applications: Structural parameters, including bond lengths, angles between bonds, and amplitudes of thermal vibrations are obtained. Precise three-dimensional diagrams can be drawn to scale. Diagrams of this type are used by physicists, chemists and other materials scientists concerned with bonding, electronic configurations, lattice and atomic vibrations, coordination, valence states, and other properties.

Availability: On a selective basis when not required for Crystallography Section programs. The instrument must be operated by Section personnel and only work of mutual interest can be undertaken.

\section{Literature:}

[1] Inorganic Chemistry, 9, 2228 (1970).

[2] Crystal Structure Communications, 1, 247 (1972).

Contact: Dr. Alan D. Mighell, Room B222, Materials Building, Phone 301-921-2950.

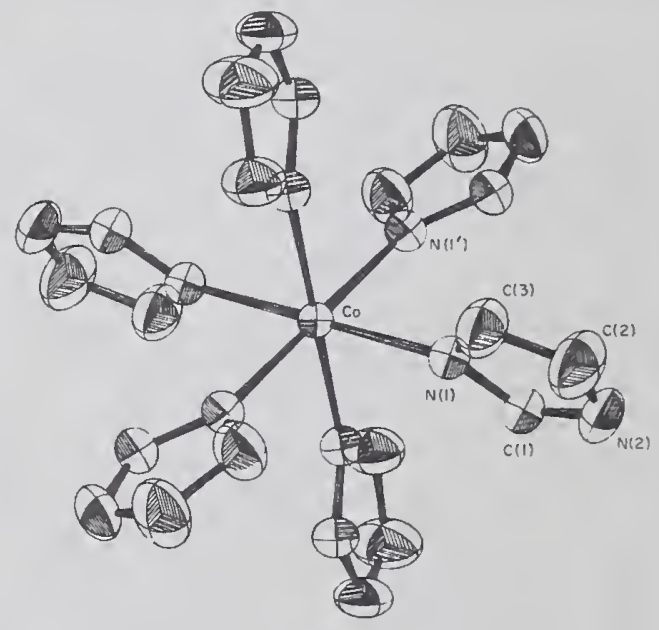

THREE CIRCLE X-RAY DIFFRACTOMETER. Diagram of the cobalt imidizole complex cation in the compound Co $\left(I m_{6}\right)$ $\left(\mathrm{NO}_{3}\right)_{2}$. The ellipsoids represent the root-mean-square amplitude of thermal oscillations of atoms. 
Accelerated Weathering Laboratories ....... 6

Acoustic Anechoic Chamber ........... 4

Acoustic Reverberation Chamber ......... 4

Acoustical Thermometer .............. 25

Alloy Preparation Laboratory ........... 21

Analytical Spectrophotometer ........... 36

Antenna Measurement Facilities .......... 5

Automatic Network Analyzer ... . . . . . . . . . 14

Automation Laboratory ............... 13

Central Computer Facilities ............ 13

Chlorine Flux Monitor . . . . . . . . . . . . . . 18

Cobalt-60 Irradiation Facility ........... 35

Concave Grating Spectrographs, $10.7 \mathrm{~m} \ldots . .37$

Cryogenic Flow Research Facility ......... 25

Czerny-Turner High-Dispersion Spectrograph. . 37

Deadweight Force Calibration Machines .... 27

Electron Energy Loss Spectrometers for Gases . 38

Electron Probe Microanalyzer .......... 45

Electron Van de Graaff Accelerator, $4 \mathrm{MeV}$... 2

Electro-optical High Voltage Field Mapping

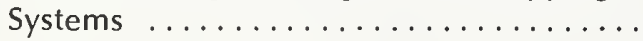

Far Infrared Spectroscopy .............. 38

Filtered Neutron Beams ................ 30

Fire Research Laboratory .............. 19

Flame Emission Spectrometry with Repetitive

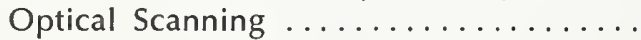

Flash Photolysis Resonance Fluorescence

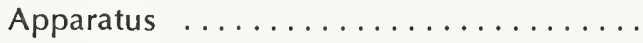

Fluid Flow Measurement ..............

Fluorine Combustion Calorimeter ..........

Fourier Transform Nuclear Magnetic Resonance

Spectrometer

Gas Chromatograph-Mass Spectrometer System

High Pressure Generators .............

High Pressure Optical Fluorescence System ...

High Pressure Photoionization Mass

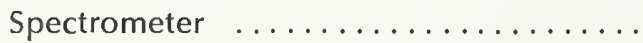

High Pressure PVT Dilatometer ...........

High Resolution Infrared Spectrometer .......

High Temperature Controlled-Atmosphere

Furnace ....................

High Temperature Vaporization Laboratory ...

Hydrogen Liquefaction Facility ...........

Inorganic Glasses: Preparation and Viscosity ..

Intermediate-Energy Standard Neutron Field

(ISNF)



Isotope Ratio Mass Spectrometers .........

Isotope Separator Laboratory .............

Laser Materials Facility ................ 23

Liquefied Natural Gas Flow Facility ... . . . . . . 26

Linear Electron Accelerator (LINAC) ........ 2
Low Temperature Adiabatic Calorimeter .... 10

Machine Tools, Numerically Controlled ...... 26

Mercury Manometer ................. 24

Microcalorimetry ................ 11

Microwave Spectroscopy Facility ......... 41

Millisecond High Temperature Thermophysical

Measurements ................ 24

Molecular Beam-Field Emission Microscope .. 46

Molecular Beam Machine .............. 46

Mössbauer Spectroscopy of Metals ........ 42

Multichannel Flame Spectrometer ........ 42

Neutron Diffractometers ................ 32

Neutron Radiography Facility ........... 33

Neutron Scattering Spectrometer .......... 33

Non-Magnetic Facility ................ 15

Nuclear Irradiation Facilities ............ 34

Nuclear Magnetic Resonance Spectroscopy ... 43

Nuclear Reactor ................... 30

Photoionization Spectrometry .......... 43

Platinum-lined Adiabatic Solution Calorimeter. 12

Plumbing Research Laboratory .......... 7

Positive-Ion Van de Graaff Accelerator, $3 \mathrm{MeV}$. 3

Precision Humidity Measurement ......... 18

Raman Spectroscopy ................ 44

Reactance Bridge for Power Loss Measurement 16

Rooftop Antenna Test Facility .......... 6

Rotating X-Ray Anode Diffraction Unit ..... 48

Rotating, Platinum-lined, Adiabatic Bomb

Calorimeter .................. 12

Scanning Electron Microscope .......... 16

Soft X-Ray Spectrometer ............ 48

Special Announcements on WWV/WWVH .. 36

Structures Laboratories ............. 7

Surface Analysis Facility ............ 47

Surface Area Analyzer .............. 47

Synchroton Ultraviolet Radiation Facility

(SURF) .................. 3

Thermal Engineering Laboratories ........ 8

Thermographic Equipment ............ 9

Three-Circle X-Ray Diffractometer ........ 49

Three-Dimensional Precision Measurement ... 28

Time-of-Flight Neutron Spectrometers ...... 34

Transmission Electron Microscope, 200 kV ... 17

Universal Testing Machine, Twelve Million

Pound-Force .................. 29

Wind Tunnel for Unsteady Flows ......... 29

WWVL VLF Broadcast Station ............ 35

Photo

A. B. National Bureau of Standards laboratories at Boulder, Colorado.

C. The 550 acre NBS-Gaithersburg site seen from the air. The seven General Purpose Laboratories and the 11-story Administration Building are in the center of the picture.

$D$. The Administration Building, seen from the courtyard of the NBS Library.

E. One of the seven General Purpose Laboratories is seen in the background. 385' $\times 105^{\prime}$, the building contains 348 laboratories and offices. 
$\Delta$

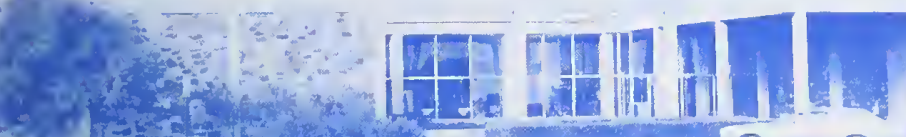

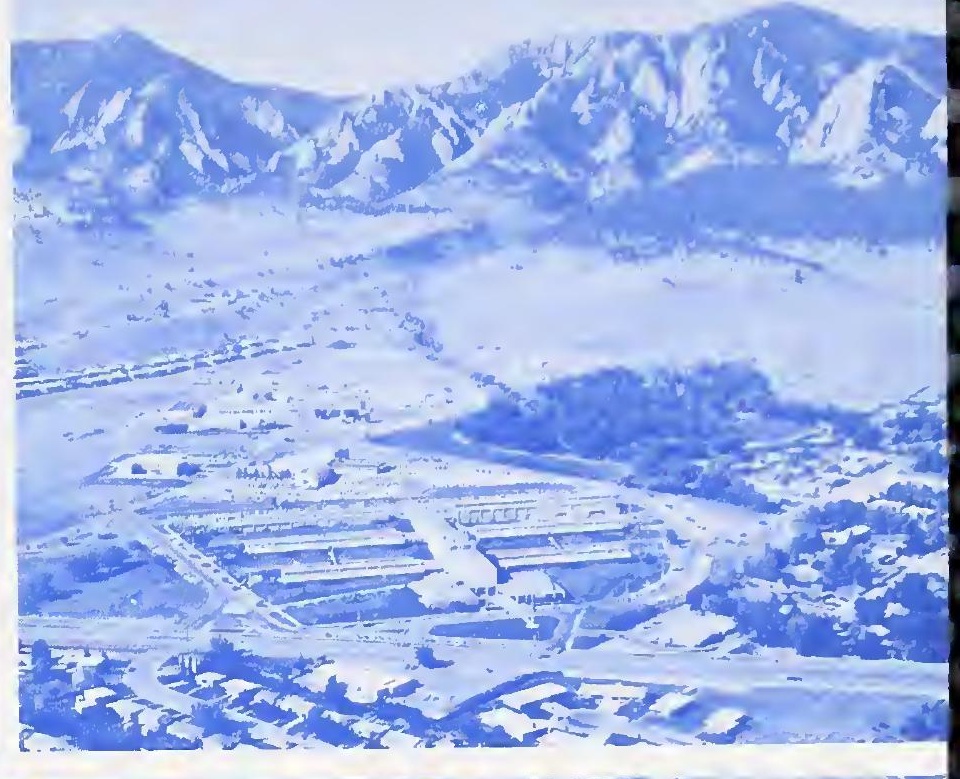

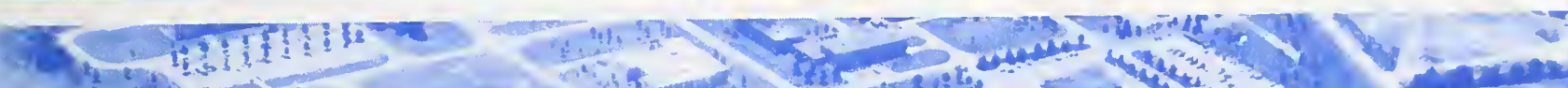

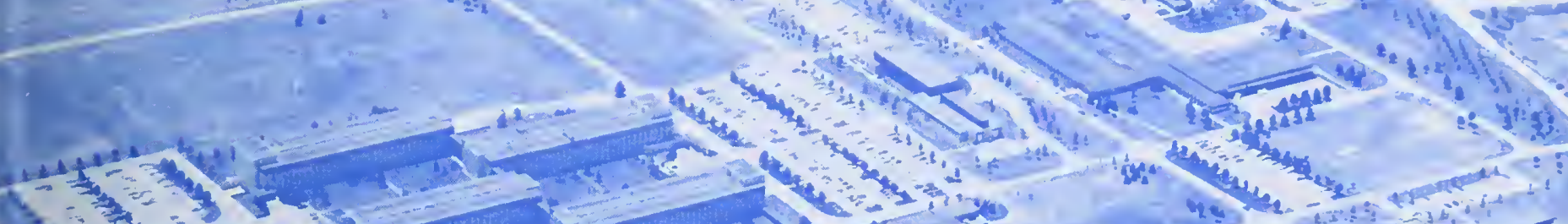

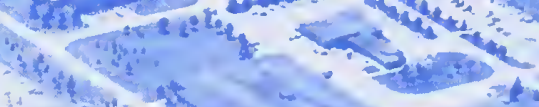
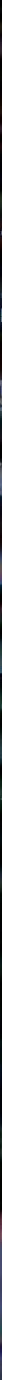
U.S. DEPARTMENT OF COMMERCE

National Bureau of Standards

Washington. D.C. 20234

OFFICIAL BUSINESS

Penalty for Private Use, $\$ 300$
POSTAGE AND FEES PAID

U.S. DEPARTMENT OF COMMERCE COM-215

Fourth-class Mail

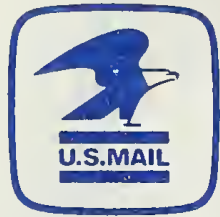

